\title{
Neue Pflanzenfunde aus dem Tertiär der Rhön. - Teil 1: Miozäne Fundstellen
}

\author{
Frank Gümbel ${ }^{1}$ \& Dieter Hans Mai $^{2}$
}

Mit 3 Abbildungen und 7 Tafeln

\section{Zusammenfassung}

Aus dem Tertiär der Rhön werden 47 Pflanzenarten aus 32 Familien nach Früchten und Samen beschrieben. Sie entstammen den braunkohlenführenden Kaltennordheimer Schichten vom Bauersberg bei Bischofsheim, Hochrain bei Gerstengrund und Kaltennordheim. Ihr untermiozänes Alter ist durch tierische Fossilien und radiometrische Altersdatierungen von Basalt festgelegt. Unklar bleibt ihre Einordnung in den Florenkomplex „Brandis-Bílina“ (etwa 20,5-18 Mio. J.) oder „KleinleipischFrantiškove Lázně" (jünger als 17,5 Mio. J.).

Schlüsselworte: Braunkohlentertiär Rhön, Untermiozän, karpologische Fossilien.

\begin{abstract}
On the base of fossil fruits and seeds 47 plant species belonging to 32 families are described. They have been derived from the browncoal-bearing layers of the Kaltennordheim section at the Bauersberg near Bischofsheim, Hochrain near Gerstengrund and Kaltennordheim. The age is Lower Miocene based on gastropods and mammals and also radiometic dates of the basalt. The assignment to the floral assemblages "Brandis-Bílina" (ca. 20,5 to 18 mio y.) or "Kleinleipisch-Františkove-Lázně" (younger than 17,5 mio y.) is still uncertain.
\end{abstract}

Key words: Browncoal-Tertiary, Lower Miocene, carpological fossils.

\section{Einleitung}

Die Rhön, das Gebirge zwischen Bayern, Hessen und Thüringen in Deutschlands Mitte, ist nicht nur durch ihre landschaftliche Schönheit reizvoll. Alte Bergwerksstollen, aufgelassene Steinbrüche, Tagebaue, Halden, Felsen und Erdfälle offenbaren vielfältige Einblicke in die geologische Geschichte des Gebirges. Besonders die durch den langjährigen Braunkohlenbergbau bekannt gewordenen kleinen Becken in der Vorderrhön und am Rande der Hohen Rhön erregten in den letzten Jahren das Interesse der Autoren und führten $\mathrm{zu}$ dieser gemeinsamen Arbeit, die neue Erkenntnisse über Pflanzenreste aus dem schon seit lange bekannten tertiären Ablagerungen erbringen soll. Neben der Beschreibung der Neufunde und einigen Bemerkungen zu den Resten aus alten Sammlungen soll auch ein neuer Versuch einer biostrati- graphischen Zuordnung der untersuchten Lokalitäten unternommen werden.

Frank Gümbel (Neidhartshausen) lieferte durch seine eifrige, erfolgreiche Sammeltätigkeit viel neues Fossilmaterial, Dieter Hans Mai (Berlin) durch seine langjährige Erfahrung das wissenschaftliche Gerüst zu dieser Arbeit. Nach der Darstellung von miozänen Fundstellen in diesem Teil I soll der Versuch einer Beschreibung von pliozänen Funden in einem Teil II erfolgen. Das Museum für Naturkunde der Humboldt Universität zu Berlin ermöglichte die Bearbeitung der fossilen Materialien und eröffnete die Möglichkeit einer schnellen Publikation in der museumseigenen Zeitschrift. Es stellte das Altsammlungsmaterial uneingeschränkt zur Verfügung und bewahrt in Zukunft auch das Originalmaterial zu dieser Arbeit aus der Privatsammlung F. Gümbel unter den Katalognummern MfN 2002/01-39 auf.

\footnotetext{
1 Hauptstr. 8, D-36452 Neidhartshausen/Rhön.

${ }^{2}$ Hamburger Str. 8, D-12623, Berlin-Mahlsdorf und Institut für Paläontologie, Museum für Naturkunde, Invalidenstraße 43, D-10115 Berlin.

Eingegangen March 2002, angenommen June 2002
} 


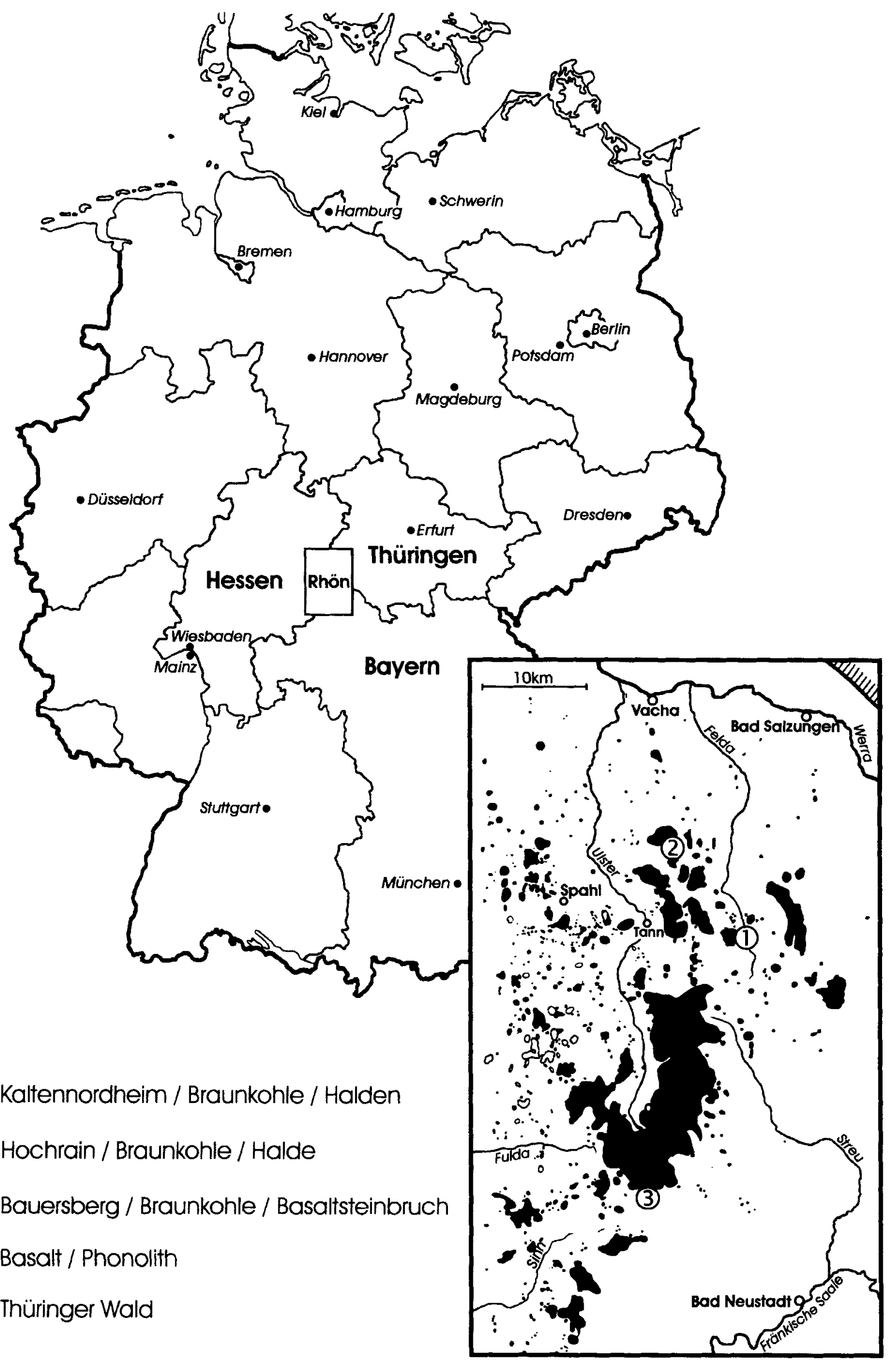

Abb. 1. Die Lage des Arbeitsgebietes und der drei Pflanzenfundstellen in der Rhön (Verbreitung vulkanischer Gesteine nach Schmecr 1964). 


\section{Geologische und biostratigraphische Bemerkun- gen zu den Fundstellen und fossilen Pflanzen}

Tertiäre Vulkanite sind in der Rhön weit verbreitet (Abb. 1), so daß dieses Bergland zu den klassischen Tertiär-Vulkangebieten Deutschlands gehört. In den letzten Jahrzehnten wurden diese Gesteine einer radiometrischen Altersdatierung unterzogen, die für den Rhön-Vulkanismus einen Förderzeitraum von 25 Mio. bis 11 Mio. Jahren, mit einem Schwerpunkt zwischen 22 und 18 Millionen Jahren ergaben (Lippolt 1982). Die Haupteruptionen fanden im Unter- bis Mittelmiozän (Burdigal bis Helvet) statt.

Tertiäre Sedimente sind in der Rhön dagegen auf kleinräumige begrenzte Vorkommen beschränkt, die sich meist im Schutze der großen Basalt- und Phonolith-Decken erhalten haben. Die ältesten Sedimente sind kaolinitische Verwitterungsreste und Quarzit, die einer prätertiären Landoberfläche entstammen und wahrscheinlich schon vor dem Eozän vorhanden waren. Sie sind nur in wenigen tektonischen Einbruchsstrukturen erhalten geblieben. In der Bohrung Sieblos 1994/1 stammen aus solchen kaolinistischen Bildungen die ältesten, mittel- bis obereozänen Pflanzenreste (Hottenrott 1998, Mai 1998). Deutlich unterschieden von diesen kaolinistischen Bildungen sind die vom Oligozän an gebildeten Sedimente verschiedener kleiner Becken, die ihre Entstehung und Erhaltung der Subrosion von Salzen im Untergrund der Rhön verdanken. Diese Sedimente, die von Sanden, Tonen, Mergeln, Kalksteinen, Blätterkohlen (Dysodilen) bis zu Braunkohlen reichen, lassen sich durch tierische Fossilien (Gastropoden, Ostracoden, Charophyten, Höhere Pflanzen, hier besonders Sporen und Pollen) meist ziemlich genau biostratigraphisch einordnen. Die Fundschichten sind darüber hinaus bisweilen mit Basalten, Tuffen, Tuffkalken oder Basaltgeröllen verzahnt und so absoluten Altersdatierungen zugänglich. Die fossilführenden Tertiärablagerungen der Rhön gliedert man bisher in die oligozänen Sieblosund Kühnstein-Schichten sowie die miozänen escheri-, Kaltennordheim- und Wollbach-Schichten (Moayedpour 1977, Martini et al. 1994).

Aus den Kaltennordheim-Schichten sind sowohl im thüringischen als auch im hessischen und bayerischen Teil der Rhön bauwürdige Vorkommen von Braunkohlen bekannt, auf die in den vergangenen Jahrhunderten zeitweise reger Bergbau gerichtet war. Jedoch sind die besonderen Entstehungs- und Lagerungsverhältnisse kompliziert und die Flöze im Durchschnitt nur
$5 \mathrm{~m}$ (Ausnahme Lettengraben: $15 \mathrm{~m}$ ) mächtig, so dass der Abbau im Verhältnis zu anderen großen Vorkommen Deutschlands gering blieb. Er wurde 1954 (Bauersberg) bzw. 1949 (Kaltennordheim) endgültig eingestellt. Die KaltennordheimSchichten sind eine faziell übereinstimmende Abfolge verschiedener limnischer Bildungen vor der eigentlichen Basaltförderung im Gebiet und müssen in den einzelnen Aufschlüssen nicht zeitgleich sein (Martini et al. 1994).

Die aus Tonen, Kalken, Kalkmergeln, Braunkohlen und Tuffiten bestehenden Schichten erbrachten in den langen Jahren ihres bergbaulichen Aufschlusses seit Anfang des 18. Jahrhunders (Voigt 1782) zahlreiche Fossilfunde, die obgleich nicht immer mit der nötigen Sorgfalt horizontiert aufgesammelt, eine ziemlich genaue biostratigraphische Datierung der Schichten ergeben. So spricht die Gastropodenfauna aus dem sog. Gyraulus-Horizont an der Basis des Kohleflözes vom Theobaldshof (Moayedpour 1977) für einen deutlichen Vergleich mit den Süßwasserkalken von Tuchořice in Westböhmen (Aquitan bis Burdigal). Noch genauer ist die Datierung durch Kleinsäuger an den gleichen Orten (Pseudotheridomys parvulus, MEIN-Zone 3b, Burdigal). Die Ostracoden-Fauna ließ sich nur mit „Post-Aquitan“ datieren (Malz \& Moayedpour 1973) Hierzu stehen die bisherigen Einstufungsversuche mit pflanzlichen Fossilien teilweise im Widerspruch (Knobloch 1971): Burdigal bis Ottnang oder Karpat, Baden.

\section{Miozäne Fundstellen:}

Bauersberg bei Bischofsheim (MTBL. 5526-Bischofsheim)

Etwa $2,5 \mathrm{~km}$ nordöstlich von Bischofsheim a.d. Rhön liegt nahe der Rhönhochstraße ein Steinbruch der Aktien-Gesellschaft Kasseler Basaltwerke am Bauersberg. Vor dessen Betrieb war der Bauersberg als Bergbaugebiet von Braunkohlen bekannt. Abbau von Braunkohle wurde 1818 im Untertagebetrieb bei einer Höhe von etwa $580 \mathrm{~m}$ ü.d.M. unterhalb der mächtigen Basaltdecke in der Zeche „Bischofsheim“ (MüllerStoll 1936) resp. „Bauersberg“ (Elborg 1956) begonnen und lief mit Unterbrechungen über 100 Jahre. Dieser Abbau zielte auf 5 Braunkohlenflöze mit einer Mächtigkeit von je 1,5-3 m. Auch in der $90 \mathrm{~m}$ höher gelegenen Zeche "Einigkeit" erfolgte Braunkohlenförderung anfänglich unter Tage durch den Karl-Julius-Stollen und ab 1854 durch den Einigkeitsstollen, ab 1857 auch im Tagebau. Hier standen drei Braunkohlenflöze mit jeweils 3-4 $\mathrm{m}$ im Abbau (aber auch Werte von 


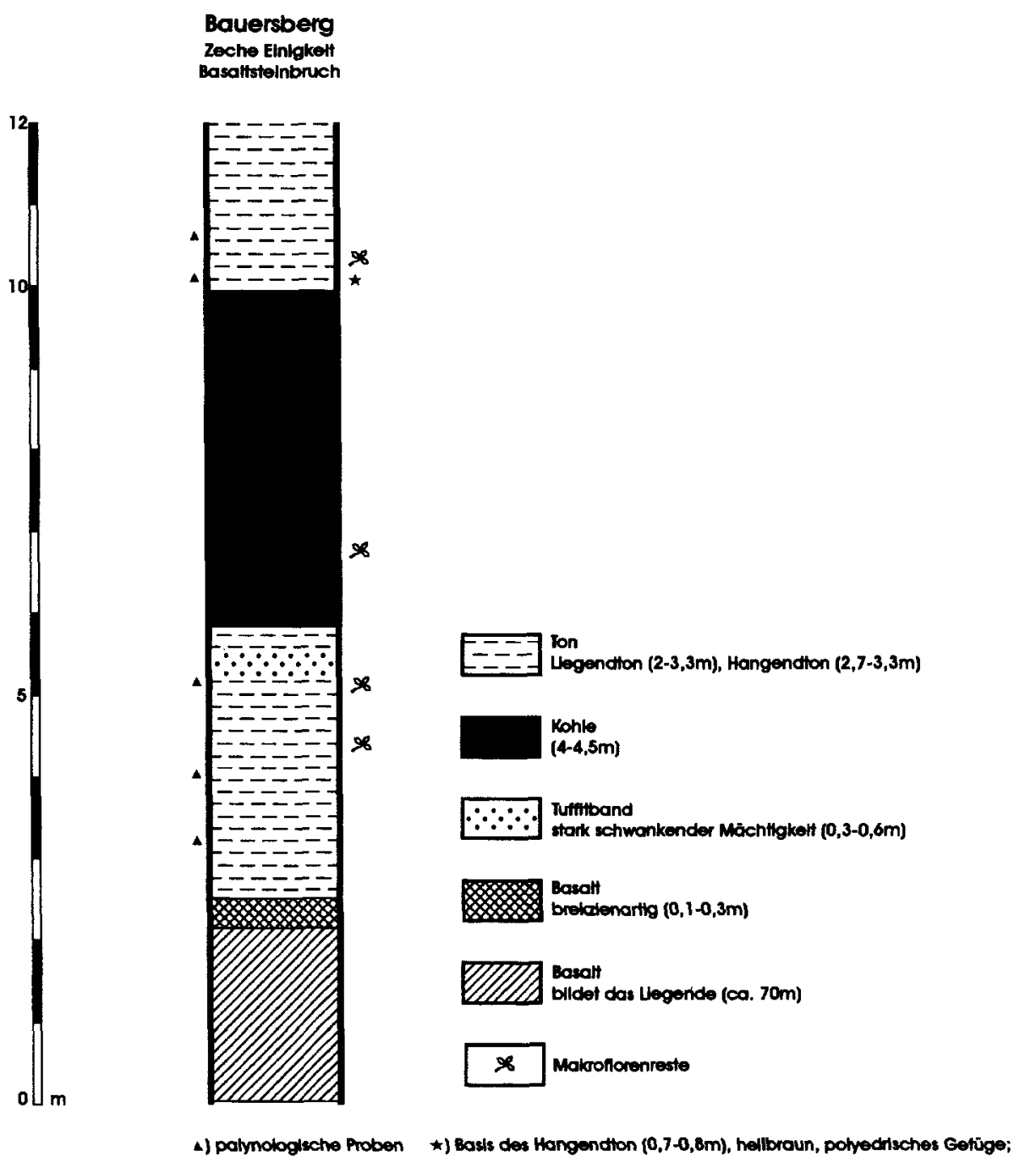

Abb. 2. Profil im Arbeitsgebiet (3) Bauersberg, NE Bischofsheim, nach Baumhauer (1990), umgezeichnet.
$20 \mathrm{~m}$ wurden für die in der Mächtigkeit stark schwankenden Flöze genannt). Starker Ascheanteil, das Vorkommen von selbstentzündlichem Schwefelkies (Grubenbrand von 1851-1854) und die unsteten und teilweise unrentablen Flözmächtigkeiten brachten den Braunkohlenbergbau ab 1930 zum Erliegen. Eine letzte Abbauphase erfolgte in der Nachkriegszeit von 1947 bis 1954 im Bischofsheimer Stollen (Martini et al. 1994).

Unmittelbar südlich der ehemaligen Zeche Einigkeit, die ab 1972 im „Geologischen Wanderpfad Bauersberg" besucht werden kann, waren und sind noch, heute allerdings in stark verwittertem Zustand, über einer Wand von $70 \mathrm{~m}$ erschlossenem Basalt Tone, Tuffite und Reste eines Braunkohlenflözes mit einer Gesamtmächtigkeit von bis zu $10 \mathrm{~m}$ aufgeschlossen (Abb. 2).

Aus dem anstehenden, schwärzlichen bis grauen „Liegendton" des Braunkohlenflözes, den Braunkohlen selbst und dem dunkel- bis hellbraunen „Hangendton“ bei etwa $675 \mathrm{~m}$ ü.d.M. konnten von 1983-1987 durch Kelber \&
Gregor (1987), 1997 durch Kramm (Fulda) sowie am 29. 09. 1997 und 12.09. 1999 durch Mai (MfN Berlin) karpologische Reste und Blattabdrücke gesammelt werden.

Die früheren Zechen Bauersberg und Einigkeit lieferten die bisher artenreichste fossile Flora der Rhön (Heer 1859, Hassencamp 1860, Schenk 1890, Engelhardt in Kinkelin 1903, Müller-Stoll 1936, Kirchheimer 1936, 1955, Knobloch 1971, Kelber \& Gregor 1987). Das Belegmaterial $\mathrm{zu}$ den Angaben dieser Autoren ist in den Sammlungen weit zerstreut (z. B. Geol. Pal. Inst. Univ. Würzburg, MfN Humb. Univ. Berlin, Senckenberg-Mus. Frankfurt a.M., Bayer. Geol. Landesamt München) und oft ohne genaue Angabe der Fundschicht. So soll aber nach Hassencamp (1860) „die größte Mehrzahl der Pflanzenreste einem grünen Schieferton entstammen, der das erste (unterste) Kohlenflöz unterteuft". Auch Müller-Stoll (1936, Fußnote 4) spricht davon, daß die unter "Bischofsheim" besprochenen Pflanzenreste nicht vom Fundort Zeche Einigkeit stammen dürften, der offenbar nur spärli- 
ches Material geliefert hat. Die Revision und Interpretation dieser Pflanzenreste kann nicht Gegenstand vorliegender Arbeit sein. In der Braunkohle selbst, allerdings ohne Angabe des genauen Flözhorizontes, fanden sich nach Hassencamp (1860), Kirchheimer (1936, 1955) und Müller-Stoll 1936):

Acer tricuspidatum Bronn

Glyptostrobus europaeus (Brongniart) Unger

Magnolia spec.

Nyssa spec.

Horizontiert aus der Braunkohle und tonigen Zwischenmitteln der Zeche Einigkeit nach Hassencamp (1860) stammen:

\section{Acer tricuspidatum Bronn \\ Alnus kefersteinii (Goeppert) Unger \\ Betula prisca Ettingshausen \\ Carpolithus impressus Heer (=? Potamogeton schenkii Kirchheimer) \\ Carya ventricosa (Sternberg) Unger \\ Equisetum spec. \\ Glyptostrobus europeus (Brongniart) Unger \\ Spirematospermum wetzleri (Heer) Chandler \\ Stratiotes kaltennordheimensis (Zenker) Keil- hack}

Durch die Untersuchungen von Gregor (1982), Kelber \& Gregor (1987), Martini et al. (1994) und unsere Aufsammlungen kann für den anstehenden Profilteil des Braunkohlentertiärs über dem Basalt in der Zeche Einigkeit nunmehr folgende revidierte Florenliste (Blätter, Früchte und Samen) vorgelegt werden:

\author{
Acer angustilobum Heer \\ Acer integrilobum Weber \\ Acer spec. \\ Ailanthus confucii Unger \\ Alnus latibracteosa Mai \\ Alnus spec. \\ Betula prisca Ettingshausen \\ Boehmeria cf. raria Mai \\ Carex hartauensis Mai \\ Carpinus miocenica Negru \\ Carpinus cf. orientalis Miller foss. \\ Carya spec. \\ Cercidiphyllum helveticum (Heer) Jähnichen, \\ Mai \& Walther \\ Cladiocarya trebovensis (Bủžek) Mai \\ Cladium oligovasculare Mai \\ Cornus brachysepala (A. Braun) Gregor \\ Cornus spec. (Carpolithus spec.) \\ Cupressospermum spec. \\ Decodon gibbosus (E. M. Reid) Nikitin
}

Decodon globosus (E. M. Reid) Nikitin

Decodon sibiricus Dorofeev

Fagus attenuata Goeppert

Fraxinus praedicta Heer

Glyptostrobus brevisiliquatus (Ludwig) Mai

Glyptostrobus europaeus (Brongniart) Unger

Koelreuteria reticulata (Ettingshausen) Edwards

Laurophyllum spec. A-C

Liquidambar spec.

Meliosma wetteraviensis (Ludwig) Mai

Naumburgia subthyrsiflora (Nikitin) Nikitin

Nymphaea cf. szaferi Knobloch

Nyssa ornithobroma Unger

Osmundacites spec.

Pilea bashkirica Dorofeev

Pinus cf. rigios (Unger) Ettingshausen

Platanus neptuni (Ettingshausen) Bůžek, Holý \& Kvaček

Pseudolarix schmidtgenii Kräusel

Rubus laticostatus Kirchheimer

Salix angustissima A. Braun

Salix lavateri Heer

Salvinia cerebrata Nikitin

Solanum foveolatum Negru

Spirematospermum wetzleri (Heer) Chandler

Styrax maximus (Weber) Kirchheimer

Taxodium dubium (Sternberg) Heer

Tetraclinis salicornioides (Unger) Kvaček

Typha tambovica Dorofeev

Ulmus pyramidalis Goeppert

Ulmus spec.

Vitis strictum (Goeppert) Knobloch

Vitis cf. teutonica A. Braun

Zanthoxylon müller-stollii Gregor

Zelkova zelkovifolia (Unger) Bůžek \& Kotlaba

Zelkova spec.

Nach Müller-Stoll (1936) und Knobloch (1971) kommt der Flora von Bischofsheim ein unter- bis mittelmiozänes Alter zu. Dem schließen sich auch Kelber \& Gregor (1987) für die Flora aus der Zeche Einigkeit an, deren paläofloristische Zusammensetzung keine gravierenden Unterschiede gegenüber der $80 \mathrm{~m}$ tiefer liegenden Flora aus den Tiefbauen „Bauersberg“ zeigen soll.

Bestätigt wird dieser Befund auch durch die palynologischen Untersuchungen vom gleichen Fundpunkt durch Hottenrott (1992). Dem Basalt, der sich nach Baumhauer (1990) als Intrusion zwischen die Braunkohlenschichten geschoben hat, kommt für die Altersdatierung des Braunkohlentertiärs am Bauersberg eine wichtige Rolle zu. Er ist mit 20 und 21 Mio. Jahren radiometrisch datiert und liegt damit genau im Burdigal (vgl. dazu S. 345 dieser Arbeit). 

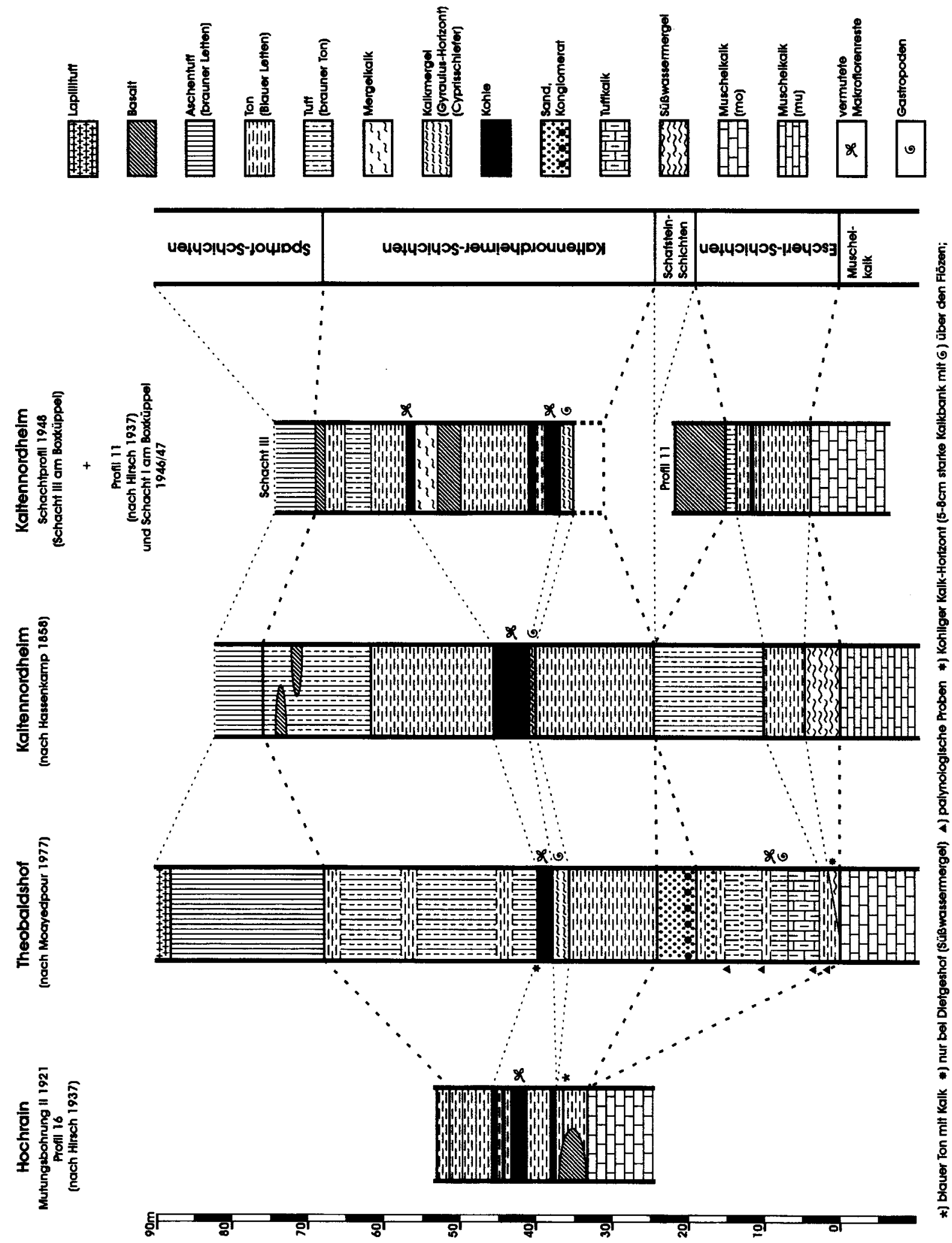

Abb. 3. Profile im Arbeitsgebiet

Hochrain/Theobaldshof und Kaltennordheim sowie deren stratigraphische Zuordnung (erweiterte Darstellung nach Moayedpour (1977), Profil 16 u. 11 nach Hirsch (1937); Schachtprofil nach Aufzeichnungen von L. Klinghammer, Steiger im damaligen Bergwerk am Boxküppel). 


\section{Hochrain und Theobaldshof (MTBL. 5326-Tann)}

$\mathrm{Zu}$ den schon seit Anfang des 18. Jahrhunderts bekannten und abgebauten Braunkohlen-Vorkommen der Vorderrhön gehört das bis heute sehr unbekannte und in Vergessenheit geratene Braunkohlen-Bergwerk am Hochrain nahe Gerstengrund. Es markiert ungefähr die nördliche Begrenzung des bekannten Braunkohlenbeckens von Kaltennordheim. Die Kohlenflöze am Hochrain wurden im ausgehenden 19. Jahrhundert erkundet (Sandberger 1879). 1921 wurden erneut Probebohrungen durchgeführt, deren Ergebnisse in einem Profilschnitt dargestellt wurden, der von Hirsch (1937) ergänzt wurde (Abb. 3). Ein Bergwerk wurde vom Zweckverband „Rhönkohle" betrieben, der in seinen Akten weitere Profile aufbewahrt. Eine völlig widerspruchslose Klärung der geologischen Verhältnisse und eine Parallelisierung mit den Profilen benachbarter Bergwerksaufschlüsse existiert nicht. Von Hirsch (1937) wissen wir, daß im Feld „Hochrain II" das Braunkohlentertiär über südlich erbohrtem Basalt lag (ca. $620 \mathrm{~m}$ ü.d.M.). Eine Basaltdecke tritt westlich des Hochrains am Kuh-Berg (642,6 $\mathrm{m}$ ü.d.M.) und östlich am Arnsberg (658 $\mathrm{m}$ ü.d.M.) und Katzenstein (610 m ü.d.M.) reliefbestimmend zu Tage.

Anders als bei den benachbarten Aufschlüssen sind mesozoische Gesteine im Liegenden nicht bekannt. Unter einem etwa $1 \mathrm{~m}$ mächtigen Braunkohlenflöz ist „Blauer Ton mit Kalk“ (= Gyraulus-Horizont) angetroffen worden, der stellenweise auch als "grauer Ton" gekennzeichnet wurde. In einer Wechsellagerung von schwarzem Ton, grünem Ton und blauem Ton folgen drei weitere Braunkohlenflöze, von denen das sog. Flöz 2 bis $3,10 \mathrm{~m}$ mächtig war. Den Abschluß des Profiles bildet ein „gelber Ton“ (evtl. „Tuff“ oder "Aschentuff“ der Nachbarprofile). Das sind sicherlich „Kaltennordheimer Schichten“.

Zur Entwässerung wurde ein Stollen angelegt, welcher bei Flöz 2 beginnt und dessen Mundloch sich am nördlichen Berghang befindet. Dieser Wasserstollen wurde 1947 erneut aufgefahren. In der Abraumhalde, welche während dieser Bauphase entstand, und die durch Wasserrisse zeitweilig angeschnitten wurde, konnte F. Gümbel in den Jahren 1995 und 1997 die Kohlenproben sammeln, die die Pflanzenfossilien für diese Arbeit lieferten.

Florenliste vom Hochrain bei Gerstengrund: Acer cyclospermum Goeppert

Alnus latibracteosa Mai

Aralia lucidoides Mai
Ceratophyllum lusaticum Mai

Cercidiphyllum helveticum (Heer) Jähnichen,

Mai \& Walther

Decodon gibbosus (E. M. Reid) Nikitin

Decodon globosus (E. M. Reid) Nikitin

Dulichinum marginatum (C. \& E. M. Reid)

Dorofeev

Glyptostrobus brevisiliquatus (Ludwig) Mai

Glyptostrobus europaeus (Brongniart) Unger

Hypericum septestum Nikitin

Microdiptera minor (Chandler) Mai

Naumburgia subthysiflora (Nikitin) Nikitin

Nyssa ornithobroma Unger

Pinus cf. rigios (Unger) Ettingshausen

Rubus laticostatus Kirchheimer

Rubus microspermus C. \& E. M. Reid

Salvinia cerebrata Nikitin

Saururus bilobatus (Nikitin) Mai

Sequoia abietina (Brongniart) Knobloch

Spirematospermum wetzleri (Heer) Chandler

Spondiaecarpum mettenii (Unger) Mai

Stratiotes kaltennordheimensis (Zenker) Keilhack

Obwohl das durch Moayedpour (1977) geologisch gut untersuchte Braunkohlenvorkommen von Theobaldshof vom Hochrain nur $3 \mathrm{~km}$ südwestlich entfernt liegt, lassen sich die dort ermittelten geologischen Verhältnisse bisher nicht unmittelbar parallelisieren.

Auf oberen Muschelkalk am Theobalshof folgt ein wenig mächtiger Basiston, der die Sedimentation am Beckenrand einleitet. Tuffkalk, Tuffite, Sande und Tone bis zu $20 \mathrm{~m}$ Mächtigkeit, die sog. escheri-Schichten, gefolgt von den konglomeratischen bis sandigen "Schafstein-Schichten" leiten zu den „Kaltennordheimer Schichten“ über, die über den bis zu $14 \mathrm{~m}$ blaugrauen Tonen ein Braunkohlenflöz enthalten, das mit maximal $2 \mathrm{~m}$ Mächtigkeit an der Grenze der Bauwürdigkeit lag. An seiner Basis liegt ein KalkmergelHorizont (Gyraulus-Horizont) mit Fossilien. Es folgt über dem Flöz eine Tuff-Ton-Wechsellagerung von fast $30 \mathrm{~m}$ Mächtigkeit, die eine Verstärkung der vulkanischen Aktivität im Gebiet anzeigt und nahtlos in die vulkanischen "Sparhofer Schichten" übergeht, welche von einer mächtigen Basaltdecke bedeckt werden.

Gegenüber dem Hochrain nimmt sich eine zusammengefaßte Florenliste vom Theobaldshof (Moayedpour 1977, Gregor 1982) sehr bescheiden aus (revidiert für diese Arbeit; Slg. Senckenberg-Mus. Frankfurt a.M.):

(escheri-Horizont):

Carya spec. aff. ventricosa (Sternberg) Unger 
Celtis cf. lacunosa (Reuss) Kirchheimer

Bryophyta indet.

Betulaceae aff. Alnus

Fagus attenuata Goeppert

Myrica spec.

Pinus spec.

(Schafstein-Schichten):

Fehlbestimmungen waren: cf. Carex spec.

(Rezent) und Rutaceae indet. (Eisenstückchen).

(Kaltennordheimer-Schichten):

Carpolithus spec.

Chara molassica Straub

Cladium oligovasculare Mai („Sparganiaceae“ Moayedpour 1977)

Cladium palaeomariscus Dorofeev (,Vitaceae“ Moayedpour, 1977)

Daphnogene polymorpha (A. Braun) Ettingshausen

Spirematospermum wetzleri (Heer) Chandler

Stratiotes kaltennordheimensis (Zenker) Keilhack

Wichtig für die Biostratigraphie dieses Vorkommens sind indessen die palynologischen Untersuchungen, die nach Hottenrott (1988) bei den coryphaeus/rurensis-Verhältniswerten für die escheri-Schichten eine Zuordnung zum unteren Untermiozän (M1) vom Landrücken in Hessen ergeben haben. Reiche Gastropodon- und Säugetierfaunen (mit Pseudotheridomys parvulus Schlosser im sog. Gyraulus-Horizont der Kaltennordheimer Schichten gestatten eine Parallelisierung mit den westböhmischen Faunen von Tuchor̆ice und der Umgebung von Chomutov sowie der Säugetierzone MEIN-3 (oberstes Aquitan bis Grenzbereich Aquitan/Burdigal). Eine genauere Datierung ist zur Zeit nicht möglich. Die Vulkanite des Beckens sind bisher radiometrisch nicht untersucht worden.

Der Abbau von Braunkohlen in dem südlich vom Theobaldshof gelegenen Talkessel erfolgte von 1693 bis etwa 1782. Als die Braunkohlen von Kaltennordheim entdeckt waren, ging der Absatz zurück und das von der Tann'sche Kohlenwerk wurde aufgegeben.

\section{Kaltennordheim (MTBL. 5326-Tann)}

Über die Braunkohlenförderung in dem Revier bei Kaltennordheim gehen die Nachrichten bis ins 18. Jahrhundert zurück. Voigt (1782) berichtete über drei Schächte, die am südlichen Hang des Windberges aus etwa $24 \mathrm{~m}$ Tiefe Kohlen für die Salinen in Schmalkalden und Salzungen för- derten. Spuren des alten Braunkohlenbergbaus mit verfallenen Stollen und flachen Halden lassen sich besonders westlich von Kaltennordheim am „Alten Berg" finden, wo nach einer Pause des Kohlenabbaus von 1926 bis 1946 eine letzte Abbauphase bis 1949 erfolgte. Technische Schwierigkeiten und eine wenig ergiebige Lagerstätte führten damals zum Abbruch der Arbeiten. Der etwa 250-jährige Kohlenbergbau von Kaltennordheim erreichte damit seinen endgültigen Abschluß. (Geyer et al. 1999). Uns blieben nur die heute noch gut sichtbaren Halden und das Sammlungsmaterial in vielen Sammlungen aus vergangenen Jahrhunderten, um über die Flora des Kaltennordheimer Braunkohlenbeckens Aussagen machen zu können. Kaltennordheimer Pflanzenfossilien enthalten die Sammlungen des MfN Berlin (Slg. H. Cotta, A. H. Braun, R. A. B. S. Ludwig, O. W. K. Speyer, P. Hoffmann, G. Böhme 1977, D. H. Mai 1993) etwa in chronologischer Folge der Aufsammlungen), Senckenberg-Mus. Frankfurt a.M., Geol.-Pal. Inst. Univ. Göttingen (Slg. von Koenen, Schwarzenberg), Geol.-Pal. Inst. Univ. Würzburg (Slg. E. Hassencamp). Dieses Material fand bisher mehr oder weniger kritische Beachtung durch folgende Autoren: Zenker 1833, Heer 1859, Hassencamp 1860, Sandberger 1879, Keilhack 1896, MüllerStoll 1936, Kirchheimer 1937, Moayedpour 1977, Gregor 1982, 1990. Unsere Aufsammlungen, allerdings unhorizontiert, lassen einige wesentliche Ergänzungen zur Flora des Kaltennordheimer Braunkohlentertiärs zu:

\section{Florenliste}

(Blätter, Früchte, Samen, nachweislich aus Braunkohlen):

Acer tricuspidatum Bronn

Actinidia germanica Mai

Carex pseudocyperoides Łańcucka-Šrodoniowa Carya rostrata (Schlotheim) Schimper

Carya ventricosa (Sternberg) Unger

Daphnogene polymorpha (A. Braun) Etttingshausen

Decodon gibbosus (E. M. Reid) Nikitin

Decodon globosus (E. M. Reid) Nikitin

Dulichium marginatum (C. \& E. M. Reid)

Dorofeev

Eomastixia hildegardis (Unger) Holý

Glyptostrobus brevisiliquatus (Ludwig) Mai

Glyptostrobus europaeus (Brongniart) Unger

Microdiptera minor (Chandler) Mai

Myrica cf. ceriferiformis Kownas

Pinus palaeostrobus Ettingshausen

Pinus spinosa Herbst 
Prunus spec. (= Equisetum spec.)

Salvinia cerebrata Nikitin

Sambucus pulchella C. \& E. M. Reid

Spirematospermum wetzleri (Heer) Chandler

Spondiaecarpum mettenii (Unger) Mai

Stratiotes kaltennordheimensis (Zenker) Keilhack

Vitis teutonica A. Braun

Zanthoxylum mueller-stollii Gregor

(Aus unterlagernden Tuffiten, Braunkohlentonen und Kalkmergeln):

Alnus julianiformis (Sternberg) Kvaček \& Holý (= Fagus deucalionis-Sandberger, 1879)

Arundo goeppertii Heer

Carya ventricosa (Sternberg) Unger

Cassia lignitum Unger

Castanea kubinyi Kováts $(=C$. recognita Sandberger, 1879)

Celastrus crassifolius A. Braun

Daphnogene polymorpha (A. Braun) Ettingshausen

Diospyros brachysepala A. Braun

Engelhardia macroptera (Brongniart) Unger

Fagus deucalionis Unger

Liquidambar europaea A. Braun

Myrica lignitum Unger (= Dryandroides acuminata Unger)

Nitellopsis meriani (A. Braun \& Unger)

Grambast \& Soulié-Märsche

Quercus drymeja Unger

Trigonobalanopsis rhamnoides (Rossmässler)

Kvaček \& Walther (= Rhamnus decheni Weber)

Zelkova zelkovifolia (Unger) Bủžek \& Kotlaba

Während die Pflanzenreste aus den Braunkohlen ziemlich eindeutig aus den Kaltennordheimer Schichten nach Moayedpour (1977) stammen, müssten Tone der ,unterlagernden braunen Tone", die nach dem genannten Autor als Tuffite oder Aschentuffe umzudeuten sind, zusammen mit dem Süßwassermergel den „escheri"-Schichten in Theobaldshof entsprechen. Auch oberhalb des nur bis zu $2 \mathrm{~m}$ mächtigen Braunkohlenflözes (oder der durch tonige Zwischenmittel getrennten Flöze geringer Mächtigkeit) kam es im Profil von Kaltennordheim nach Abschluss der Aschenförderung zur Ausbildung einer mächtigen Serie von Tonen (= „Blauer Letten“, bis 16,20 m mächtig). Es folgen Tuffe mit Basaltgeröllen, Aschentuff und als Abschluss eine Basaltdecke. „Blauer Letten“, „Kalkmergel" und das tiefste Kohlenflöz (,Sohlkohle") waren wichtige Horizonte für tierische Fossilien, denen wie im
Profil von Theobaldshof stratigraphischer Leitwert, wenn auch von geringer Präzision, zukommt (Sandberger 1879, Moayedpour 1977).

Die tertiären Ablagerungen von Theobaldshof, Hochrain und Kaltennordheim lassen sich parallelisieren (vgl. Abb. 3). Sie zeigen im Einzelnen kleine Faziesunterschiede. Aus dem Vergleich geht eine Ablagerung in einem gemeinsamen Becken hervor, wobei die tertiären Sedimente von Theobaldshof und Hochrain im BeckenrandGebiet, jene von Kaltennordheim mehr im Bekkeninneren zur Ablagerung gekommen sind. Die flache Senke war durch Auslaugung salinarer Schichten im Untergrund entstanden. Die Pflanzenreste lieferten ein recht genaues Bild dieser Verhältnisse, was sowohl die Biostratigraphie als auch die Paläoökologie anbelangt.

\section{Systematische Beschreibung der Neufunde}

Die Abkürzungen bei den Aufbewahrungsorten des Materials bedeuten: $\mathbf{B b}=$ Bauersberg, $\mathrm{Ho}=$ Hochrain, $\mathrm{Ka}=$ Kaltennordheim in der Privatsammlung von F. Gümbel, Neidhartshausen und $\mathrm{MfN}=$ Museum für Naturkunde der HumboldtUniversität zu Berlin mit den jeweiligen Sammelnummern; Slg. = Sammlung.

\section{Charophyta}

\section{Characeae}

\section{Nitellopsis (Tectochara) meriani bicarinata (Mädler) J.-P. Berger}

Tafel 1: 1-3

1955 Tectochara meriani bicarinata Mädler, Geol. Jahrbuch, 70: 284; Tafel 24, Fig. 9-13 - NW Beiningen (Untermiozän).

1983 Nitellopsis meriani bicarinata J.-P. Berger, Geobios, 16 (1): 23, fig. 3, no. 6 - Chamberonne N (Untermiozän)

Kaltennordheim MfN No. 2002/23 (Ka 014); Slg. Geol. Pal. Inst. Univ. Würzburg (Orig. Müller-Stoll 1936, Tafel I, Fig. 1-2)

Gyrogonite mit elliptischer bis verkehrteiförmiger Gestalt, gebildet von spiralig-linksgewundenen Hüllzellen, gebunden unter sich durch \pm wulstige Nähte, Nahtlinien eingesenkt. Die sichtbaren Spiralwindungen sind 10--9; Außenwände sind meistens konkav oder plan, was von dem Reifestadium des Oogoniums abhängig ist. Die gleiche Breite und Dicke der Hüllzellen ist fast auf der ganzen Länge der Gyrogonite erhalten. Sichtbare Veränderungen, wie Vermindern der Breite, sind lediglich an der Spirale zu beobachten. Die Breite der Hüllzellen ist an der Äquatorebene etwa $160-180 \mu \mathrm{m}$ und der Winkel, den die Spiralwindungen mit der genannten 


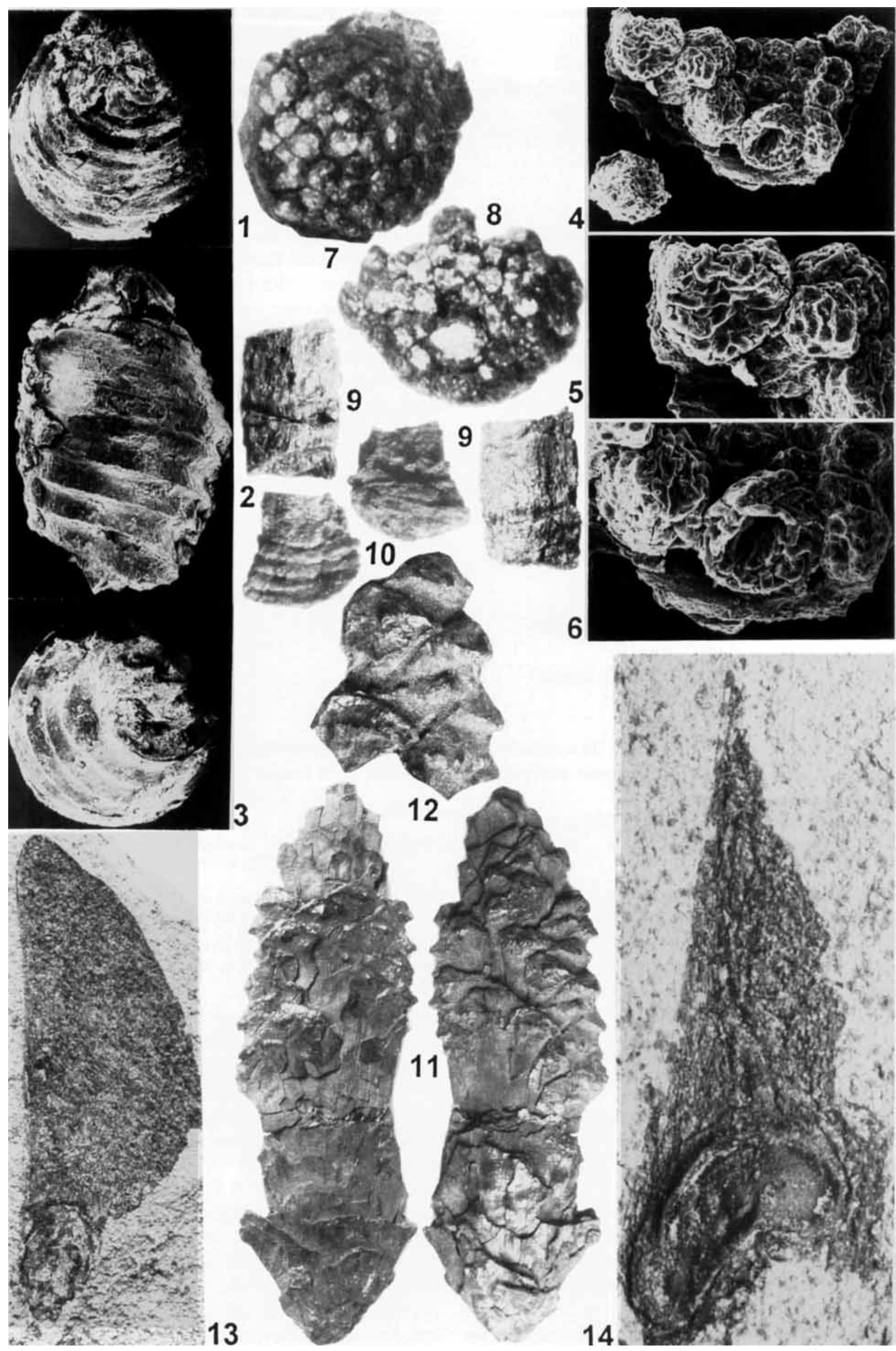


Ebene bilden, ist 10 bis $15^{\circ}$. Der Apikalteil der Gyrogonite endet mit einem Deckel, der von den knötchenartigen Enden der Hüllzellen gebildet und durch eine Dehiszenzfurche vom eigentlichen Oogonienkörper getrennt wird. Gipfelknoten wenig kräftig, Basis konisch, abgerundet oder etwas herabgezogen. Der basale Teil der Gyrogonite besitzt eine kleine 5-eckige Öffnung (das Stielloch), eingesenkt in den Boden eines kleinen Trichterchens. Die basale Öffnung hat einen Durchmesser von 50 bis $90 \mu \mathrm{m}$.

Länge $0,72-1,10 \mathrm{~mm}$; Dicke $0,63-0,90 \mathrm{~mm}$; Breiten der Spiralzellen 100-130 $\mu \mathrm{m}$.

Die Gyrogonite haben die gleiche Gestalt wie die Normalform, sind nur im Durchschnitt kleiner und nähern sich damit der Nitellopsis helvetica. Von der Stammform unterscheiden sie sich durch die vorwiegend konkaven Spiralzellen, deren Ränder aufgeworfen bis wulstig sind. Dadurch entstehen eingesenkte Nähte, so daß die Stücke wie doppelt suturiert aussehen. Sie stammen aus dem „Gyraulus"-Horizont.

Vorkommen: Oberoligozän bis Mittelmiozän (Mädler 1955), besonders häufig im Untermiozän („Aquitanien inférieur“; Berger 1983). Die Sammelart Nitellopsis meriani (A. Braun in Unger) Grambast \& Soulié-Märsche ist langlebig, vom Paläozän bis ins oberste Miozän in Mitteleuropa (Berger 1983); auf der Balkanhalbinsel bis ins Miozän (Palamarev 1972).

\section{Pteridophyta}

\section{Salviniaceae}

\section{Salvinia cerebrata Nikitin}

Tafel 1: 4-8

1948 Salvinia cerebrata Nikitin, Dokl. Akad. Nauk USSR, 61: 1103 (nomen nudum).

1955 Salvinia cerebrata Nikitin in Dorofeev, Mèot. Flory Odessy: 116, pl. 2, fig. 4, 5 - B.Fontan/Odessa (Obermiozän).

Bauersberg MfN No. 1998/444; Hochrain MfN No. 2002/02 (Ho 0002), Kaltennnordheim MfN No. 1988/97, Ka 006 a+b
Megasporen annähernd kugelförmig bis kugeligtetraedrisch, mit vorsprindender, dreieckig-pyramidenartiger Spitze, auf der sich die dreistrahlige Dehiszenzmarke befindet; $0,37-0,5 \mathrm{~mm}$ im Durchmesser. Oberfläche mit langen und gewundenen Wülsten ornamentiert, glänzend. Massulae mit zahlreichen, wesentlich kleineren, aber gleichartig ornamentierten Mikrosporen und einigen Megasporen.

Die Funde in den Braunkohlen der Rhön machen es immer wahrscheinlicher, dass die Art mit der von Kirchheimer (1930) untersuchten $S$. hassiaca Kirchheimer identisch ist, von der aber nur mikroskopische Bilder vorliegen, die charakteristische Einzelheiten der äußeren Skulptur nicht erkennen lassen.

Vorkommen: In tertiären Ablagerungen von Osteuropa weit verbreitet; im übrigen Europa bisher vom Oberoligozän bis Miozän (Mai \& Walther 1991), selten im Pliozän (Mai \& Walther 1988); noch im Waal-Interglazial von Nordbrabant (Coll. Mai, No. MfN 1993/6750).

\section{Coniferophytina}

\section{Pinaceae}

\section{Pinus cf. rigios (Unger) Ettingshausen}

Tafel 1: 9, 10

1852 Pinites rigios Unger, Iconograph. plant. foss.: 97, Tafel 36, Fig. 3 - Preschen (Brěštány) bei Bílina (Untermiozän).

1866 Pinites rigios Ettingshausen, Foss. Fl. Bilín I: 41, Tafel XIII, Fig. 11, 12, 15 - Preschen u. Priesen b. Bílina (Untermiozän).

Bauersberg MfN No. 1998/440; Hochrain MfN No. 2002/15 (Ho 0022) (1 Expl.).

Nadelbüschel mit 3 Nadeln, die im Querschnitt halbmondförmig sind. Nadelscheide aus glänzenden, zerschlitzten Schuppen, die das Nadelbüschel bis zu $10 \mathrm{~mm}$ Länge umhüllen können. Material vom Bauersberg und Hochrain schlecht erhalten und abradiert. Keine Nadelfunde.

Tafel 1. 1-3. Nitellopsis merianii bicarinata (Mädler) J.-P. Berger - Kaltennordheim, Gyraulus-Horizont MfN No. $2002 / 23$. 1. Apikalsicht eines Gyrogonites mit Deckel; SEM $\times 35$. 2. Gesamtansicht des gleichen Gyrogonites; SEM $\times 35$. 3. Basaler Teil des Gyrogonites; SEM × 35. 4-8. Salvinia cerebrata Nikitin - Hochrain MfN No. 2002/02. 4. Teil eines Massula und einzelne kugelförmige Megasporen; SEM $\times 45.5,6$. Megasporen verschiedener Form und Größe im Massula; SEM $\times 65.7,8$. Massulae mit Megasporen und kleineren Mikrosporen, $\times 30.9$, 10. Pinus $\mathrm{cf}$. rigios (Unger) Ettingshausen. 9. Basaler Teil eines Nadelbüschels mit 3 Nadeln - Bauersberg MfN No. 1998/440; $\times 12$. 10. Basisteil eines Nadelbüschels mit Ringnarben der abgefallenen Nadelscheiden - Hochrain MfN No. 2002/15; $\times 12$. 11, 12. Pinus spinosa Herbst - Kaltennordheim MfN No. 1989/20 (Orig. 1176; Müller-Stoll 1936, Tafel 1, Fig. 3 u. 4). 11. Zapfen von beiden Seiten, stark abradiert; $\times 1 / 1$. 12. Aposhylen aus der Zapfenmitte mit uncinatem Mucro; $\times 2$. 13. Pseudolarix schmidtgenii Kräusel - Bauersberg MfN No. 2002/34, Flügelsamen mit Flügelzange um den abgefallenen Samen; $\times$ 4. 14. Glyptostrobus brevisiliquatus (Ludwig) Mai - Bauersberg MfN No. 2002/35, Flügelsamen mit breitem, einseitswendigem Flügel an dem gekrümmten Samen; $\times 10$. 
Pinus rigios (Unger) Ettingshausen wird wie viele andere auf Nadeln gegründete "Arten“ als Sammelart von großer stratigraphischer und regionaler Reichweite aufgefaßt.

Derartige Nadeln wurden vorrangig mit jenen von $P$. rigida Miller, $P$. taeda Linné (Subsect. Australes Loudon) oder anderen Arten der Sect. Pinaster Loudon (= Sect. Taedoponderosoides Gaussen ) verglichen (Ettingshausen 1872, Gaussen 1960). Aber auch Kiefern der Sect. Sula Mayr blieben im Gespräch (Gaussen 1960).

Vorkommen: Oberoligozän bis Pliozän in Europa.

\section{Pinus spinosa Herbst}

Tafel 1: 11, 12

1844 Pinus spinosa Herbst, N. Jahrb. Min. f. 1844: 567-568 (ohne Abb.), Mai 1965, Abh. ZGI Berlin, 1: 40-43, Tafel 3, Fig. 3-16 - Kranichfeld (Pliozän).

Kaltennordheim MfN No. 1989/20 (Orig. 1176; Müller-Stoll 1936, Tafel 1, Fig. $3+4$ ).

Großer, $10 \mathrm{~cm}$ langer, schwach gekrümmter, lang-eiförmiger Zapfen; Apophysen pyramidal gewölbt, uncinat nach unten gebogen, mit stark gewölbtem Umbo, der in einen bis $3 \mathrm{~mm}$ spitzen und langen Mucro übergeht, centroerectomucronat.

Diese Art ist ein charakteristisches Fossil der miozänen und pliozänen Braunkohlen Europas. Über ihre nomenklatorische Abgrenzung hat sich Mai $(1965,1986)$ ausführlich geäußert. Verwechselbare fossile Arten gibt es kaum.

Rezente Analoge findet man sowohl bei der Pinus taeda-teocote-rigida-Gruppe (Sect. Pinaster Subsect. Australes Loudon) als auch bei Pinus pinaster Solander. Abweichungen in mehreren morphologischen Details der fossilen Zapfen kennzeichnen die Art allerdings als Vertreter einer selbstständigen Gruppe innerhalb der Sektion Pinaster Loudon.

Vorkommen: In Westsibirien bereits im Oligozän (Dorofeev 1963). In Europa erscheint P. spinosa im unteren Miozän und wird im Pliozän häufig.

\section{Pseudolarix schmidtgenii Kräusel}

Tafel 1: 13

1938 Pseudolarix schmidtgenii Kräusel, Paläont. Z. 20, Tafel 3, Fig. 7, f. text. $4 \mathrm{~m}-$ p. - Mainz-Kastel (Untermiozän).

Bauersberg MfN No. 2002/34 (Slg. E. Kramm, Fulda).
Flügelsamen mit geradem Rücken und gebogener, nach oben zu gerade und spitz auslaufender Bauchkante, den Samen ohne Zange seitlich umfassend, Flügel eiförmig, dreieckig, nach unten zu breit werdend. Flügel $20,0 \mathrm{~mm}$ lang, $8,0 \mathrm{~mm}$ breit. Größte Breite stets unterhalb der Mitte. Samen eiförmig, länglich, flach, mit Runzeln, $7 \mathrm{~mm}$ lang, abfällig.

Große Flügelsamen, die den Samen seitlich ohne Zange umfassen, kommen nur bei den Gattungen Keteleeria Carrière, Pseudolarix Gordon und Abies Miller vor. Dabei besitzen Abies und Keteleeria Flügelsamen, deren größte Breite in der Regel über der Mitte liegt. Die Samen sind hier nicht abfällig. Unsere Reste gehören daher zu Pseudolarix Gordon, die ähnlich gebaute Samen im Miozän des Mainzer Beckens hinterlassen hat. Kräusel (1938) beschrieb sie als Pseudolarix schmidtgenii Kräusel und wies auf ihre große Ähnlichkeiten mit den Samen der chinesischen Pseudolarix kaempferi (Lindley) Gordon hin (Relikt in Ostchina).

Vorkommen: Oberoligozän bis Pliozän in Mitteleuropa, besonders im Untermiozän (Mai 1964, 1999a).

\section{Taxodiaceae}

\section{Glyptostrobus brevisiliquatus (Ludwig) Mai}

Tafel 1: 14, Tafel 2: 1-5

1857 Genista brevisiliquata Ludwig, Palaeontographica, 5: 101, Tafel 20, Fig. 18 - Dorheim/Wetterau (Pliozän).

1988 Glyptostrobus brevisiliquata Mai \& Walther, Quartärpal., 7: 68, Tafel VI, Fig. 4-9. - Gerstungen und Dorheim/Wetterau (Pliozän).

Bauersberg MfN No. 2002/35 (Slg. E. Kramm u. Bb 006a) (5 Expl.), Kaltennordheim MfN No. 2002/22 (Ka 002 a,b,c), MfN No. 1889/4, Roth (Slg. R. Ludwig), Hochrain MfN No. 2002/07 (Ho 0007), Sieblos - Braunkohle MfN No. 1989/42

Samen von 3-7 mm Länge und 1,6-2,5 mm Breite, länglich-oval, aber sehr veränderlich in Form und Größe; Hilum klein, in der Hauptsache seitlich verschoben; Randsaum primär breit, aber nicht extrem. Flügel breit ansitzend; an der Basis rinnig, nach der Seite gekrümmt oder fast gerade spitz-dreieckig, bis $10 \mathrm{~mm}$ lang; Spermoderm dünn, obere Schicht aus engen, ovalen, meist eckig zusammengedrückten Zellen mit stark verdickten Wänden und kleinem Lumen, untere Schicht fünfmal dünner als die obere.

Dieser Typ von Samen ist im europäischen Mittel- und Jungtertiär außergewöhnlich häufig vertreten. Es wird sich vermutlich um die Samen der ebenso häufigen $G$. europaeus (Brongniart) 
Unger (Sammelart!) handeln. G. brevisiliquatus (Ludwig) Mai \& Walther (1988) ist eindeutig älteres Synonym zu $G$. pannonicus Dorofeev (1974a). Unklar sind bisher die Beziehungen zu der an Hand von Abdrücken aus den obermiozänen Kalken von Öhningen beschriebenen $G$. vagans (Heer) Ettingshausen (1890) (= Pterospermites vagans Heer, Pt. lunulatus Heer 1859).

Vorkommen: Miozän bis Pliozän in ganz Europa, teilweise sehr häufig.

\section{Glyptostrobus europaeus (Brongniart) Unger}

Tafel 2: 6, 7

1833 Taxodium europaeum Brongniart, Ann. Sci. Nat., 30: 168; Abb. In Exped. Sci. De Morée Geol.: 235, pl. 12. - Iliodroma-Insel/Griechenld. (Miozän).

1850 Glyptostrobus europaeus Unger, Sitz-Ber. Akad. Wiss. Math.-nat. K1., 5: 434-435.

Bauersberg Bb 006 (3 Expl.), Hochrain MN No. 2002/13 (Ho 0012-0015), Kaltennordheim Ka 002b, Roth MfN No. 1989/47 a + b (Slg. Ludwig).

Zapfen birnenförmig, gestielt, bis $2 \mathrm{~cm}$ lang. Schuppen schmal keilförmig, nicht schildförmig, sehr lang. Frucht- und Deckschuppe fest verwachsen. Deckschuppe $1 / 2$ bis $3 / 4 \times$ so lang wie Samenschuppe. Samenschuppe am gekerbten oberen Rande \pm zerschlitzt. Geringe Abweichungen in der Länge des freien Endes der Deckschuppe.

Diese mit der heutigen Gl. pensilis (Staunton) $\mathrm{K}$. Koch in wesentlichen Merkmalen übereinstimmende Konifere ist fossil eine Sammelart und ebenso formenmannigfaltig wie die heutige Art. Zahlreiche Synonyme belegen das Bemühen um die Bestimmung und Abgrenzung der fossilen Organe.

Vorkommen: Obereozän bis Pliozän in Europa sehr verbreitet und häufig. Wichtige Sumpfpflanzen und Braunkohlenbildner in ganz bestimmten Gesellschaften.

\section{Sequoia abietina (Brongniart) Knobloch}

Tafel 2: 8, 9

1822 Phyllites abietina Brongniart, Descript. végét. foss. terrain sed. supérieur: 362 , pl. 11, fig. 13 - Habichtswald bei Kassel (Untermiozän).

1964 Sequoia abietina Knobloch, N. Jahrb. Geol. u. Paläontol., Monatsh. 1961 (10): 601 - Habichtswald bei Kassel (Untermiozän).

1960 Cupressospermum chamaecyparoides Mai, Paläont.Z. 34: 75--76, Tafel III, Fig. 8-11 - Olbersdorf (Untermiozän).

Hochrain Ho 008, 0026, 0043 und MfN No. 2002/10 (Ho 0010)
Zweige, Zapfen und Samen mit den Hauptmerkmalen der heutigen Sequoia sempervirens (D. Don) Endlicher. Flügelsamen herzeiförmig, 2,4-3,0 $\mathrm{mm}$ lang, $2 \mathrm{~mm}$ breit. Basis etwas abgeschrägt. Samenfach länglich oval, vom Flügel rings umgeben. Hilum etwas eingezogen, oval bis linsenförmig. Spermoderm dreischichtig. Epidermiszellen im Querschnitt stets zusammengedrückt, in der Aufsicht tetragonal bis fast quadratisch. Mittelschicht aus drei bis vier Zelllagen sehr dicker, rundlicher Sklereiden bestehend, $8-15 \mu \mathrm{m}$. Mittellamellen dick, von wenig Tüpfelkanälen durchzogen, deutlich hervortretend. Sekundäre Auflagerung, die die Zelle bis auf ein winziges Lumen einengt, mit vielen reich verzweigten Tüpfelkanälen. Innere Schicht stark zusammengedrückt, aus polygonalen Zellen.

Entsprechend einer gewissen Polymorphie der Art, wie das auch bei der rezenten S. sempervirens der Fall ist, hat die Nomenklatur der fossilen Reste stark geschwankt. Erst nachdem die Entdeckung der botanischen Zugehörigkeit der Reste durch Heer (1855) allgemein bekannt wurde, hatte man sich in Europa ganz allgemein den Namen Sequoia langsdorfii (Brongniart) Heer zu eigen gemacht.

Knobloch (1964) hat die Unhaltbarkeit eines solchen Vorgehens begründet und den ältesten Namen für die Art eingesetzt. Streng genommen gilt das Epitheton S. abietina (Brongniart) Knobloch nur für Zweigreste, die den Typus stellen. Für Samen, wie sie aus der Fundstelle Hochrain vorliegen, müßte ein anderer Namen gewählt werden. Hier bieten sich Cupressospermum chamaecyparoides Mai (1960) oder Sequoia rossica Dorofeev (1975) aus dem Miozän des TambovGebietes an. Wir sehen von einer solchen nomenklatorischen Zersplitterung einer gut bekannten Koniferen-Art ab.

Wesentliche morphologische Unterschiede $\mathrm{zu}$ dem heutigen Relikt $S$. sempervirens sind bei dem fossilen Material genau genommen nicht feststellbar. Man folgt daher nur einer allgemeinen Gepflogenheit, indem man für das Fossilmaterial einen besonderen Namen benutzt. Diese $S$. abietina des Tertiärs war ganz sicherlich unmittelbar Vorfahre der heutigen Art.

Vorkommen: Vom Obereozän bis Pliozän, weit verbreitet und häufig.

\section{Taxodium dubium (Sternberg) Heer}

ohne Abb.

1823 Phyllites dubius Sternberg, Versuch geogn. bot. Darst. Flora Vorwelt I, (3. Heft): 37, 39, Tafel 36, Fig. 3 Brěšt'any b. Bílina (Untermiozän). 

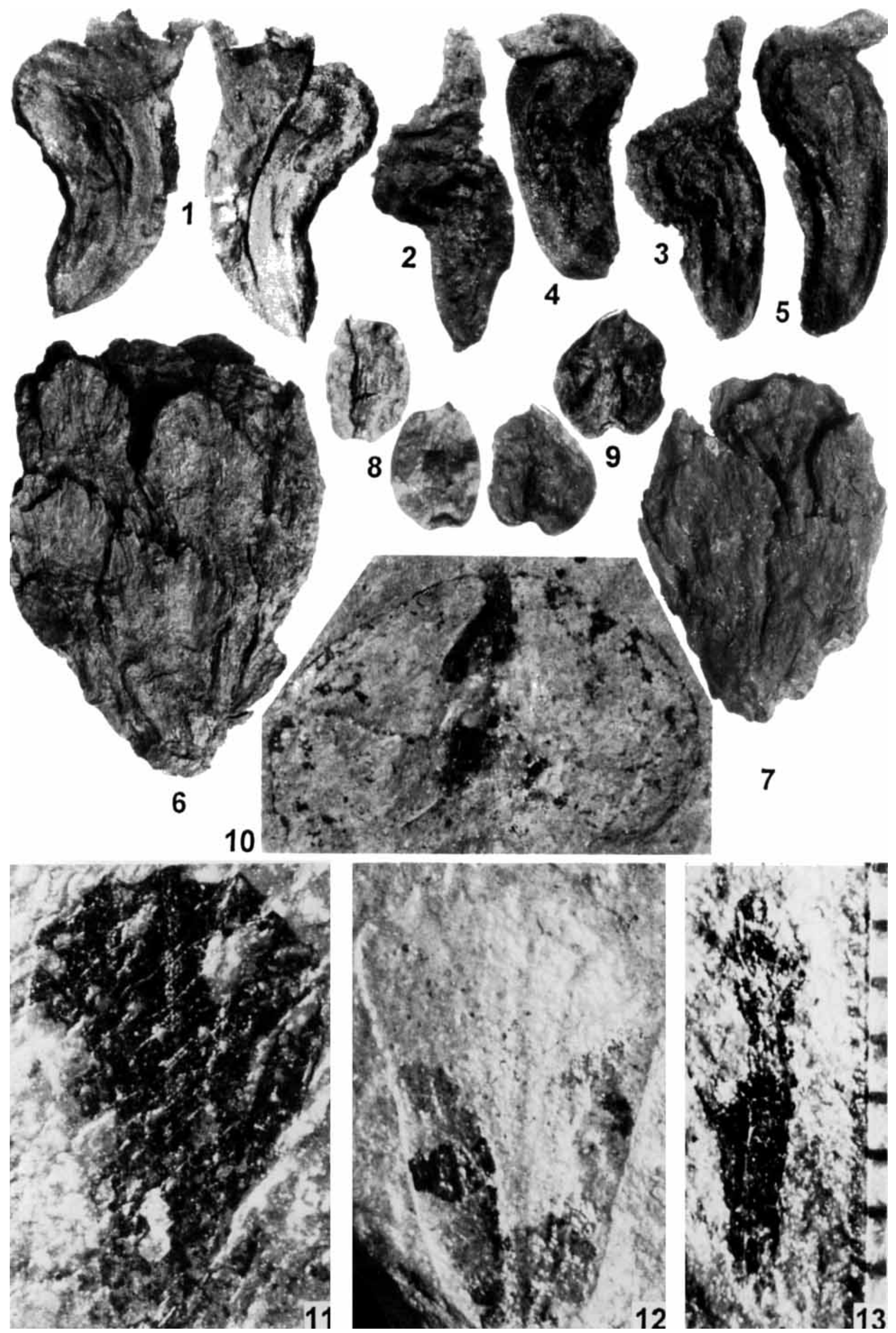
1855 Taxodium dubium Heer, Fl. tert. Helv. I: 49-50, Tafel 17, Fig. 5-15 - Hohe Rhonen, Eriz, Rallingen, Bílina (Oligozän bis Untermiozän).

Bauersberg MfN No. 1998/441 (Nadelreste).

Kurztriebe mit spiralig gestellten Nadeln; Nadeln in eine lange Spitze ausgezogen, am Stengel herablaufend; an den Basen der Kurztriebe und an den Blattknospen kleinere, schuppenförmig ausgebildete Nadeln sitzend, deren Ränder mit einem unregelmäßig gezackten, scharfkantigen Hautsaum versehen sind.

Derartige Nadeln, Zweige, Zapfenschuppen und Samen sind von zahlreichen Fundstellen vom Oberoligozän bis Pliozän aus Europa, Westasien und der Arktis abgebildet worden. Nomenklatorisch gilt Phyllites dubius Sternberg (1823) aus den Preschener Tonen (Brěšt'any b. Bílina) als Typus, obgleich es auf die am wenigsten charakteristischen Organe, nämlich die Zweige begründet wurde. Schon von Unger (1852) und Göppert (1855) werden hierzu auch Zapfen und Zapfenschuppen gestellt. Aus den Typus-Schichten bilden neuerdings Bůžek \& Holý (1964) auch die den Zapfenschuppen zugehörigen Samen ab, so daß man jetzt an einer Zusammengehörigkeit aller Organe kaum noch Zweifel haben kann.

Vergleichbar sind die Zapfenschuppen sowohl mit $T$. ascendens Brongniart als auch mit $T$. distichum (Linné) L. C. Richard (atlantisches SüdostNordamerika), wobei die erstere Art nur wärmere Arealteile von Florida und Alabama besiedelt, gleichzeitig aber auch ökologische Differenzierung zeigt (Moorböden).

Vorkommen: Oberoligozän bis Pliozän, häufig in ganz Europa.

\section{Cupressaceae}

\section{Tetraclinis salicornioides (Unger) Kvaček}

Tafel 2: 10-13

1838 Hellia salicornioides Unger, Steierm. Z. II: 375. - Radoboj (Mittelmiozän).
1841 Thuytes salicornioides Unger, Chloris protogaea (1): 11-13, Tafel II, Fig. 1-4, 7 - Radoboj (Mittelmiozän).

1847 Libocedrites salicornioides Endlicher, Synopsis Conif: 275 (Abb. 1850 Göppert, Monogr. foss.Conif.: 180, Tafel 18, Fig. 1-2 - Liessem, Radoboj (Miozän).

1855 Libocedrus salicornioides Heer, Fl. tert. Helvet I: 47, Tafel 21, Fig. 2 - Monod (Oberoligozän).

1960 Calocedrus salicornioides Palfálvy \& Nagy, All. Földt. Int. Evi Jelent: 227 - Eger (Oberoligozän)

1986 Tetraclinis salicornioides Kvaček, Časopis národ. Muzea Prahe, ř. prírod., $155(1-2)$ : 48-51, pl. I, fig. 11; pl. II, fig. 2-14; pl. III, fig. 3, 4, textfig. 1 - Div. Loc. (Oligozän - Miozän)

Bischofsheim MfN No. 2002/29, 37-38 (O. Speyersche Slg.); Wüstensachsen (Kelber \& Gregor 1987, Tafel 3, Fig. 7).

Zweigstücke in einzelne Glieder zerfallend; Einzelblätter stark reduziert und in Viertelwirteln gestellt, teilweise bis ganz verwachsen, je nachdem, ob das Glied von einem Triebende oder einem zentralen Triebteil stammt; Kantenblätter kahnförmig, mit freiem Endteil; Stammblätter breit rhombisch, ohne zentrale Schwiele.

Flügelsamen mit geradem, eiförmigem Embryo-Fach und zwei schräg von der Basis abgehenden, halbkreisförmigen Flügeln; Länge $4,5 \mathrm{~mm}$, Breite mit Flügeln $8 \mathrm{~mm}$.

Um fossile Tetraclinis-Reste rankt sich eine Vielzahl nomenklatorischer Probleme. Erste Abbildungen und Beschreibungen von Zweigen, die zu Tetraclinis gehören, stammen von Brongniart (1822) unter "Equisetum brachyodon" aus den mitteleozänen Kalken von Montrouge bei Paris. Dessen formale nomenklatorische Zuordnung erfogte aber erst durch Mai \& Walther (1985) und Kvaček (1986), aber mit unterschiedlicher Ansicht über die Anzahl der fossilen Arten. Zapfen werden als Tetraclinis brongniartii (Endlicher) Kräusel (1938) bezeichnet. Für die Flügelsamen existiert bisher kein eigener Namen. Sie wurden entweder mit den Zapfen oder den Zweigen vereinigt.

Für das Laub kann man unter folgenden $\mathrm{Na}$ men wählen:

Tetraclinis brachyodon (Brongniart 1822) Mai \& Walther (1985)

Tetraclinis salicornioides (Unger 1841) Kvaček (1986).

Tafel 2. 1. Glyptostrobus brevisiliquatus (Ludwig) Mai - Kaltennordheim MfN No. 2002/22, Samen mit Rest eines Flügels von beiden Seiten; $\times 10.2-5$. Glyptostrobus brevisiliquatus (Ludwig) Mai - Hochrain MfN No. 2002/07. 2, 3. Flügelsamen mit Resten des Flügels; $\times 10.4$, 5. Samenflügel fast vollständig abgebrochen; $\times 10.6,7$. Glyptostrobus europeus (Brongniart) Unger - Hochrain MfN No. 2002/13. Zapfen verschiedener Größe und Form; × 5. 8, 9. Sequoia abietina (Brongniart) Knobloch - Hochrain MfN No. 2002/10. 8. Samen mit deutlichem Samenfach und Hilumgrube; $\times 10$. 9. Breiter, herzförmiger Samen mit Flügelrand; $\times 10$. 10-13. Tetraclinis salicornioides (Unger) Kvaček - Bauersberg, verm. Zeche "Einigkeit" (Speyer'sche Slg.) MfN No. 2002/29 und 37, 38. 10. Flügelsamen; Beleg zu „ef. Dodonaea sp." zu Müller-Stoll 1936: $121 ; \times 10(2002 /$ 37). 11, 12. Großes Zweigglied, Abdruck und Gegendruck, leicht mit Lack überzogen; $\times 10$ (2002/37). 13. Endstück eines Zweigleins mit seitlicher Verzweigung und mindestens 4 Zweiggliedern; $\times 10(2002 / 38)$. 


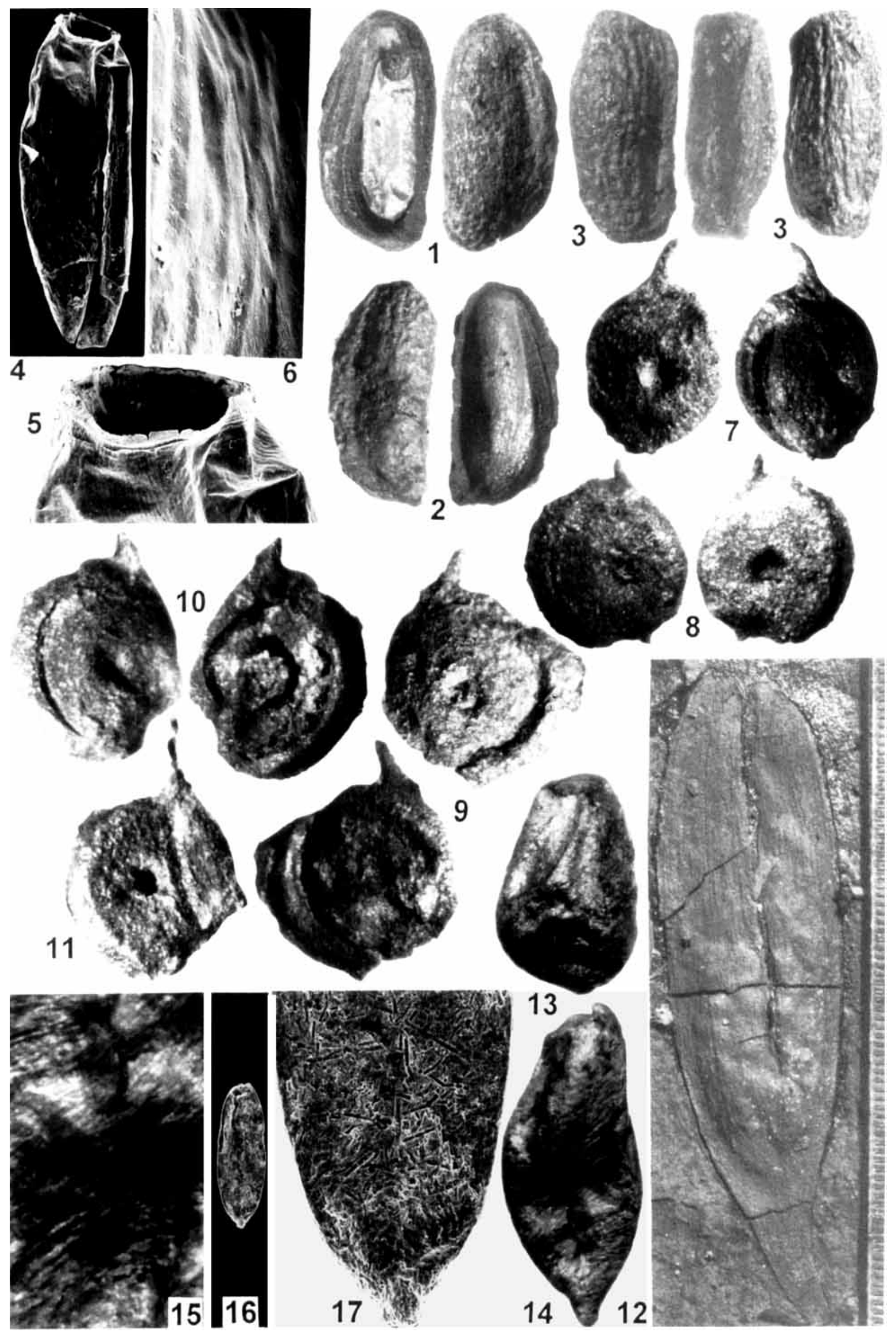


Vorkommen: Untereozän bis Obermiozän in ganz Europa, im Pliozän nur Relikt.

\section{Magnoliophyta}

\section{Hydrocharitaceae}

\section{Stratiotes kaltennordheimensis (Zenker) Keil- hack}

Tafel 3: 1-6

1833 Folliculites kaltennordheimensis Zenker, N. Jahrb. Geol. Min.: 177, Tafel 4, Fig. A3-7 - Kaltennordheim/Rhön (Untermiozän).

1896 Stratiotes kaltennordheimensis Keilhack, Z. deutsch. geol. Ges. 48: 987-989 - Kaltennordheim/Rhön (Untermiozän).

Bauersberg/Bischofsheim MfN No. 1989/22; Bb 002a, Hochrain MfN No. 2002/06 (Ho 006), Kaltennordheim MfN No. 1989/472 (Orig. 1173; Müller-Stoll 1936, Tafel 2, Fig. 6), No. 1977/343 (Slg. Böhme), MfN No. 1988/95-100 (Slg. A. Braun), No. 1988/93 (Slg. R. Ludwig), MfN No. 1989/ 473-475, MfN No. 1993/701 (Slg. D. Mai), Ka 009 a, b, Theobaldshof Senckenberg-Mus. Frankfurt a.M. (Orig. Moayedpour 1977, Tafel 14, Fig. 7), Wüstensachsen MfN o. Nr. (Orig. Müller-Stoll 1936, Tafel 2, Fig. 5b, c).

Länglich-eiförmige Samen mit basalem, dickem, etwas schräg abgesetztem Mikropylarknoten. Rapheleitbündel von subbasal bis subapikal durchziehend. Oberfläche des Samens längsrunzelig. Länge zwischen 6 und $8 \mathrm{~mm}$, Breite zwischen 3 und 3,4 mm. Samenfach mit hyalinem Tegmen (Tafel 3: 4).

Leicht mit Stratiotes amarus Mai (1987) und St. tuberculatus E.M. Reid (1920) zu verwechseln.

Das Typusmaterial von Zenker (1833) war bis heute nicht auffindbar, aber im MfN Berlin liegt sehr viel Material, das die Populationsbreite der Art deutlich macht.

Vorkommen: Oberoligozän bis Obermiozän in Europa, besonders häufig aber im mittleren bis oberen Miozän.

\section{Potamogetonaceae}

\section{Potamogeton schenkii Kirchheimer}

Tafel 3: 7-11

1936 Potamogeton schenkii Kirchheimer, Palaeontographica Abt. B, 82: 123-124, Tafel XIII, Fig. 6a-d - Bischofsheim, Bauersberg (Untermiozän).

1965 Potamogeton corticosus Nikitin, Akvitan. fl. Lagernovo Sada: 55, pl. IV, fig. 16-18 - Lagernii Sad/Ob (Untermiozän).

Bauersberg (Braunkohle) MfN No. 1989/22 (Orig. 3744; Kirchheimer 1936, Tafel 13, Fig. 6a-c, Müller-Stoll 1936, Tafel 2, Fig. 1a, b [Paratypen]).

Steinkerne groß, dick, von breit-elliptischer fast kreisförmiger Umrissform, an der Basis mit mitunter kurzem Stiel, Griffelrest maximal 0,63 mm lang. Keimklappe gekielt (meistens abgebrochen), mit häutigen Zacken, Seitenflächen platt oder schwach aufgewölbt, in Einzelfällen stark aufgewölbt (vgl. Tafel 3: 7,8). Zentrales Foramen stets vorhanden, stellenweise von tropfenförmiger Gestalt, stellenweise elliptisch oder rundlich, nicht durchgehend. Die Größe (ohne Griffel) schwankt zwischen 1,8-2,6 und 1,6-2,4 mm. Endokarp bis $0,003 \mathrm{~mm}$ dick, aus stark sklerotisierten, rundlichen, getüpfelten Zellen.

Nach den Ausführungen von Dorofeev (1986) eine Art aus der Gruppe Potamogeton corticosus Nikitin, obwohl er unsere Art aus der Rhön gar nicht erwähnt. Nach Knobloch (1977) müssen für die artliche Zuordnung vor allem vier Arten berücksichtigt werden: Potamogeton schenkii Kirchheimer (1936), P. tertiarius Dorofeev (1959a), $P$. irtyshensis Dorofeev (1963) und P. corticosus Nikitin (1965), besser $P$. corticosus Nikitin in Dorofeev (1963).

Aus der ausführlichen Diskussion dieser Arten bei Knobloch (1977: 32) entnehmen wir folgendes:

„Was die Länge des Griffelrestes und die Form des Foramens anbelangt, scheint es sich um sehr variable Merkmale zu handeln, die

Tafel 3. 1-6. Stratiotes kaltennordheimensis (Zenker) Keilhack - Hochrain MfN No. 2002/06. 1. Samen von außen und innen, mit Tegmen (weiß gefärbt); $\times 6,5$. 2. Samen, dehisziert, von außen und innen; $\times 6,5$. 3. Samen in drei Ansichten; $\times 6,5$. 4. Tegmen aus einem Samen; SEM $\times 15.5$. Tegmen im chalazalen Bereich; SEM $\times 50$. 6. Langgestreckte Oberflächenstreifung eines Tegmen; SEM $\times$ 500. 7-11. Potamogeton schenkii Kirchheimer - Bauersberg MfN No. 1989/22. 7. Steinkern, dehisziert, mit fehlender Keimklappe (rechts) und langem Griffelrest; Paratypus; $\times 15$. 8. weiterer Steinkern mit deutlichem Foramen; $\times$ 15. 9. Steinkern mit deutlich gekielter Keimklappe und starkem Griffelrest; möglicherweise Holotypus von Kirchheimer $(1936) ; \times 15$. 10. Steinkern, völlig gespalten längs des größeren Umfangs, mit hufeisenförmigem Fach und Kondylus (rechts); $\times$ 15. 11. weiterer Steinkern mit langem Griffel und Stielchen; $\times 15,12-15$. Spirematospermum wetzleri $(\mathrm{Heer})$ Chandler Bauersberg Slg. Kramm und Hochrain MfN No. 2002/04. 12. Frucht mit Dehiszenzspalt in der Mitte (Bauersberg); $\times 2.13,14$. Isolierte Samen verschiedener Form; $\times 6,5$. 15. Oberfläche eines Samen mit Spiralstreifung; $\times 20$. 16, 17. Typha tambovica Dorofeev - Bauersberg MfN No. 1998/443. 16. Tegmen eines Samens; SEM $\times 50$. 17. Basaler Teil des Samens mit dickem Stielsatz und hexagonal quergestellten Zellen; SEM $\times 250$. 
kaum zu einer artlichen Abtrennung von $P$. corticosus und $P$. tertiarius zu gebrauchen sind. Demgegenüber scheint die größere Aufwölbung der Seitenflächen und das Vorhandensein eines Höckers an der Schulter für $P$. corticosus und $P$. schenkii charakteristisch zu sein.

Von $P$. corticosus wurden von Nikitin (1965, Tafel IV: 16-18) nur einige wenige Exemplare abgebildet, die die Variabilität dieser Art nicht zeigen. Vor Nikitin (1965) gebrauchte den gleichen Namen schon Dorofeev $(1958,1963)$. Da in Nikitin (1965) kein Holotypus zu Potamogeton corticosus genannt wird (als Holotypus wird nur die Kollektion Lagernyj Sad II bezeichnet), ist die Art im Sinne der geltenden nomenklatorischen Regeln ungültig beschrieben. Da sie von Dorofeev (1963) früher als von Nikitin (1965) veröffentlicht wurde und auch das von Dorofeev abgebildete Material die Variabilität besser darstellt, schlägt Knobloch (1977) vor, das von Dorofeev (1963) abgebildete Material als Typusmaterial aufzufassen (Lectotypus: Abb. $15 / 7$ bei Dorofeev 1963) (Lectotypus nach Dorofeev 1986: Tafel 4/18 bei Nikitin 1965).

Wenn wir die zahlreichen Abbildungen von Potamogeton corticosus bei Dorofeev (1963) und die wenigen Abbildungen von $P$. schenkii bei Kirchheimer (1936) miteinander vergleichen, stellen wir lediglich einen deutlicher entwickelten Höcker an der Schulter und bei einigen Exemplaren deutlichere und zahlreichere häutige Zacken an den Seiten fest. In diesen zwei Merkmalen tendieren unsere Funde eindeutig zur sibirischen Art, obwohl nicht ausgeschlossen werden kann, daß $P$. schenkii eine gleiche Variabilität aufweist als letztere und dann $P$. corticosus ein Synonym zu $P$. schenkii darstellen würde." (Ende des Zitates).
Diese hier geforderte Variabilität ist tatsächlich an dem über hundert Exemplare zählenden Material aus Bischofsheim festzustellen, so dass P. corticosus Nikitin keine systematische Berechtigung mehr besitzt.

Die ganze Artengruppe besitzt einen Typ von Früchten, die sehr wenig ähnlich zu den heutigen ist und nach Dorofeev (1986) nur sehr angenähert bei Potamogeton confervoides Reichenbach (Kanada) vorkommt.

Vorkommen: Oligozän Westsibiriens (Dorofeev 1986), Obermiozän von Südmähren (Knobloch 1977), in Süddeutschland nur ,älteste Schichtglieder der OSM“ (Ottnangium; Gregor 1982).

\section{Zingiberaceae}

\section{Spirematospermum wetzleri (Heer) Chandler}

Tafel 3: 12-15

1859 Gardenia wetzleri Heer, Fl.tert.Helvet.III: 192, Tafel CXLI, Fig. 81-103 - Günzburg (Mittelmiozän).

1925 Spirematospermum wetzleri Chandler, Upper Eoc. Fl. Hordle: 19-20, pl. I, fig. 8, textfig. 5 - Hordle/Hants (Obereozän).

Bauersberg MfN No. 1998/435; Slg. E. Kramm, Fulda; Slg. Geol. Pal. Inst. Univ. Würzburg (Orig. Müller-Stoll 1936, Tafel 1, Fig. 6, 7); Slg. Kelber Burggrumbach (Orig. Kelber \& Gregor 1987, Tafel 4, Fig. 4), Hochrain MfN No. 2002/04 (Ho 004), Kaltennordheim Ka 009, MfN No. 1993/700, Roth bei Fladungen MfN No. 1989/49, Sieblos MfN No. 1989/43 (Orig. Muiller-Stoll 1936, Tafel 1, Fig. 8a-c); Theobaldshof Senckenberg Mus. Frankfurt a.M.; (Orig. Moayedpour 1977, Tafel 15, Fig. 1, 2)

Samen groß, 5-10 $\mathrm{mm}$ lang, elongat, fast zylindrisch; basal truncat, Hilumgrube oft mit Resten des fädig gebauten Arillus; apikales Ende zugespitzt bis abgerundet; Chalaza tief im Gewebe verborgen, als großer Hohlraum ausgebildet. Sa-

Tafel 4. 1, 2. Carex hartauensis Mai - Bauersberg MfN No. 1998/431. 1. Nüsschen von beiden Seiten, mit deutlicher Kante (links); $\times 25$. 2. weiteres Nüsschen mit Resten des engnervigen und engangliegenden Utriculus; $\times 25$. 3. Carex pseudocyperoides Łańcucka-Środoniowa - Kaltennordheim MfN No. 2002/20, Nüsschen von beiden Seiten; $\times 20.4$. Dulichium marginatum (C. \&. E.M. Reid) Dorofeev - Kaltennordheim MfN No. 2002/21, Nüßchen von beiden Seiten mit Resten der Basalborsten $\times 20.5-7$. Cladium oligovasculare Mai - Bauersberg MfN No. 2002/30. 5. Steinfrucht von zwei Seiten mit meridionalen Leitbündelfurchen; $\times 25.6$. weitere Steinfrucht von beiden Seiten; $\times 25.7$. Steinfrucht, längsgespalten, mit großem, ovalem Fach und Öffnung im Fußteil; $\times 25.8$. Cladiocarya trebovensis (Bůžek) Mai - Bauersberg MfN No. 1998/433, Endokarp mit aufgeblähtem Mittelteil und abgestutztem Basalteil; × 25. 9, 10. Saururus bilobatus (Nikitin) Mai - Hochrain MfN No. $2002 / 14$. 9. Samen, oval geformt, von beiden Seiten; $\times 30$. 10. Abgeflachte Teilfrucht, zerbrochen, in der Mitte mit Samen, von beiden Seiten; $\times 30$. 11, 12. Ceratophyllum lusaticum Mai - Hochrain MfN No. 2002/39. 11. Frucht, dehisziert, innen (rechts) mit verzweigten Leitbündeln; $\times 12$. 12. weitere Frucht, ebenfalls mit deutlichen Leitbündeln und ohne Griffel; $\times 12$. 13-15. Boehmeria raria Mai - Bauersberg MfN No. 1988/437. 13. Nüßchen, Randsaum stark erodiert; SEM $\times 30$. 14, 15. Zellstruktur vom Randsaum und aus der Mitte eines Nüsschens; SEM $\times 375$. 16, 17. Pilea bashkirica Dorofeev - Bauersberg MfN No. 1998/ 436. 16. Nüsschen von beiden Seiten, randlich angebrochen; $\times 25$. 17. weiteres Nüsschen; kleiner und schmäler, von beiden Seiten; $\times 25$. 18-20. Cercidiphyllum helveticum (Heer) Jähnichen, Mai \& Walther - Hochrain MfN No. 2002/05. Balgfrüchte verschiedener Form und Größe, mit deutlichen Dehiszenzspalten; $\times 6,5$. 

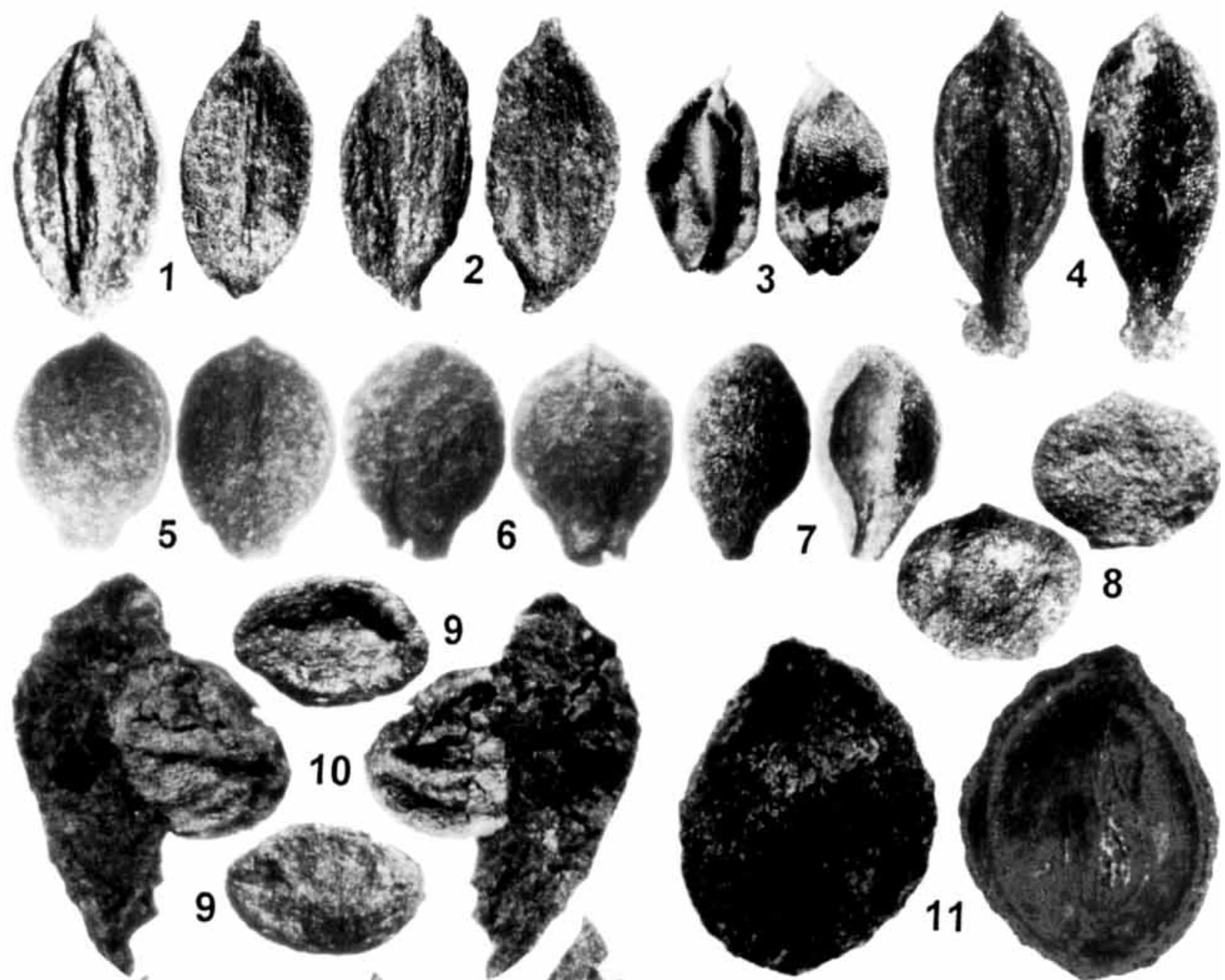

$3 \times 1508$
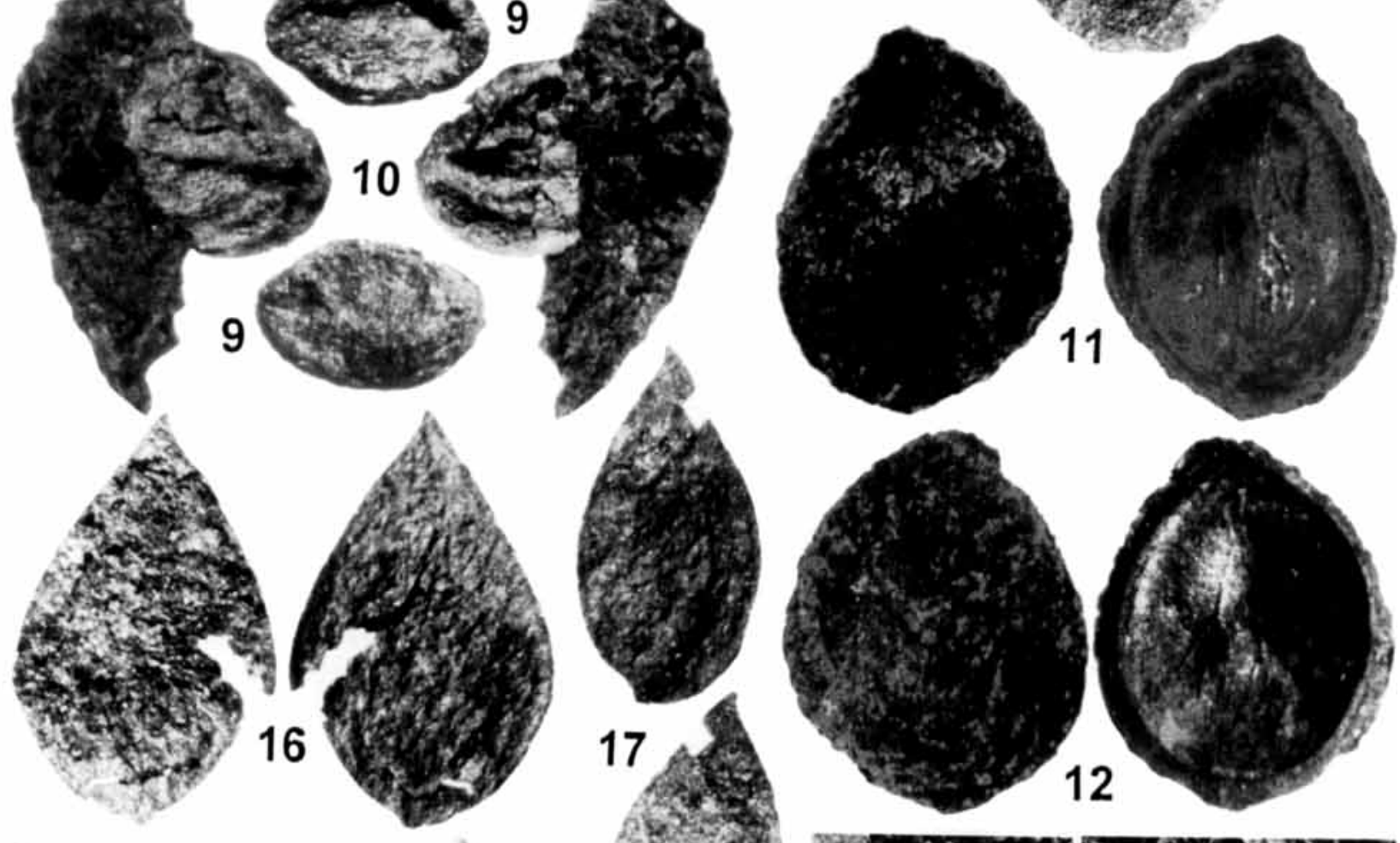
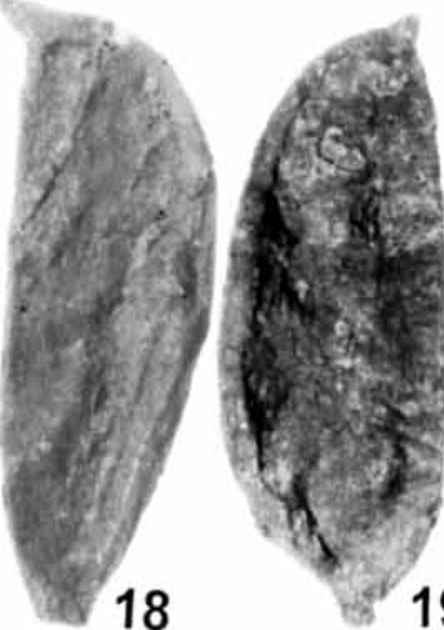

18

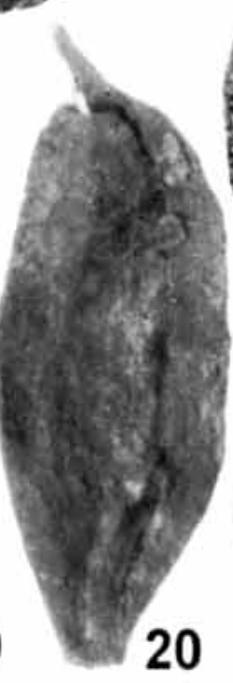

is $5 x-20$.

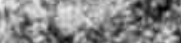

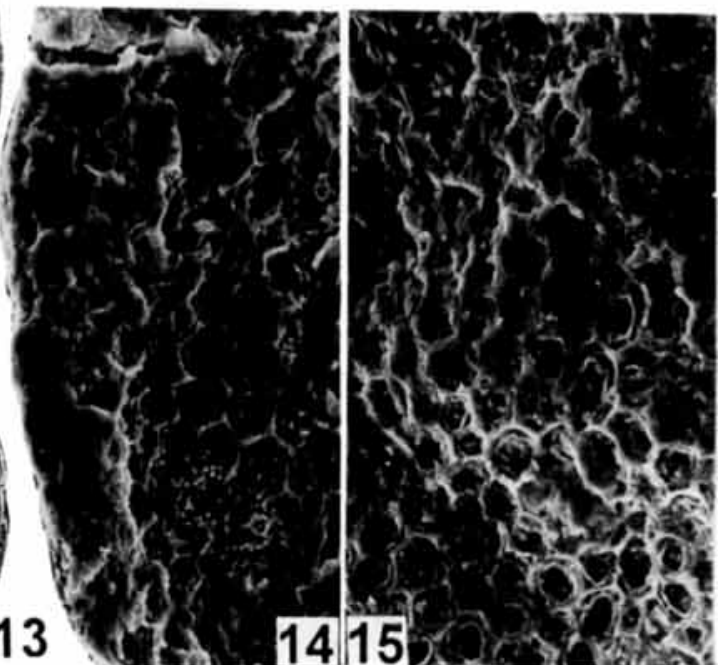


menoberfläche mit feinrissiger Spiralstreifung. Oft mit Verdrückungsmalen durch benachbarte Samen in der Frucht. Frucht trilocular, abgeflacht, mit Dehiszenzspalt in der Mitte, zentralwinkelständige Plazentation.

Ausgestorbene Gattung. Typische Art für Sumpfpflanzengesellschaften mit Glyptostrobus und Osmunda. Die fossile Art hat Beziehungen zur rezenten Cenolophon oxymitrum (Schumann) Holttum, einer Art der thailändischen Gebirgsflora.

Vorkommen: Obereozän bis Pliozän, im Oberoligozän/Miozän fast ganz Eurosibirien.

\section{Cyperaceae}

\section{Carex hartauensis Mai}

Tafel 4: 1, 2

1991 Carex hartauensis Mai in Mai \& Walther, Abh. Mus. Mineral. Geol. Dresden 33: 132-133, Tafel 17, Fig. 26 , 27 - Tongrube Hartau (Untermiozän, VI).

Bauersberg MfN No. 1998/431.

Dreikantige, im Umriss elliptische Früchtchen. Schläuche enganliegend, mit starken Nerven. Früchte basal verschmälert, stielartig oder abgerundet, ohne Diskus; Griffelrest kurz bis mittellang, gerade abgestutzt, dicklich, gebogen; Oberflächenstruktur punktat bis fast glatt, schwach glänzend, auffallend dünnwandig. Früchtchen (ohne Griffel) 1,4 bis 1,9 mm lang und 0,6 bis $1,2 \mathrm{~mm}$ breit.

Die sehr dünnwandigen Früchte stecken oft in dauerhaften, vielnervigen Schläuchen, die terminal auffällig stumpf sind und wohl schon ursprünglich sehr flach waren. Derartige Schläuche konnten bei dem Material aus der Rhön bisher nicht gefunden werden, lediglich deren Nerven waren abgedrückt. Den Früchtchen und Utriculi ist keine heutige europäische Art vergleichbar. Auch mit der amerikanischen Carex venusta Dewey hat die Art nichts gemein (vgl. dagegen Mai 1964). Ein Vergleich ist bisher nicht geglückt.

Vorkommen: Miozän Nordböhmens (Bủžek \& Holý 1964), Oberoligozän bis Untermiozän in Nordwestsachsen, in der Lausitz bis Obermiozän (Mai 2000c).

\section{Carex pseudocyperoides Lańcucka-Środoniowa}

Tafel 4: 3

1979 Carex pseudocyperoides Łańcucka-Środoniowa, Acta Palaeobot., 20 (1): 91, pl. XIV, fig. 14-17 - Nowy Sącz (Untermiozän).

Kaltennordheim MfN No. 2002/20.
Schmal-elliptische, scharf dreikantige, mittelgroBe Früchtchen. Früchtchen mit mittellangem, dünnem, zugespitztem Griffelrest und kurzem, basalem Stielchen mit Diskus, scharf dreikantig, mit zellig-grubiger Oberflächenstruktur, matt, Früchtchen (ohne Griffel) 1,4-1,8 mm lang und 0,6-0,9 mm breit. Größte Breite in der Mitte.

Derartige Merkmale verweisen die Art zur heutigen Sektion Pseudocypereae. Von den beiden rezenten Arten $C$. pseudocyperus Linné und C. comosa Boott ist die fossile Art durch schlankere, elliptische Gestalt und etwas kräftigere Griffelreste der Früchte und die höhere Anzahl der Nerven in den Schläuchen unterschieden.

Vorkommen: Nur Miozän von Polen (Eańcucka-Środoniowa 1979) bis Odessa (Negru 1986). In Deutschland vom Untermiozän bis Obermiozän (Mai 2000c).

\section{Cladium oligovasculare Mai}

Tafel 4: 5-7

1978 Cladium oligovasculare Mai in Knobloch, Vĕstn. ÚÚG, 53: 158 , t. I, f. $1-3,8-9-$ Bhg. T $38 / 56$ bei Schrakau (Untermiozän).

Bauersberg MfN No. 2002/30 (Bb 003), (8 Expl.), Theobaldshof Senckenberg-Mus. Frankfurt a.M. (Orig. Moayedpour 1977, Tafel 14, Fig. 8-10).

Steinkerne eiförmig, mit weniger stark aufgeblähtem Mittelteil, mit 3-5 tief eingeschnittenen, meridionalen Leitbündelfurchen. Halsteil sehr kurz, stark verengt, Fußteil wenig verbreitert, zur Spitze hin allmählich zugespitzt. Länge 1,2-1,8 mm, Breite 1-1,4 mm.

Früchte bei guter Erhaltung eiförmig, mit abgestutzter Basis und allmählich zulaufendem, fleischigem Griffel, Exokarp dünn, runzelig.

Steht nach der Morphologie zwischen Cladium trilobatum Mai (1987) und C. palaeomariscus Dorofeev (1969), die aber einen breiteren Fußteil zeigt.

Die Früchtchen, welche Moayedpour (1977) zu den Sparganiaceae stellte, gehören nach GröBe, allgemeiner Form und den Leitbündelfurchen zu der vorliegenden Art von Cladium P. Browne.

Vorkommen: Mittelmiozän in Polen und Südmähren, Unter- bis Mittelmiozän in Deutschland (Mai \& Walther 1991, Mai 1999a, 2000c).

\section{Cladiocarya trebovensis (Bůžek) Mai}

\section{Tafel 4: 8}

1963 Sparganium trebovense Bůžek, Časopis Mineral. Geol. 8: 126-134, pl. 11-13 - Semanín (Untermiozän). 
1978 Cladiocarya trebovensis Mai in Mai \& Walther, Abh. Staatl. Mus. Mineral. Geol. Dresden, 28: 144, Tafel 48, Fig. 39 - Haselbach (Mitteloligozän).

Bauersberg MfN No. 1998/433, Theobaldshof SenckenbergMus. Frankfurt a.M. (Orig. Moayedpour 1977, Tafel 14, Fig. 3-5).

Früchte eiförmig bis kugelig, bisymmetrisch, stark aufgeblasen im Mittelteil, mit 2, selten 3 mehr oder weniger hervortretenden Leitbündelwülsten, die besonders isolierte Endokarpien auszeichnen. Basalteil abgestutzt; Keimloch vom Hilarpfropf verschlossen. Griffelrest am terminalen Pol allmählich verschmälert. Mikropylarhöcker kurz. Oberfläche fein granulat. Länge 0,8 bis $1,8 \mathrm{~mm}$, Breite 0,6 bis $1,5 \mathrm{~mm}$.

Nach den Merkmalen, die auch das Typusmaterial teilweise erkennen läßt, keine SparganiumSteinkerne. Besonders gut erhaltene Exemplare mit Exokarp und Endokarp wurden aus den untermiozänen Cyprisschiefern (Westböhmen) bekannt (Bůžek, Holý \& Kvaček 1996). Vergleichbare heutige Formen wurden bei Cladium juncoides Elmer (Luzon) und $\mathrm{Cl}$. deplanchei C.B. Clarke (Neukaledonien) gesehen. Was Moayedpour (1977, Tafel 14, Fig. 3-5) als „Vitaceae“ abbildete, dürfte Cladiocarya trebovensis sein.

Vorkommen: Seit Obereozän, besonders häufig im Mittelmiozän.

\section{Dulichium marginatum (C. \& E. M. Reid) Do- rofeev}

Tafel 4: 4

1915 Dulichium spathaceum var. marginatum C. \& E. M. Reid, Plioc. floras Dutch-Prussian Border: 66, t. III, fig. 5, 6-Reuver (Pliozän).

1959b Dulichium marginatum Dorofeev, Dokl. Akad. Nauk USSR 127 (5): 1104 - Kozjulino/Toma‘ (Oligozän).

Hochrain Ho 0019, Kaltennordheim MfN No. 2002/21 (Ka 001).

Gestreckt eiförmige, 2-3,2 mm lange Früchtchen mit kurzem oder, wenn langem, dann abgestumpftem Stylus, der an seiner Basis scharfe Kanten bis schmale Flügelleisten ausbildet; ein wenig verschmälertes Stielchen zum basalen, borstentragenden Diskus hin. Oberflächenstruktur deutlich grubig. Index Länge zu Breite $3-3,7$.

Dorofeev $(1959 b, 1963)$ führt im Gegensatz zu Kirchheimer (1957), der alle bekannten fossilen Dulichium-Reste in einer Art (D. vespiforme C. \& E. M. Reid 1908) vereinigt, diese gut kenntlichen, langgestreckten kurzgriffligen und stark strukturierten Reste als eigene Art. Diese Art steht $D$. arundinaceum (Linné) Britton aus Nordamerika näher als $D$. vespiforme.

Vorkommen: Oberoligozän bis Oberpliozän von Westeuropa bis Westsibirien.

\section{Typhaceae}

\section{Typha tambovica Dorofeev}

Tafel 3: 16-17

1982a Typha tambovica Dorofeev, Palaeokarpol. issled. Kajnozoja: 21 , pl.4, fig. 16-35 - Abakumovka/Tambov (Miozän).

Bauersberg MfN No. 1998/443.

Beschreibung: Samen elliptisch, größte Breite in der Mitte, mehr als 3 mal so lang wie breit, $0,9 \mathrm{~mm}$ mal $0,3 \mathrm{~mm}$; Spitze des Samens nur 2 mal schmäler als die allergrößte Breite des Samens, mit Hals; Keimdeckelchen eingesenkt; Griffelrest klein, dünn; Basis zugespitzt, mit dicklichem Stielrest. Maschenschicht der Testa aus großen, hexagonalen, quergestellten Zellen, die in Längsreihen angeordnet sind, aber voneinander in großen Abständen stehen.

Sehr verbreitete tertiäre Typha-Art mit Verwandtschaft zu T. capensis Rohrbach (Südafrika). Durch andere Form und Größe und weiten Abstand der Zellen der Maschenschicht gut von weiteren tertiären Arten von Typha zu unterscheiden.

Vorkommen: Miozän von Tambov/Russ. Plattform und Rostov (Dorofeev 1982a). Oberoligozän-Obermiozän von Bitterfeld und der Lausitz (Mai 1987, 2000c).

\section{Saururaceae}

\section{Saururus bilobatus (Nikitin) Mai}

Tafel 4: 9, 10

1963 Carpolithus bilobatus Nikitin in Dorofeev, Tretičn. flory Zapadnoj Sibiri: 277, Abb. 37, fig. 2, 3 -- Lagernii Sad/ $\mathrm{Ob}$ (Untermiozän).

1965 Carpolithus bilobatus Nikitin, Akvitan.fl.Lagernovo Sada: 92-93, pl. XVIII, fig. 12, 13, pl. XIX, fig. 1, 2 - Lagernii Sad/Ob (Untermiozän).

1978 Saururus bilobatus Mai in Mai \& Walther, Abh. Mus. Mineral. Geol. Dresden, 28: 45, 46, Tafel 25, Fig. 1, 2 Borna-Ost (Mitteloligozän).

Hochrain MfN No. 2002/14 (Ho 0014); Ho 0025 (7 Expl.).

Teilfrucht (Kokkus) ovoid bis rundlich, einseitig etwas abgeflacht, zerstört, nur Bruchstück bis $1,5 \mathrm{~mm}$ im Durchmesser; Oberfläche runzelig, warzig und wabig; Perikarp aus vielen Schichten getüpfelter, starrwandiger Parenchymzellen. Samen eiförmig-rundlich bis fast kugelig, 0,7 bis 


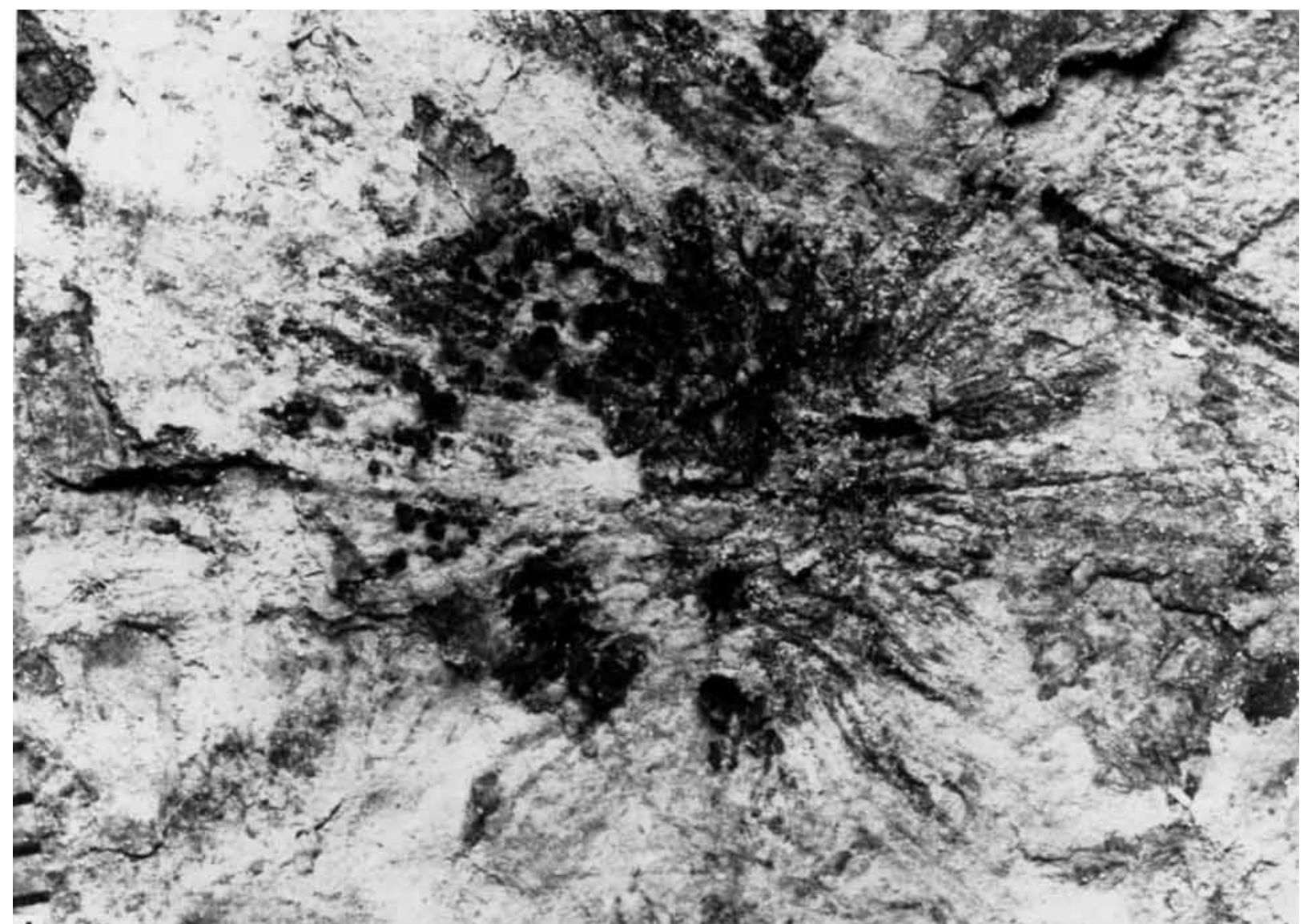

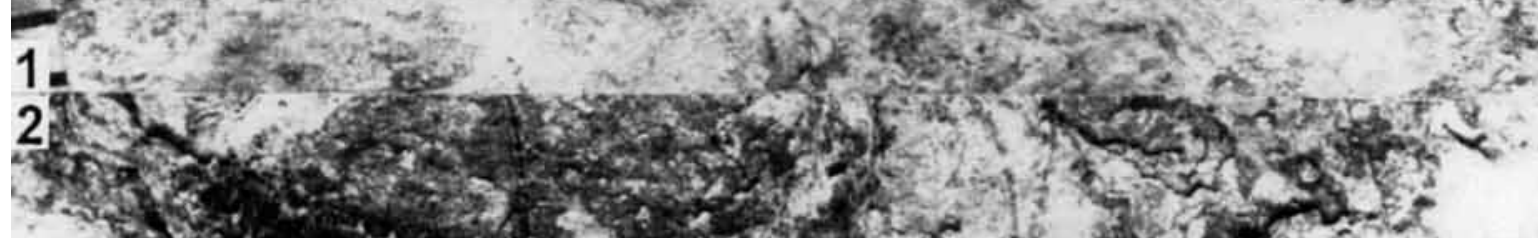

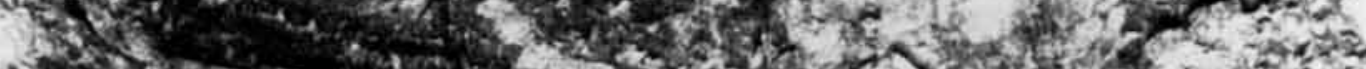

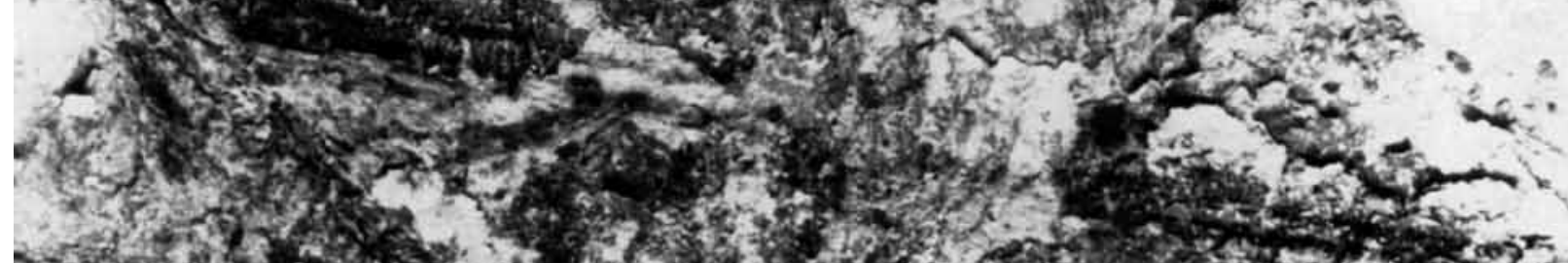

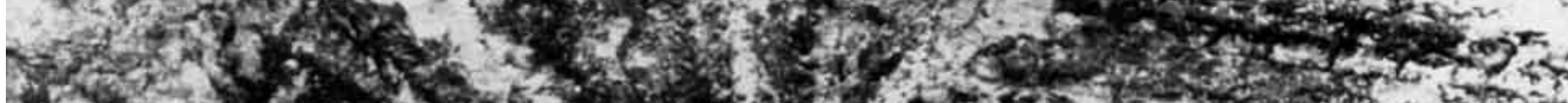

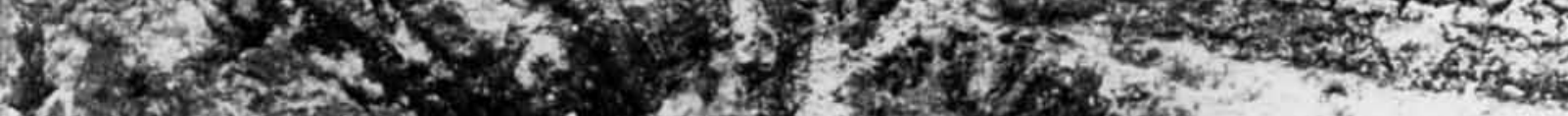

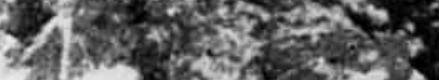
12.

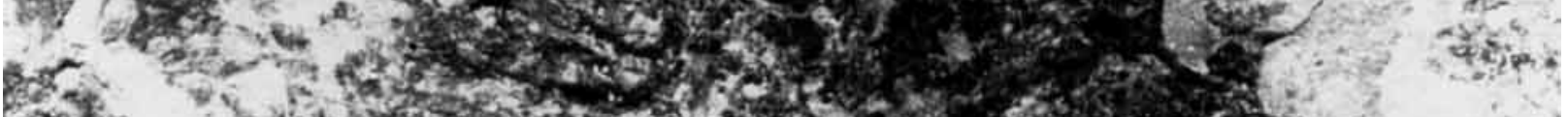

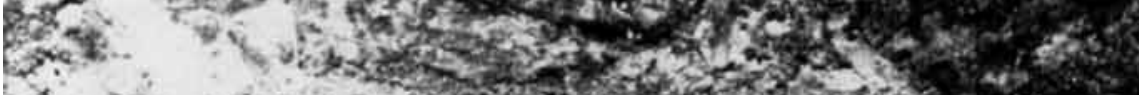

6.

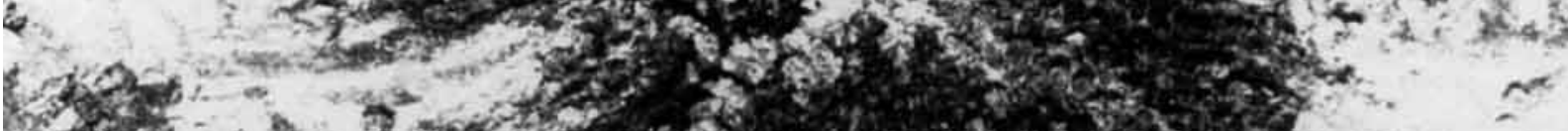

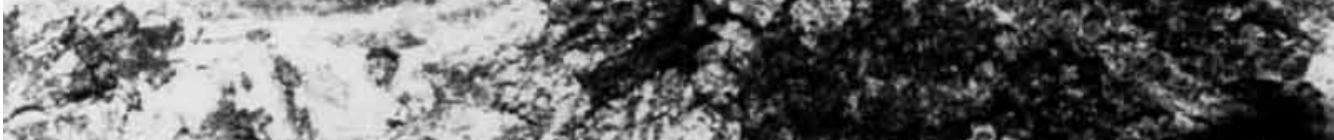

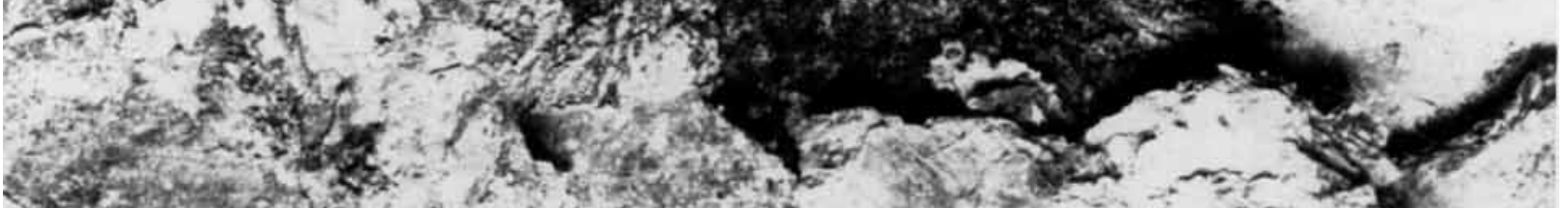


1,0 mm im Durchmesser, orthotrop, mit abgerundeter Mikropylarspitze, die bei der Keimung ausgezackt aufreißt, basal mit großer, kreisrunder Chalaza, von der aus die Strukturzellen in strahlenartigen Reihen ausstrahlen; innere Schicht als festes, hyalines Tegmen ausgebildet, das aus faserigen, stark verdickten Zellen besteht; äußere Schicht aus lockeren, rundlichen Zellen, die eine warzig-retikulate Oberfläche ergeben, sich aber leicht abreiben lassen, so daß oft die Außenseite des Tegmens stark glänzend erscheint.

Diese Kokken und Samen von Saururus wurden von Nikitin (1965) bereits sehr genau untersucht, ohne daß diesem Autor eine botanische Zuordnung gelang. Mai \& Walther (1978) fanden einen zutreffenden Vergleich mit den Teilfrüchtchen und eingeschlossenen Samen von Saururus Linné. Sehr gut zum Vergleich eignet sich $S$. cernuus Linné (atlant. Nordamerika). Sie wird aus Röhrichten (Knapp 1965) und aus den Cladium-Gesellschaften der Everglades von Florida (Loveless 1959) genannt.

Vork ommen: Obereozän bis Pliozän in Europa, Oligo-Miozän Westsibiriens.

\section{Ceratophyllaceae \\ Ceratophyllum lusaticum Mai}

Tafel 4: 11-12

1978 Ceratophyllum lusaticum Mai in Mai \& Walther, Abh. Staatl. Mus. Mineral. Geol. Dresden 28: 47, Tafel 25, Fig. 5 - Schlabendorf-Süd KB 160/66 (Untermiozän, VII).

Hochrain MfN No. 2002/39 (Ho 0018).

Früchte ohne langen Griffelrest und seitlichen oder basalen Stacheln, ohne Hautsaum, bisweilen aber etwas zähnig am Rande; Oberfläche kurzstachelig bis warzig; Perikarp dünn, äußeres Palisadensklerenchym etwa die Hälfte der Wanddicke einnehmend; Frucht klein, meist unter $3(2,6) \mathrm{mm}$ lang.

Eine Art aus der Submersum-Gruppe, von $C$. submersum Linné durch die geringe Größe und dünne Wand unterschieden. Auch von allen bisher bekannten fossilen Arten der Gruppe ( $C$. protanaiticum (Nikitin) Dorofeev, C. spinulosum Dorofeev, C. tenuicostatum Dorofeev 1974b) durch abweichende Merkmale unterscheidbar. In der äußeren Ornamentation etwas variabel.
Vorkommen: Mitteloligozän bis Untermiozän in Nordwestsachsen, besonders aber im Untermiozän bis Obermiozän der Lausitz (Mai \& Walther 1978, 1991, Mai 2001a).

\section{Cercidiphyllaceae}

\section{Cercidiphyllum helveticum (Heer) Jähnichen, Mai \& Walther}

Tafel 4: $18-20$

1855 Widdringtonia helvetica Heer pro parte, $\mathrm{Fl}$ tert. Helvet, I: 48; Tafel 16, Fig. 4, 5a; 6, 9, 11, 12 - Höhrhonen (Untermiozän).

1980 Cercidiphyllum helveticum Jähnichen et al., Blätter und Früchte europ. Tertiär: 371-372; Tafel VII, Fig. 1-3Höhrhonen (Untermiozän).

Hochrain MfN No. 2002/05 (Ho 005); Bauersberg Bb 007 (1 Expl.); Slg. Kelber, Burggrumbach (Orig. Kelber \& Gregor 1987, Tafel 4, Fig. 9).

Balgfrüchte $8,0-12 \mathrm{~mm}$ lang, 2,5-3,5 $\mathrm{mm}$ breit, mit kurzem, dickem Stiel; Griffelrest als krummes Spitzchen, auf der etwas aufgeblähten Bauchseite entlang dem Leitbündelstrang aufspringend; Rückenseite mit starkem Nerv. Exokarp parenchymatisch, Endokarp derb, quergestreift, aus ungewöhnlich stark verdickten, spindelförmigen Zellen.

Die gut kenntlichen Balgfrüchte von Cercidiphyllum beschrieb als erster Brown (1935) (Öhningen). Da sie mit $C$. crenatum-Blättern häufig in einer Schicht lagen, wurden sie mit diesen unter dem gleichen Namen vereinigt. Korrekte Nomenklatur und Synonymie stellten Jähnichen et al. (1980) zusammen. Vergleichbar ist in allen Fällen Cercidiphyllum japonicum Siebold \& Zuccarini (Japan, Mittelchina).

Vorkommen: Oligozän und Untermiozän, Nordböhmen und Sachsen; Mittel- und Obermiozän von Schwaben, Lausitz, Österreich, Polen, Schweiz; Pliozän Frankfurt (Main); Transkarpaten und Thüringen (Mai \& Walther 1988).

\section{Plantanaceae}

\section{Platanus neptuni (Ettingshausen) Bůžek, Holý \& Kvaček}

Tafel 5: 1,2

1866 Sparganium neptuni Ettingshausen, Foss. Fl. Bilin I: 31, Tafel 7, Fig. 9-15 (non 17, 18) - Kučlín (Obereozän).

Tafel 5. 1, 2. Platanus neptuni (Ettingshausen) Bůžek, Holý \& Kvaček - Bauersberg MfN No. 2002/33. 1. Fruchtstand mit Stiel, stark zusammengedrückt; $\times 6,5$. 2. Fruchtstand, in der Mitte mit netzigem Fruchtstandboden; $\times 6,5$. 
1967 Platanus neptuni Bůžek, Holý \& Kvaček, Monatsber. Deutsch. Akad. Wissen. Berlin, 96 (3): 203-215, Tafel 1-4 - Div. Fundorte Nordböhmen (Oligozän-Untermiozän).

Bauersberg MfN No. 2002/33.

Früchte zu kugeligen Köpfchen vereint, die zu 1-6 an einem Stiel hängen, wenig zahlreiche Karpelle werden in der Sammelfrucht zu Karyopsen, die meist durch gegenseitigen Druck vierkantig, verkehrt-pyramidenförmig werden, am Grunde dicht mit sehr langen Schildhaaren besetzt, in der Mitte bauchig erweitert, allmählich in den Griffelrest verschmälert. Nach dem Abfallen der Früchte verbleibt der kugelige Blütenboden (Achsenschwellung) und zeigt netzig verbundene, durch ablösbare Faserbündel begrenzte, eckige Waben, deren Ränder von fransigen Resten der Kelchblätter umgeben sind. Karyopsen (Früchte) sind in der Achse eingesenkt, 4,5-7 mm lang, damit Fruchtköpfchen bis $12 \mathrm{~mm}$ im Durchmesser, Blütenböden nicht über $5 \mathrm{~mm}$ im Durchmesser.

Reife Früchte wurden von Mai \& Walther (1985) mitgeteilt. Große Analogien bestehen zu der endemisch vorkommenden Platanus kerrii Gagnepain aus Laos, trotzdem kann von einer Übereinstimmung beider Formen (Kvaček 1970) nicht gesprochen werden. Die heutige Art ist ein Element subtropischer Auenwälder.

Vorkommen: Vom Mitteleozän bis Mittelmiozän Mitteleuropas nachgewiesen. In einigen Floren (z. B. Oberoligozän von Markvartice) vorherrschend.

\section{Urticaceae}

\section{Pilea bashkirica Dorofeev}

Tafel 4: 16, 17

1982b Pilea bashkirica Dorofeev, Iskop. cvetkov. rasten. SSSR, 2: 52; pl. 129, fig. 9-13 - Moskovo (Pliozän).

Bauersberg MfN No. 1998/436.
Nüsschen wenig bikonvex, abgeflacht, spindelförmig, leicht schief. Griffelrest als Spitzchen auf der ausgezogenen Apikalregion, öfter zur Seite geneigt, subbasal oder zentralbasal mit keilförmigen oder röhrenförmigem Funikularstielchen. Wände dünn, Oberfläche fein grubig-punktat, buckelig und feinwarzig. Länge $1,4-2 \mathrm{~mm}$, Breite $0,7-1 \mathrm{~mm}$.

Die Nüsschen sind sehr gut mit denen von $P i$ lea pumila (Linné) A. Gray zu vergleichen. Nach der Größenstatistik und der Morphologie sind auch sehr enge Beziehungen zu den Früchtchen von P. cantalensis (E. M. Reid) Dorofeev 1963 vorhanden. Mit einer Länge von $1-1,7 \mathrm{~mm}$ und Breite von 0,5-0,9 mm sind diese aber im Mittel etwas kleiner; ihre Oberfläche ist fast immer mit länglichen dunklen Flecken bedeckt, die mitunter zusammenfließen können. Die heutige Vergleichsart Pilea pumila kommt koloniebildend auf feuchten, nährstoffreichen, beschatteten Böden in der Laubwaldzone des atlantischen Nordamerika und in der Krautschicht der Larix gmelinii-Wälder der chinesischen Nordostprovinzen vor (Gleason 1963, Wang 1961).

Vorkommen: Pliozän im europäischen Teil von Russland (Dorofeev 1982b) und in Thüringen (Mai \& Walther 1988).

\section{Boehmeria raria Mai}

Tafel 4: 13-15

1987 Boehmeria raria Mai, Feddes Repert. Berlin, 98: 110, Tafel V, Fig. 10, 11; Tafel XI, Fig. 6, 7 - Sandförstgen (Untermiozän).

Bauersberg MfN No. 1998/437 (1 Expl.).

Nüsschen eiförmig, zweiseitig gewölbt, an den Rändern zusammengedrückt, ohne oder mit sehr schmalen Säumen; gewölbte Mitte mit netziger Skulptur; Perikarp dünn, außen aus großlumigen Zellen, innen aus sehr flachgedrückten, tangentialen Elementen. Länge $0,8 \mathrm{~mm}$, Breite $0,5 \mathrm{~mm}$.

Tafel 6. 1-3. Alnus latibracteosa Mai - Hochrain MfN No. 2002/17. 1. Flügelfrucht von beiden Seiten; $\times 12$. 2. Flügelfrucht, seitlich beschädigt; $\times 12$. 3. Flügelfrucht mit Griffel von beiden Seiten; $\times 12$. 4, 5. Alnus latibracteosa Mai - Bauersberg MfN No. 2002/32. 4. weiblicher Strobilus ohne Stiel; $\times 5$. 5. Teil eines zerbrochenen Strobilus mit deutlichen zweilappigen Brakteen; $\times$ 5. 6. Carpinus miocenica Negru - Bauersberg MfN No. 2002/36. Nüsschen mit zarten Leitbündeln, ohne Involukrum; $\times 10$. 7. Myrica cf. ceriferiformis Kownas - Kaltennordheim MfN No. 2002/24, Steinkern, dehisziert, von außen ohne Harzwarzen, von innen mit herzförmigem Fach; $\times 10.8$. Engelhardia macroptera (Brongniart) Unger - Kaltennordheim MfN No. 2002/25, Teil eines Involukrum, basal mit Abdruck einer Nuss und deren krönchenartiger Vorblatthülle; $\times 6,5$. 9. Styrax maximus (Weber) Kirchheimer - Bauersberg MfN No. 2002/31, Samen von beiden Seiten, rechts mit meridionalen Längsfurchen und schiefer Hilum-Narbe; $\times 5$. 10. Hypericum septestum Nikitin - Hochrain MfN No. 2002/18, Samen von beiden Seiten; $\times 50$. 11-14. Actinidia germania Mai - Kaltennordheim MfN No. 2002/28. 11, 12. Samen, in Braunkohle eingedrückt, von beiden Seiten; $\times 20.13,14$. Oberflächenretikulation der Samentesta; $\times 40$. 15. Acer cyclospermum Goeppert - Hochrain MfN No. 2002/16, Abdruck eines flachen, kreisförmigen Endokarps in der Braunkohle, links der Flügelansatz; $\times 6,5$. 


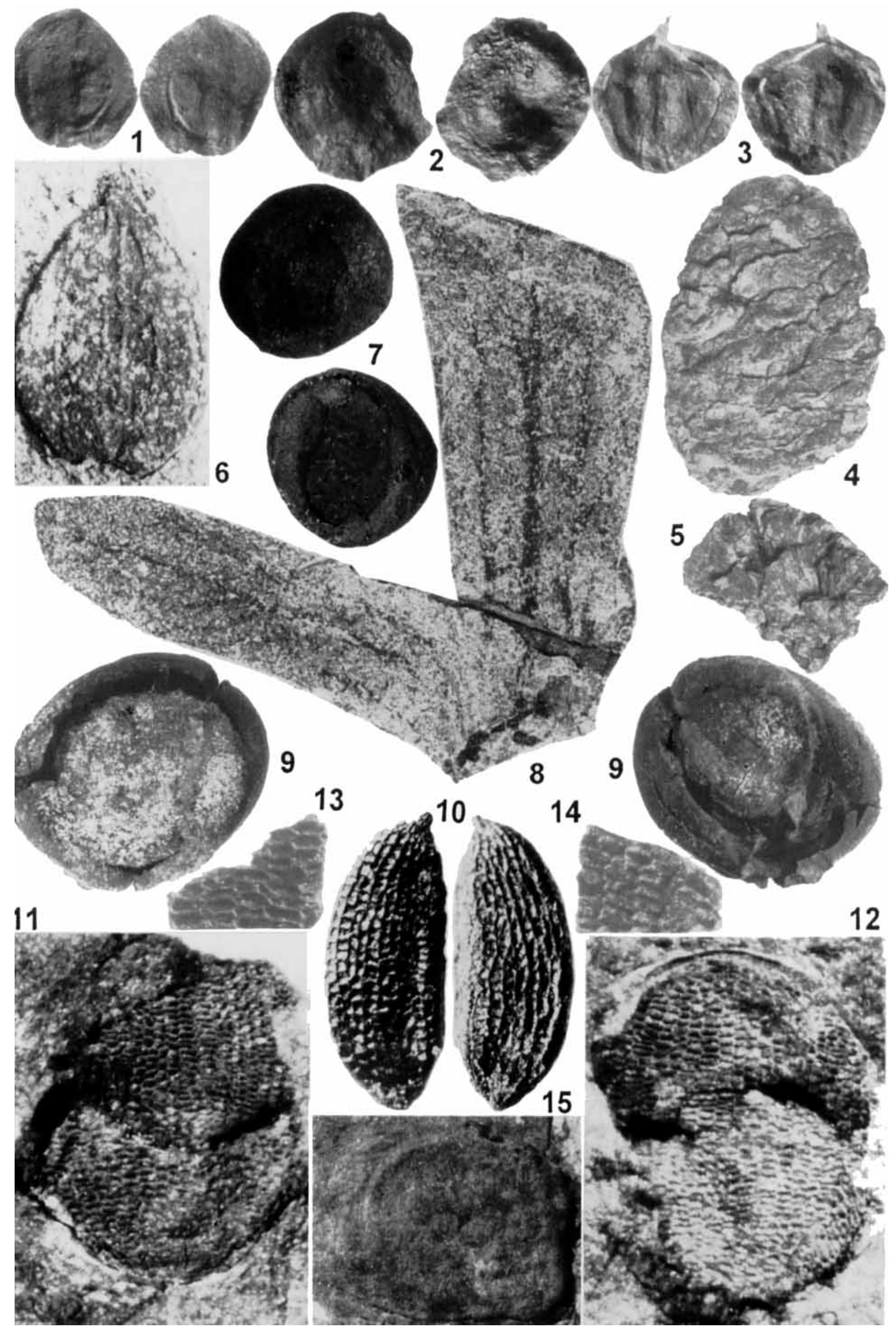


Eine sehr kleinfrüchtige Boehmeria-Art, die durch die Struktur des Mittelteiles und den nahezu fehlenden oder schmalen Saum sehr deutlich von der Art Boehmeria sibirica Dorofeev (1959a) zu unterscheiden ist. Eine entsprechende rezente Vergleichsart wurde bisher nicht gesehen. Das Nüsschen vom Bauersberg ist schlecht erhalten und deshalb etwas unsicher in der artlichen Zuordnung.

Vorkommen: Untermiozän von Nordwestsachsen und der Lausitz (Mai 1987).

\section{Betulaceae}

\section{Alnus latibracteosa Mai}

\section{Tafel 6: 1, 5}

1987 Alnus latibracteosa Mai, Feddes Repert. Berlin, 98: 110-111, Tafel V, Fig. 12 - Muldenstein, Deckton (Untermiozän).

Bauersberg MfN No. 2002/32 (Bb 014) (1 Strobilus), Hochrain MfN No. 2002/17 (Ho 0017) (9 fruct.).

Kätzchen (Strobili) oval, weniger als doppelt so lang wie breit, bis $14 \mathrm{~mm}$; Schuppen sehr dicht stehend, groß, mit tief gelapptem Vorderrand, innerste Vorblätter gut entwickelt, über große Strecken frei, seitliche Vorblätter als $7 \mathrm{~mm}$ breite, gerundete Lappen, alle Vorblätter meist länger als das Deckblatt. Früchte (Nüsschen) eiförmig, herzförmig oder rundlich, groß, relativ breitflügelig, mit schwach angedeuteter Spitze und zarten Griffelresten. Länge der Nüsschen 2,4-3,2 mm, Breite der Nüsschen 1,7-3 mm.

Eine Art des Subgen. Gymnothyrsus Spach aus der Verwandtschaft von $A$. cordata (Loiseleur) Duby, A. subcordata C. A. Meyer, A. japonica (Thunberg) Steudel, $A$. formosana (Burkill) Makino, die alle nahezu gleich gebaute Schuppen zeigen. Nach den Früchtchen stehen $A$. cordata und $A$. formosana am nächsten. Nur $A$. formosana hat aber ähnlich engstehende Schuppen im Strobilus wie unsere fossile Art. Aus diesem Verwandtschaftskreis wurden eine Anzahl fossiler Arten beschrieben. Sie zeigen Strobili mit weniger dicht stehenden Schuppen. Besonders ähnlich erscheint $A$. bilobata Dorofeev (1982b) aus dem Oligozän und Untermiozän Westsibiriens. Da Dorofeev (1982b) ihre Reste auch im Obermiozän Polens und dem Pliozän im deutschholländischen Grenzgebiet vermutet, ist die Art vielleicht identisch mit unseren Resten. Gleich große und sehr ähnlich gebaute Früchte wie unsere Art besitzen auch einige Arten von Dorofeev (1982b): A. heerii, A. omoloica, A. ruthenica, A. tambovica, A. tertiaria und $A$. uralensis, deren Strobili aber noch unbekannt sind. Die Früchte scheinen aber meistens einen wesentlich schmäleren Flügelsaum als unsere Früchte zu besitzen.

Die am nächsten stehende heutige Art $A$. formosana ist aus dem oberen „Evergreen OakLaurel Forest" bei ca. $2000 \mathrm{~m}$ Höhe in Taiwan mit anderen sommergrünen Bäumen genannt (Wang 1961).

Vorkommen: Oberoligozän bis Mittelmiozän von Nordwestsachsen und der Lausitz (Mai 1987, 1999b).

\section{Corylaceae}

\section{Carpinus miocenica Negru}

Tafel 6: 6

1969 Carpinus miocenica Negru, Bot. Žurn., 54: 763-765, pl. I, fig. 9-15, pl. II, fig. 1-4-Bursuk (Mittelmiozän).

Bauersberg MfN No. 2002/36 (Slg. E. Kramm, Fulda) (1 Expl.).

Nüsschen wesentlich kleiner als die von Carpinus betulus Linné, auffällig eiförmig bis rundlich dreieckig, 5,0 mm lang, 3,5 mm breit, mit Basiswinkel von mehr als $150^{\circ}$, Apex ohne Griffelrest, Rippen 3-6 auf jeder Seite, aber nur schwach entwickelt. Perikarp dünn, aus kleinen Zellen, die nur im Mittelteil größer werden.

Involukren dieser Art, die sehr typisch sind, wurden am Fundort Bauersberg bisher nicht nachgewiesen. Aber die Nüsschen weichen ebenfalls von $C$. betulus Linné ab und vereinigen Merkmale von C. caroliniana Walton und C. laxiflora Blume.

Vorkommen: Mittel- bis Obermiozän, vielleicht bis Pannon (Berger 1953, Mai 2001a).

\section{Myricaceae}

\section{Myrica cf. ceriferiformis Kownas}

Tafel 6: 7

1955 Myrica ceriferiformis Kownas, Acta geol. Polon., 5: 459-461, fig. 8a, b - Dobrzyń/Wisla (Obermiozän).

Kaltennordheim MfN No. 2002/24 (Ka 004); Ka 016, 017 (3 Expl.).

Steinkerne klein, rundlich-oval bis eiförmig, 2,5$3,0 \mathrm{~mm}$ lang, $2,0-2,5 \mathrm{~mm}$ breit, etwas abgeflacht, dünnwandig; Exokarp mit lockerstehenden und kleinen Harzwarzen übersät, oft abradiert. Fach eiförmig.

Die Möglichkeit einer Verwechselung dieser Art mit anderen Arten besteht nur für Myrica ceriferiformoides Bůžek \& Holý 1964. Jedoch 
sind deutliche Unterschiede durch die geringere mittlere Größe und die kleineren, locker stehenden Harzwarzen bei Myrica ceriferiformis-Populationen vorhanden. Diese Harzwarzen sind bei dem Material aus der Braunkohle in der Rhön wegen der starken Kompression nicht mehr erhalten, so dass die Zuordnung mit „cf.“ geschieht.

Heutige Vergleichsart ist Myrica pensylvanica Loiseleur. In ihrer Heimat ist diese Art ein sehr häufiger Strauch trockener Hügel, der Dünen und der Ufer nahe der Meeresküste. Sie lebt in verschiedenen Gesellschaften, namentlich den Küsten-Wacholder-Gehölzen und den KiefernEichen-Wäldern (Knapp 1965). Sehr nahe verwandt ist auch Myrica cerifera Linné. Diese überaus polymophe Art hat ein weites Verbreitungsgebiet im atlantischen Nordamerika von Süd-New Jersey bis Nordost-Mexiko. Sie ist Charakterart der immergrünen Pocosin-Moorgehölze, besiedelt aber ebenso zahlreich auch die Lebenseichen-Wälder des küstennahen Virginia bis Texas und die Palmetto-Kiefern-Wälder Südfloridas und der anschließenden Antillen-Inseln.

Vorkommen: Miozän von Polen (Kownas 1955), Lausitz (Mai 1999b) und Bulgarien (Palamarev 1968); Verbreitungsschwerpunkt im höherem Miozän (Mai 2001a).

\section{Juglandaceae}

\section{Carya ventricosa (Sternberg) Unger}

ohne Abb.

1824 Juglandites ventricosa Sternberg, Versuch geognost. botan. Darstell. I: 44, Tafel 53, Fig. 5a, b - Salzhausen (Mittelmiozän).

1861 Carya ventricosa Unger, Sylloge plant. foss. I: $40-41$, Tafel 18, Fig. 5-8 - Salzhausen (Mittelmiozän).

Kaltennordheim Geiseltal-Mus. Halle/Sa. (vidi 1966); Slg. Geol. Pal. Inst. Univ. Würzburg (Orig.: Müller-Stoll 1936, Tafel 2, Fig. 2b-c), Wüstensachsen Slg. Kelber (Burggrumbach) (Orig.: Kelber \& Gregor 1987, Tafel 3, Fig. 8), Theobaldshof (?) Senckenberg-Mus. Frankfurt a.M. (Orig.: Moayedpour 1977, Tafel 14, Fig. 1).

Nüsse eiförmig bis etwa kugelig, $17-30 \mathrm{~mm}$ lang, 13-23 mm breit, stumpf oder mäßig zugespitzt, an der Basis gerundet oder abgeflacht und mit einem rautenförmigen Schildchen versehen, wenige Fundstücke sind im oberen Drittel schwach vierkantig; Oberfläche fast glatt aber mit verzweigten und verbundenen Längsfurchen, dünn- oder dickwandig (bis 1,5 mm Wanddicke); mit mäßig großen Lakunen; sekundäre Septen als schmale Flügelleisten an der Mittelsäule bis ins obere Drittel des Faches bemerkbar; Raphe- leitbündel intrors, dünn; Plazentaleitbündel einfach.

Material aus Theobaldshof nur kalkige Fachausfüllung und deshalb unsicher.

Bei der Art handelt es sich um ein häufiges und typisches Fossil aus der europäischen Verwandtschaft des südostasiatischen Carya poilanei-Formenkreises (Mai 1981).

Vorkommen: Im Oberoligozän sehr fraglich; Unter- bis Mittelmiozän nahezu in ganz Europa (Mai 1981), selten im Pliozän (Engelhardt \& Kinklelin 1908).

\section{Engelhardia macroptera (Brongniart) Unger}

Tafel 6: 8

1828 Carpinus macroptera Brongniart, Ann. Sci. Nat., 15: 48; pl. 3, fig. 6 - Armissan (Untermiozän).

1866 Engelhardia macroptera Unger, Denkschr. Akad. Wiss., 25: 52; Tafel 16, Fig. 9-11 - Radoboj (Mittelmiozän).

Kaltennordheim MfN No. 2002/25 (Ka 005) (1 Expl.); Dietrichsberg (Slg. Gümbel), Wüstensachsen (Slg. Gümbel).

Frucht mit Involukrum, dreilappig, dessen Mittellappen stärker betont, dreinervig, aber mit \pm deutlichem Hauptnerv, Seitenlappen kurz. Griffelrest von krönchenartiger Vorblatthülle umgeben.

Frucht von rundlicher bis herzförmiger Gestalt (ohne flügelartige Tragblatthülle), mit etwas ausgezogenem Stylushöcker und deutlicher, rundlicher, basaler Ansatzstelle. Dehiszenz in zwei gleiche Klappen. Mit gut ausgebildeter Scheidewand senkrecht zur Dehiszenzfläche und unvollständigen, gekrümmten Septen in der Mitte der Nuss; Endokarp dünn, glatt bis streifig. Durchmesser $4 \mathrm{~mm}$ (verdrückt!).

Jähnichen et al. (1977) begründen die systematische Stellung derartiger fossiler Reste in einer Sektion Palaeocarya (Saporta) Knobloch \& Kvaček 1976 und weisen auf eine enge Verwandtschaft mit E. roxburghiana Lindley (Südchina bis Sumatra, Nordkalimantan/Malaysia: Regenwälder mit Eichen-Pineten) hin.

Vorkommen: Mitteleozän bis Pliozän in Europa vom Atlantik bis zum Kaukasus.

\section{Hypericaceae}

\section{Hypericum septestum Nikitin}

Tafel 6: 10

1948 Hypericum septestum Nikitin, Dokl. Akad. Nauk USSR, 61 (6): 1104 (nomen nudum).

1957 Hypericum septestum Dorofeev, Sbornik pamj. Kryshtofovichi: 307, pl. 4, fig. 18 - Lagernii Sad bei Tomsk (Miozän). 
Hochrain MfN No. 2002/18 (Ho 0020) (1 Expl.).

Samen oblong bis zylindrisch, mit spitz zugerundeten Polen und grubig gebauter Oberfläche. Grübchen groß, mehr oder weniger trapezförmig bis rundlich-rechteckig, in 8-10 Längsreihen angeordnet. Länge $0,9 \mathrm{~mm}$, Breite $0,5 \mathrm{~mm}$.

Diese Art ist im westsibirischen Oligozän und Miozän sehr verbreitet. Vergleichbare Samen gibt es bei einigen heutigen Arten. Am nächsten steht aber wohl doch $H$. virginicum Linné aus der Sektion Triadenia (atlantisches Nordamerika). Dorofeev (1963) gibt für den Vergleich weiter $H$. aegypticum Linné (Nordafrika) an. Negru (1972) vergleicht ähnliche Samen mit $H$. scabrum Linné (Kleinasien, Transkaukasien, Mittelasien).

Vorkommen: In Europa bisher im Oberoligozän bis Untermiozän von Nordwestsachsen und der Lausitz, Obermiozän des Don-, Sal- und Moldaugebietes und der Lausitz (Dorofeev 1959c, Negru 1972, Mai 2001a) bis Westsibirien verbreitet (Dorofeev 1963).

\section{Acitinidiaceae}

\section{Actinidia germanica Mai}

Tafel 6: $11-14$

2001 b Actinidia germanica Mai, Palaeontographica B, 257: 79, Tafel 14, Fig. 18, 19 - Kleinleipisch, Fdpkt. 3 (Mittelmiozän).

Kaltennordheim MfN 2002/28 (Ka 018) (1 Expl.).

Samen 2,8 mm lang, rundlich-oval, asymmetrisch, sekundär verfaltet, ursprünglich vielleicht aufgeblasen-rundlich. Grübchen der Oberfläche $70-100 \mu \mathrm{m}$ im Durchmesser, tief, mit senkrecht stehenden Wänden, Ränder dick, stumpflich, Grübchen regellos, mit schwacher Tendenz zur längsreihigen Anordnung, sehr zahlreich, über 40 auf der maximalen Breite.

Diese fossile Art kommt der A. eocenica Chandler (1963) aus dem englischen Eozän nahe, was Größe, Gestalt, Testaverfaltung und Kleinheit der Grübchen anbelangt. Sie unterscheidet sich aber durch die Unregelmäßigkeit der Anordnung der Grübchen und deren dicke, stumpfliche Ränder. Eine rezente Art zum Vergleich wurde nicht ermittelt. Vielleicht handelt es sich um eine subtropische Art von Actinidia Lindley oder gar um eine Art der verwandten Gattung Clematoclethra Maximowicz.

Vorkommen: Mittelmiozän der Lausitz (Mai 2001b).

\section{Styracaceae}

\section{Styrax maximus (Weber) Kirchheimer}

Tafel 6: 9

1852 Nyssa maxima O. Weber, Palaeontographica, 2: 185, Tafel 20, Fig. 12 - Orsberg (Oberoligozän).

1852 Nyssa obovata O. Weber, Palaeontographica, 2: 184-185, Tafel 20, Fig. 11 - Orsberg (Oberoligozän).

1939 Styrax obavatus Mädler, Abh. Senckenberg naturf. Ges. 446: 135-136 - Orsberg (Oberoligozän).

1949 Styrax maximus Kirchheimer, Ber. Oberhess. Ges. f Natur- und Heilkunde, 24: 221-222 - Orsberg (Oberoligozän).

Bauersberg MfN No. 2002/31 (Bb 013) (1 Expl.).

Samen kugelig bis gestreckt-eiförmig, $9,5 \mathrm{~mm}$ lang und $9,0 \mathrm{~mm}$ breit, apikal gerundet, selten mit einem kleinen Wärzchen, basal mit großem, geradem oder häufiger schief abgeflachtem, rundlichem, etwas vertieftem Hilum. Testa dick, glatt, häufig glänzend, mit 2 und 3 von den Scheidewänden des Perikarps geprägten Längsfurchen, Raphe als breite Rinne einer dieser Längsfurchen folgend, vom oberen Rand des schiefen Hilums ausgehend; Oberfläche bei stärkerer Vergrößerung durch die zugespitzten Enden der Radialsklereiden vieleckig-netzig.

Von den heutigen Arten besitzt St. japonicus Siebold \& Zuccarini besonders ähnliche Samen, andererseits sind manche Samen auch denen von St. obassia Siebold \& Zuccarini oder St. shirainus Makino nicht weniger ähnlich. Auch St. mollis Dunn wurde zum Vergleich herangezogen (Czeczott \& Skirgiełło 1967). Alle diese Arten gehören zur Sektion Imbricatae Gürke, die jene Arten mit extratropischem Areal umfasst.

Die durch Mädler (1939) eingeführte Bezeichnung St. obovatus (Weber) Mädler ist mit Rücksicht auf das ältere Homonym St. obovatus Ridley zu verwerfen.

Vorkommen: Oberoligozän bis Pliozän, besonders im Mittelmiozän und höherem Pliozän West- und Mitteleuropas, vielleicht auch Schwarzmeergebiet und Kolchis.

\section{Primulaceae}

\section{Naumburgia subthyrsiflora (Nikitin) Nikitin}

Tafel 7: 1

1935 Lysimachia subthrysiflora Nikitin, Dokl. Akad. Nauk SSSR, 3: 134: (nomen nudum) - Tomsk (Miozän).

1957 Naumburgia subthyrsiflora Nikitin, Plioc. i četvert. fl. Voronež obl.: 179-180; pl. 7, fig. 31, 32 - Krivoborjel Don (Pliozän).

Bauersberg MfN No. 1998/442, Hochrain Ho 0035 (1 Expl.). 
Samen stark abgeflacht, fast linsenförmig, $1,2 \mathrm{~mm}$ lang und $0,8 \mathrm{~mm}$ breit. Ventralseite schwach erhaben mit langem, linealem Nabel, meist deutlich radial-runzelig. Doralseite etwas gewölbt, fast glatt. Oberfläche der Testa dicht durch epithelartige Säulchen besetzt, hell, matt.

Eine $N$. thyrsiflora (Linné) Reichenbach nahe verwandte Art, die sich nur durch etwas größere Samen auszeichnet. Bemerkenswert ist die Radialrunzelung auf der Ventralseite, die sich nahezu gleichartig auch bei Steironema terrestris (Linné) Rafinesque findet.

Vorkommen: Miozän von Westsibirien (Nikitin 1935, Dorofeev 1963), Mittel- bis Obermiozän in Mittel- und Osteuropa (Mai 2001a); Pliozän von Baschkirien, Thüringen und Wetterau (Mai \& Walther 1988).

\section{Rosaceae}

\section{Rubus laticostatus Kirchheimer}

Tafel 7: 2, 3

1942 Rubus laticostatus Kirchheimer, Planta 32: 438-440, Abb. 1 - Wiesa (Untermiozän).

Bauersberg MfN No. 1998/438, Hochrain Ho 0024 (1 Expl.).

Steinkerne abgeflacht, 1,4-2,6 mm lang, $1-1,6 \mathrm{~mm}$ breit, mit halbkreisförmig gewölbtem Rücken, Ventralseite fast gerade oder schwach gekrümmt, apikal spitz gerundet, basal rundlich abgestutzt, Kiel über den Rücken stumpf, aber deutlich entwickelt. Oberfläche netzig-grubig, mit breiten, stumpfen Netzrippen, Gruben eckig bis rundlich, nur wenig gestreckt, sehr verschieden groß.

Eine Art des Subgenus Ideobatus Focke, die sich mit $R$. phoenicolasius Maximowicz (nach Negru 1972) oder R. illecebrosus Focke (eigene Vergleiche) vergleichen lässt. Von den anderen fossilen Arten der Ideobati in erster Linie durch die breiten Muri der Netze unterscheidbar.

Vorkommen: Mitteloligozän bis Untermiozän in Nordwestsachsen (Mai \& Walther 1991) und der Lausitz (Mai 2000a), Miozän von Mittel- bis Osteuropa (Negru 1972), Pliozän Balkanhalbinsel (Palamarev 1970).

\section{Rubus microspermus C. \& E. M. Reid}

\section{Tafel 7: Fig. 4}

1910 Rubus microspermus C. \& E. M. Reid, Lignite Bovey Tracey: 169 , pl. 15, fig. 13-17 - Heathfield/Devon (Mitteloligozän).

Hochrain MfN No. 2002/19 (Ho 0023) (1 Expl.).
Steinkerne mittelgroß, $1,6 \mathrm{~mm}$ lang, $1,1 \mathrm{~mm}$ breit, stark zusammengedrückt, halbmondförmig bis schief eiförmig, Ventralseite gerade, etwas eingekrümmt, Basis gerundet, Spitze stumpf, über den gebogenen Rücken mit stumpfem Kiel, Oberfläche netzig-grubig, Gruben uneinheitlich, unten und ventral stets länger als oben, Rippen dünn und scharf; Endokarp dünn.

Von C. \& E. M. Reid (1910) wurden die Steinkerne nur mit $R$. fructicosus Linné s.l. (Subgenus Rubus) verglichen. Sie gehören aber nach Form und Skulptur sicherlich in das Subgen. Ideobatus Focke und sind mit ostasiatischen Arten mehr oder weniger gut vergleichbar (z. B. R. phoenicolasius Maximowicz). Von den ähnlichen Steinkernen der fossilen $R$. pseudo-occidentalis Dorofeev (1977a) sind sie im wesentlichen durch die dünnere Wand, die feinere Skulptur und etwas anderen Umriss, von $R$. laticostatus Kirchheimer (1942) in erster Linie durch die Stärke der Muri des Retikulums unterscheidbar.

Vorkommen: Obereozän bis Pliozän, von England bis Bulgarien.

\section{Lythraceae}

\section{Decodon gibbosus (Dorofeev) Nikitin}

Tafel 7: 5-8

1920 Diclidocarya gibbosa E. M. Reid, Graines du Pont-deGail: 82, pl. 4, fig. 23, 25 - Pont-de-Gail (Unterpliozän) 1929 Decodon gibbosus Nikitin, J. Botany, London: 37, pl. 589, fig. 8, 9 - Pont-de-Gail (Unterpliozän).

Bauersberg MfN No. 1998/430; Kaltennordheim Ka o. Nr., Hochrain MfN No. 2002/01 (Ho 0011 u. Ho 0041a).

Samen pyramidal, keilförmig, abgeflacht, rundlich, von halbkugelig bis verlängert oval, sehr variabel in der Form. Ventralseite abgeflacht, mit schmaler oder breiter, dreieckiger, glatter Keimklappe, die kürzer als die halbe Ventralseite ist. Dorsalseite buckelig, Buckel aus Aerenchym gebildet, mitunter sehr auffällig, die dorsal-lateralen Seiten meist konkav, mit Verdrückungsmalen. Durchmesser der Samen von 0,9-1,5 mm.

Nach Kirchheimer (1957: 617) besteht der wesentliche Unterschied zwischen den Arten $D$. globosus und D. gibbosus in der starken Entwicklung des schwammigen Parenchyms am Rücken der Samen der letztgenannten. Dorofeev (1955) trennt die variable Art in zwei Formen: forma eugibbosus Dorofeev und forma elongatus Dorofeev. Nach Dorofeev (1977b) sind noch weitere Formen vorhanden. Die ganze Gruppe ist systematisch sehr schwierig und bedarf nach diesem Autor einer Untersuchung. Als 


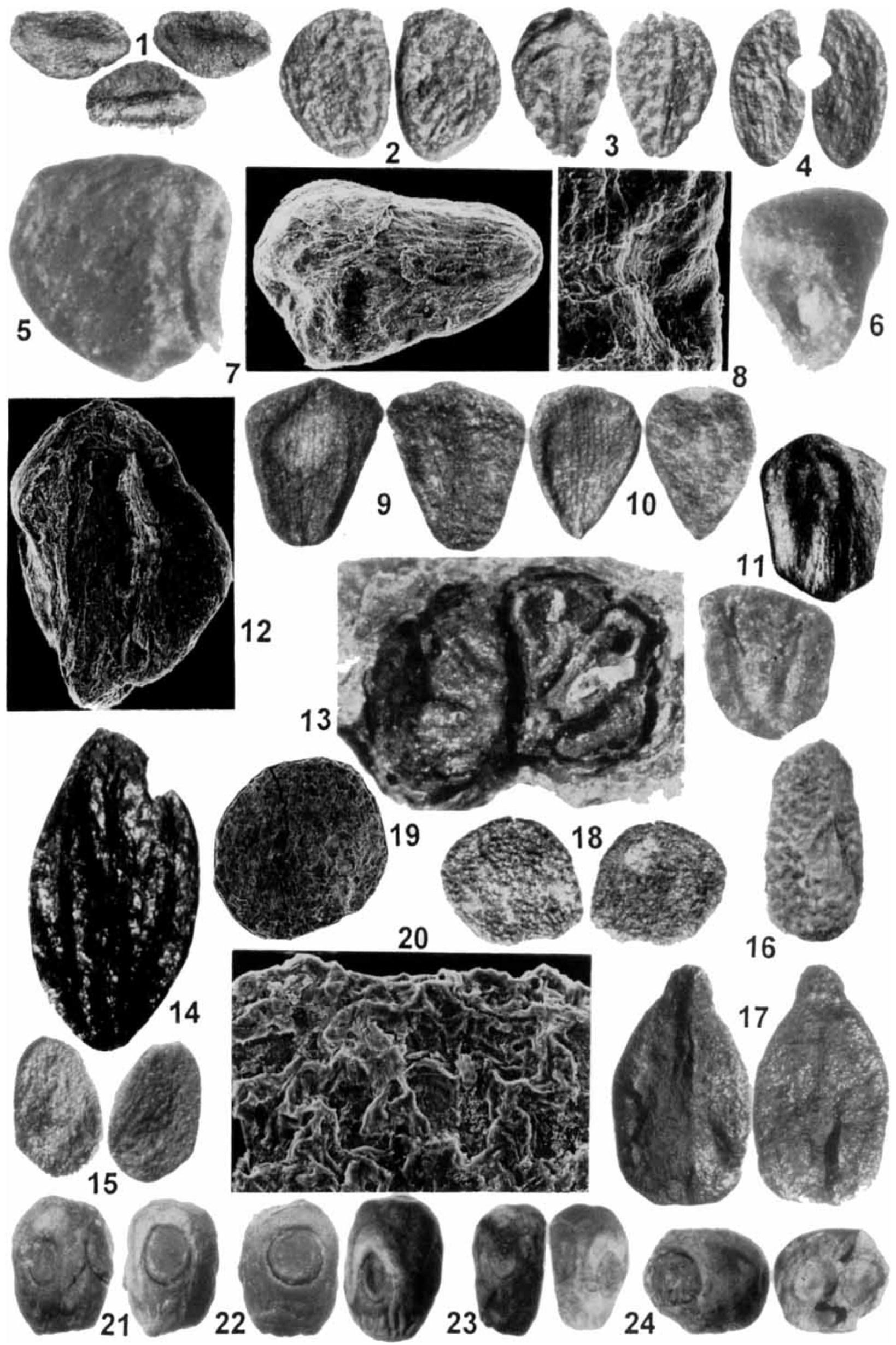


Sammelart im jüngeren Tertiär überaus verbreitet und häufig.

Vorkommen: Selten im Obereozän (Chandler 1960, Mai \& Walther 1985), hauptsächlich Oligozän und Miozän an vielen Fundorten, im Pliozän in Westeuropa selten (E.M. Reid 1920).

\section{Decodon globosus (E. M. Reid) Nikitin}

ohne Abb.

1920 Diclidocarya globosa E. M. Reid, Graines du Pont-deGail: 81, pl. 5, fig. 24 - Raevels/Belgien (?Miozän).

1929 Decodon globosus Nikitin, J. Botany, London: 33-36, pl. 1, fig. 1, 3, 5, 7 - Raevels.

Hochrain Ho 001, Ho 0031-32; Kaltennordheim Ka 003; Bauersberg Bb 004 .

Samen subglobular bis verkehrt-eiförmig, ventral konkav mit zungenförmiger bis dreieckiger Keimklappe, die fast die ganze Ventralseite einnimmt. Oberfläche der Keimklappe glatt bis kleinwabig strukturiert, Waben in meridionalen Reihen. Oberfläche der übrigen Testa glatt, meist hellbraun, glänzend. Hilum als kleines basales Loch. Raphe dorsal, als Kante nicht stark hervortretend. Durchmesser der Samen von 0,9 bis $1,4 \mathrm{~mm}$.

Das reichlich vorhandene Material verschieden alter Fundorte zeigt eine so große morphologische Variabilität der Art, dass es uns schwierig wird, Formen oder Arten abzutrennen. Nach Dorofeev (1977b) gehören in die Artengruppe, die er um $D$. globosus vereinigt, mehrere schwer abgrenzbare Arten. Wir fassen D. globosus als Sammelart auf (Mai 2000a).

Nächst verwandt mit der heutigen nordamerikanischen Art D. verticillatus (Linné) J. F. Gmelin.
Vorkommen: In der Hauptsache Miozän und Pliozän im westl. Europa, selten im Altpleistozän (Geissert 1967) und Mittelpleistozän/Needian (Florschütz \& Jonker 1942).

\section{Decodon sibiricus Dorofeev}

Tafel 7: 9,10

1959b Decodon sibiricus Dorofeev, Dokl. Akad. Nauk. SSSR 127 (5): 1104 (nomen nudum) - Kozjulino/Toma (Oligozän).

1962 Decodon sibiricus Dorofeev, Biostratigr. Zapadn. Sibiri: 406-407, Abb. 103 - Kozjulino/Toma (Oligozän).

Bauersberg MfN No. 1998/432.

Samen breit-keilförmig bis verkehrt-eiförmig, etwas kantig, ventral gerade bis schwach konkav, mit großer dreieckiger Keimklappe, die nahezu die ganze Ventralseite bedeckt und auf die Spitze übergeht. Oberfläche der Keimklappe mit deutlicher Zeichnung aus quadratischen Grübchen, die in meridionalen Reihen angeordnet sind. Oberfläche der übrigen Testa bisweilen gänzlich, mindestens aber um den Rand der Keimklappe grubig strukturiert. Raphe als deutliche Kante hervorstehend. Terminaler Pol sehr oft abgestutzt. Durchmesser der Samen von 1,0 bis $1,5 \mathrm{~mm}$.

Die Samen dieser Art sind durch Form, Keimklappe, Struktur und dünner Testa deutlich von der D. gibbosus-globosus-Gruppe geschieden.

Vorkommen: Oligozän und Miozän von Westsibirien, Jakutien; Mittel- bis Obermiozän Ost- und Mitteleuropa (Dorofeev 1977b, Mai 2001a).

Tafel 7. 1. Naumburgia subthyrsiflora (Nikitin) Nikitin - Bauersberg MfN No. 1998/442, Samen von der Doralseite (oben) und Ventralseite (unten); $\times 20$. 2, 3. Rubus laticostatus Kirchheimer - Bauersberg MfN No. 1998/438. 2. Steinkern; $\times 20$ 3. Steinkern von der gekielten Rückenseite und der dehiszierenden Bauchseite; $\times 20$. 4. Rubus microspermus C. \& E. M. Reid - Hochrain MfN No. 2002/19, Steinkern von beiden Seiten, etwas beschädigt; $\times 20$. 5-8. Decodon gibbosus (E. M. Reid) Nikitin - Hochrain MfN No. 2002/01. 5. Samen, seitlich, mit geöffneter Keimklappe; $\times 40$. 6. Samen, von der Ventralseite, mit eingesenkter Keimklappe; $\times 40.7$. Samen, von der Seite, mit langem Aerenchymbuckel und eingesenkter Keimklappe; SEM $\times$ 40. 8. Keimklappe von der Seite; SEM $\times 100.9$ 10. Decodon sibiricus Dorofeev - Bauersberg MfN No. 1998/432. 9. Samen von ventral und dorsal; $\times 25$. 10. Samen von ventral und dorsal. Keimklappe fast die ganze Ventralseite einnehmend; $\times 25$. 11-13. Microdiptera minor (Chandler) Mai - Hochrain MfN No. 2002/11. 11. Samen von ventral und dorsal; $\times 25$. 12. Samen von dorsal, mit Rapheleiste und lateralen Furchen; SEM $\times 40$. 13. Querbruch durch eine Frucht in der Braunkohle, mit Agglomeraten von mehreren Samen; $\times 25$. 14. Nyssa ornithobroma Unger - Hochrain MfN No. 2002/09, Steinkern mit abgebrochener Keimklappe; ×6,5. 15. Aralia lucidoides Mai - Hochrain MfN No. 2002/08, Endokarp von beiden Seiten; $\times 20$. 16. Sambucus pulchella C. \& E. M Reid - Kaltennordheim MfN No. 2002/27, Samen mit runzelig-buckeliger Oberfläche; $\times 15$. 17. Vitis teutonica A. Braun - Kaltennordheim MfN No. 2002/26, Samen mit Raphekante (links) und Chalazaknoten (rechts) $\times$ 10. 18-20. Solanum foveolatum Negru - Bauersberg MfN No. 1998/434. 18. Samen von einer Seite; SEM $\times 40$. 19. Weiterer Samen von einer Seite; SEM $\times$ 40. 20. Oberfläche des Samen mit retikulater Struktur der Testa; SEM $\times 250.21-24$. Spondiaecarpum mettenii (Unger) Mai - Hochrain MfN No. 2002/03. 21-23. Steinfrüchte verschiedener Form und Größe mit klappigen Aperturen; $\times 6,5$. 24. Steinfrucht, geöffnet, mit kugligen Loculi; $\times 6,5$. 


\section{Microdiptera minor (Chandler) Mai}

Tafel 7: 11-13

1960 Diclidocarya minor Chandler, Bull. Brit. Mus. N.H., 4 (6): 232-233, pl. 34, fig. 134-137 - Highcliff (Obereozän).

1972 Mneme minor Eyde, Brittonia, 24: 114.

1985 Microdiptera minor Mai in Mai \& Walther, Abh. Staatl. Mus. Mineral. Geol. Dresden, 33: 100 - Haselbach (Obereozän).

Hochrain MfN No. 2002/11 (Ho 0021), Kaltennordheim Ka 012 .

Samen breit-oval, stark zusammengedrückt, daher Seiten sekundär kantig, nie flügelig, mit klar durch die schwachen lateralen Verdickungen abgegrenztem Samenkörper, Keimklappe oval, kurz; Rapheleiste von tiefen, breiten Furchen flankiert. Testa dünn. Länge $0,9-1,2 \mathrm{~mm}$, Breite $1,1 \mathrm{~mm}$. In Agglomeraten in einer mehrfächrigen Kapselfrucht angeordnet (Tafel 7: 13). Kapsel über 2,5 $\mathrm{mm}$ im Durchmesser.

Die Samen der Art sind stets viel kleiner und dünnwandiger als die von $M$. sibirica (Nikitin) Mai oder M. menzelii (E. M. Reid) Mai. Im Unterschied zur letzteren, als deren unmittelbarer Vorläufer sie vielleicht aufzufassen sind, zeigen sie oft sehr tiefe Furchen zu beiden Seiten der Raphe. Die Unterschiede zu der stratigraphisch gleichzeitig auftretenden $M$. lusatica Mai sind erheblich, vor allem was Form, Oberflächenstruktur und die Keimklappengröße betrifft.

Vorkommen: Eozän von England (Chandler 1960), in Deutschland bis Untermiozän (Mai \& Walther 1991, Mai 2000a).

\section{Aceraceae}

\section{Acer cyclospermum Goeppert}

Tafel 6: 15

1852 Acer cyclospermum Goeppert in O. Weber, Palaeontographica, 2: 224, Tafel XXV, Fig. 4 - Liessem bei Bonn (Untermiozän).

1915 Acer striatum E. M. Reid, Plioc. fl. Dutch-Prussian Border: 110, pl. 11, fig. 5 - Reuver (Oberpliozän).

Hochrain MfN No. 2002/16 (Ho 0016) (1 Expl.).

Endokarpien (Fruchtfächer) abgeflacht-oval bis kreisförmig, $5 \mathrm{~mm}$ lang, dünnwandig, glatt, von den Leitbündeln des Perikarps bedeckt, über der Frucht retikulat divergierend. Winkel der Divergenz zweier Teilfrüchte etwa $90^{\circ}$ bis $45^{\circ}$; Endokarp dadurch schief.

A. cyclospermum Goeppert (in $\mathrm{O}$. Weber 1852 ) ist ein eindeutiger Name für Flügelfrüchte, die man sehr oft zu A. trilobatum (Sternberg) A. Braun gestellt hat.
Vorkommen: Mitteloligozän bis Oberpliozän in Europa.

\section{Nyssaceae}

\section{Nyssa ornithobroma Unger}

Tafel 7: 14

1860 Nyssa ornithobroma Unger, Syll. plant. foss. I: 16, Tafel 8, Fig. 15-18 - Salzhausen (Mittelmiozän).

Bauersberg MfN No. 1998/445 (2 Expl.) Bb 005 (4 Expl.), Hochrain MfN No. 2002/09 (Ho 009) (1 Expl.), Roth MfN No. 1989/40 (2 Expl.), Sieblos MfN o. No. (Orig. Müller-Stoll 1936, Tafel 5, Fig. 3a-c).

Steinkerne verkehrt eiförmig bis langoval, 9-20 mm lang, 5,5-10 mm breit, mit der größten Breite über der Mitte, 1-fächrig bis 4-fächrig, dünnwandig und stark zusammengedrückt. Oberfläche mit 10-15 longitudinalen Furchen, in denen Faserbündel-Reste liegen. Dazwischenliegende Rippen an der Basis breit beginnend und im apikalen Bezirk scharfkantig hervortretend. Keimklappen von eiförmiger bis dreieckiger Form, mehr oder weniger schmal, nach oben spitzbogig zugespitzt. Endokarp aus verflochtenen Sklerenchymfasersträngen, zwischen die Steinzellnester eingestreut sind.

Über die Abtrennung der großen, sehr charakteristisch berippten Steinkerne von $N$. disseminata (Ludwig) Kirchheimer, mit der sie bisher vereinigt wurden, haben Mai $(1965,1973)$ und Mai \& Gregor (1982) geschrieben. N. ornithobroma Unger ist mit keiner heutigen Art unmittelbar verwandt. Hinsichtlich des häufigen Auftretens von zwei (und mehr) Fächern stehen die Arten $N$. sinensis Oliver und $N$. talamancana Hammel \& Zamora nahe. Im Berippungstyp allerdings ist $N$. ogeche Marshall näherstehend.

Vork ommen: Unteroligozän bis Obermiozän in Europa, aber auch Westsibirien (Dorofeev 1963) und Kazachstan (Kryshtofovich et al. 1956), im Norden bis Dänemark, im Süden bis Bulgarien; im Pliozän bisher nur Kranichfeld (Mai 1965).

\section{Araliaceae}

\section{Aralia lucidoides Mai}

Tafel 7: 15

1978 Aralia lucidoides Mai \& Walther, Abh. Mus. Mineral. Geol. Dresden, 28: 123 (nomen nudum).

1987 Aralia lucidoides Mai, Feddes Repert. Berlin, 98: 116, Tafel VIII, Fig. 8, 9 - Schlabendorf Süd (Untermiozän).

Material: Hochrain MfN No. 2002/08 (Ho 0033-34) (3 Expl.). 
Endokarpien fast halbkreisförmig, abgeflacht, kurz, breit, mit stumpflichem apikalem Ende, Wand dünn; Oberfläche glatt, quergestreift, seidenglänzend, nahe der Dorsalseite selten schwach runzelig. Länge $1,4-1,5 \mathrm{~mm}$, Breite $0,9-1,0 \mathrm{~mm}$.

Die bisher kleinfrüchtigste Art des Verwandtschaftskreises der fossilen glattwandigen, seidenglänzenden Arten. Sehr nahe verwandt ist Aralia lucida Dorofeev (1963) aus dem Oligo-Miozän Westsibiriens. Beide Arten lassen sich nur mit $A$. racemosa Linné vergleichen, deren Steinkerne aber die Abmessungen der Fossilien erheblich übersteigen. Wahrscheinlich ein Element der Mixed Mesophytic Forests.

Vork ommen: Nur am Locus typicus im Untermiozän der Lausitz (Mai 1987).

\section{Vitaceae}

\section{Vitis teutonica A. Braun}

Tafel 7: 17

1854 Vitis teutonica A. Braun, Neues Jahrb. Mineral. usw. 147, Tafel 3, Fig. 8-15 - Salzhausen (Mittelmiozän).

Kaltennordheim MfN No. 2002/26 (Ka 010) (1 Expl.).

Samen länglich-verkehrt-eiförmig, Chalazaknoten lang, oval, klein, mit über die Spitze verlängertem Rapheband, Apex gerundet, wenig eingekerbt, Basis allmählich zugespitzt in einen kurzen, mit schwachen, warzigen Protuberanzen besetzten Schnabel, ventrale Einfaltungen schmal, tief, $2 / 3$ bis $3 / 4$ der Samenlänge, dorsale Seite um die Chalaza ungestreift. Länge $4,0 \mathrm{~mm}$, Breite 2,5 mm.

Der Typus aus Salzhausen wurde durch Braun (1854), Ludwig (1859) und Unger (1861) nur mangelhaft abgebildet und diagnostiziert. Die Folge davon waren zahlreiche Fehlbestimmungen anderer Autoren. Von Mai \& Gregor (1982) wurde die von vielen Autoren zu weit oder falsch aufgefasste Vitis-Art neu typisiert und diagnostiziert, nachdem das Original von A. Braun (1854) aufgefunden worden war.

Als Vergleichsarten wurden ostasiatische $\mathrm{Ar}$ ten, z. B. V. balsamaeana Planchon (Hainan) und V. thunbergii Siebold \& Zuccarini (Japan, China, Korea, Taiwan) namhaft gemacht.

Vorkommen: Vom Oberoligozän bis Pliozän in ganz Europa genannt, aber sehr oft falsch bestimmt.

\section{Sambucaceae}

\section{Sambucus pulchella C. \& E. M. Reid}

Tafel 7: 16

1915 Sambucus pulchella C. \& E. M. Reid, Plioc. fl. DutchPrussian Border: 135-136, pl. 17, fig. 7-10 - Reuver (Pliozän).

Kaltennordheim MfN No. 2002/27 (Ka 001) (1 Expl.).

Samen elliptisch-eiförmig, zugespitzt, abgeflacht zu rundlich-triangulärem Querschnitt, generell etwas nach innen gebogen, 2,8-2,5 mm lang und 1,3-1,0 mm breit. Oberfläche schwarz, mit zahlreichen, gebogenen, transversalen Wülsten, die sehr eng stehen.

Von mehreren bisher fossil beschriebenen Arten unterscheiden sich die Samen der S. pulchella C. \& E. M. Reid (1915) durch ihre Schlankheit und die Grazilität der Oberflächenornamentation. Szafer (1947: 173) bezieht in diese Art nur Samen vom Längen-Breiten-Index 3/1 ein. Alle anderen Exemplare bezieht er auf die rezenten Arten Sambucus ebulus Linné oder Sambucus racemosa Linné. Vergleiche mit dem fossilen Material der $S$. pulchella sind indessen viel wahrscheinlicher mit den schmalsamigen Arten $S$. williamsii Hance (Ostchina) und $S$. caerulea Rafenesque, $S$. glauca Nuttall (Nordamerika) zu ziehen. Diese Arten zeigen auch die große Anzahl der transversalen Wülste.

Vorkommen: Mittelmiozän bis Obermiozän der Lausitz, Ukraine, Weichselgebiet, Mähren, vielleicht auch Westsibirien (Mai 2001a); Pliozän von Holland bis ins Dongebiet (C. \& E. M. Reid 1915, Nikitin 1957).

\section{Solanaceae}

\section{Solanum foveolatum Negru}

Tafel 7: $18-20$

1986 Solanum foveolatum Negru, Mèotičeskaja flora SeveroZapatn. Pričernomor'ja: 128-129, pl. XVIII, fig. 2-7 B. Fontan/Odessa (Obermiozän).

Bauersberg MfN No. 1998/434 (8 Expl.).

Samen im Umriss fast kreisförmig, an der Basis ein wenig grubig eingetieft und abgestutzt, fast eben über die Seiten. Testa relativ dünnwandig, von auBen grubig. Grübchen rundlich-vieleckig, tief, mit ungleich hohen, dünnen, gleichförmigen Wänden. Am Hilum die Grübchen viel kleiner, eng.

Von den heutigen Arten sind die Samen von Solanum luteum Miller sehr ähnlich, was die allgemeine Form, die geringe Dicke der Testa und die Gleichmäßigkeit der Zellwände der Grüb- 
chen auf der Oberfläche anbelangt. Unterschiede sind in der Größe der Samen, den Abmessungen der Grübchen und ihrer Anzahl auf der Oberfläche feststellbar. Die Samen von $S$. dulcamara Linné weichen von den Fossilien durch ihre größeren Abmessungen und eine größere Dicke der Testa ab. S. luteum ist eine krautige Pflanze mit Verbreitung in Zentral- und Südeuropa, Kleinasien und Kaukasien.

Vorkommen: Obermiozän (Mèot) im Schwarzmeer-Gebiet (Negru 1986).

\section{Incertae sedis}

\section{„Spondiaecarpum“ mettenii (Unger) Mai}

Tafel 7: 21-24

1861 Pistacia mettenii Unger, Syll. Plant. foss. I: 46, Tafel 21, Fig. 15 - Salzhausen (Mittelmiozän).

1909 Carpolithus hafniensis Hartz, Bidrag Danm. tert. diluv. fl.: 122 , pl. 5 , fig. 6a-c - Valby Bakke b. Kopenhagen (Miozän im Quartär).

1913 Spondiaecarpum turbinatum Menzel, Jahrb. preuß. geol. Landesanst., 34: 6, Tafel 1, Fig. 8-13 - Hermühlheim/ Rheinl. (Obermiozän).

1922 Ilex dardenniana Gilkinet, Ann. Soc. Géol. Belg., 2 (1/ 2): 35 , pl. 17, fig. 60 - Champseau bei Andenne (Untermiozän).

Hochrain MfN No. 2002/03 (Ho 0003), Kaltennordheim Ka 008 , MfN No. 1993/702 (häufig).

Steinfrüchte turbinat bis subglobos, etwas zusammengedrückt und viereckig, apikal stumpf zugespitzt, quersulcat, basal abgestutzt und ausgehöhlt; mit 4 runden Aperturen, die durch Deckelchen verschlossen sind; 4-fächrig; mit 4-6 ovalen Samen in jedem Fach; Endokarp aus verdickten, rundlichen Parenchymzellen; Fasern fehlend. Länge 4-8 mm, Breite 3-6 mm.

Spondiaecarpon Langeron (1899) und Spondiaecarpum Menzel (1913) gehören nicht in eine Gattung, sondern sind homonym. Die Steinkerne sämtlicher Anacardiaceae-Spondieae enthalten in jedem Fach nur 1 Samen. Ihr Endokarp besteht nur aus Fasern, während ein Parenchym zurücktritt und nur in Gestalt von Steinzellen vorhanden ist. Damit können die Fossilien nicht als erloschene Gattung den Spondieae angeschlossen werden (Kirchheimer 1936: 102). Die ältere Deutung von Unger (1861) als Pistacia Linné (Anacardiaceae) oder die von Gilkinet (1922) als Ilex Linné (Aquifoliaceae) ist abzulehnen.

Vorkommen: Im Oligozän in Westsibirien (Dorofeev 1963, Nikitin 1965); in Mittel- und Westeuropa vom Untermiozän bis Obermiozän (Mai 2001a), vom Rheinland bis in die Ukraine (Dorofeev 1959c).

\section{Diskussion der neuen Pflanzenfunde}

Gemessen an anderen Jungtertiärfundstellen Deutschlands ist die Anzahl der bisher gefundenen pflanzlichen Makrofossilien im Miozän der Rhön sehr gering. Dabei lieferten die drei Fundstellen Bauersberg, Hochrain und Kaltennordheim mit 47 Arten aus 32 Familien wesentlich mehr Fossilreste als alle weiteren bekannten Rhönfundstellen zusammen (Eisgraben: 29 Arten; Müller-Stoll 1936; Zeche „Barbara“ bei Wüstensachsen: 27 Arten; Müller-Stoll 1936, Kelber \& Gregor 1987; Theobaldshof: 14 Arten; Moayedpour 1977; Gregor 1982; Roth: 9 Arten; Müller-Stoll 1936). Auch liegen mit unserem Material einige Erstnachweise von Arten für das gesamte Rhöntertiär vor. Beachtet man die Erfahrung, daß nur Makrofloren mit etwa 30 Arten biostratigraphisch auswertbar sind, so liegen die Floren von Hochrain: 23 Arten und Kaltennordheim: 28 Arten (nach Hassencamp 1860, MüllerStoll 1936, Gregor 1990) noch unter dieser Auswertungsgrenze; die Floren vom Bauersberg, Zeche „Einigkeit": 54 Arten (nach Hassencamp 1860, Müller-Stoll 1936, Kelber \& Gregor 1987) und Bauersberg, Zeche „Bischofsheim": 53 Arten (nach Hassencamp 1860, Müller-Stoll 1936) deutlich darüber. An solchen Versuchen einer biostratigraphischen Auswertung hat es nicht gefehlt (Müller-Stoll 1936, Knobloch 1971, Kelber \& Gregor 1987, Gregor 1982, 1990). Am miozänen Alter der Floren zweifelt keiner der genannten Autoren, jedoch schwankt die Einstufung von „Burdigal“ bis „Ottnang“ oder „Karpat/Baden" und umfasst damit das höhere Untermiozän bis Mittelmiozän. Dieser Zeitraum wird in den benachbarten Ablagerungsräumen von Nordwestsachsen, Westböhmen und der Lausitz immerhin durch drei unterschiedliche Florenkomplexe charakterisiert: Brandis-Bílinia, WiesaEichelskopf und Kleinleipisch-Františkove Lázně. Es gilt im Folgenden festzustellen, ob sich die Rhönfloren in einen dieser zeitlich gut eingegrenzten Florenkomplexe einordnen oder ihm wenigstens annähern lassen.

Bei einer Auswertung muss in allen drei Lokalfloren mehr als die Hälfte der jeweils vorhandenen Arten unberücksichtigt bleiben, da sie nach den vielfältigen Untersuchungen verschiedener Autoren Durchläufer darstellen, die sehr langlebig waren und die in der Regel vom Unteroligozän bis zum Oberpliozän bekannt sind. Mehr Beachtung müssen jene Arten erfahren, von denen ein zeitliches Erlöschen im Obermiozän festzustellen war: Acer angustilobum, Ailan- 
thus confucii, Alnus latibracteosa, Betula prisca, Carex hartauensis, Carex pseudocyperoides, Carpinus miocenica, Celtis lacunosa, Ceratophyllum lusaticum, Cladiocarya trebovensis, Cupressospermum spec., Daphnogene polymorpha, Decodon sibiricus, Hypericum septestum, Koelreuteria reticulata, Laurophyllum spec., Myrica ceriferiformis, Platanus neptuni, Potamogeton schenkii, Salix angustissima, Salix lavateri, Spondiaecarpum mettenii, Stratiotes kaltennordheimensis, Tetraclinis salicornioides, Vitis strictum. Noch früher im Untermiozän erlöschen Carya rostrata und Microdiptera minor. Andererseits treten ab Unterbzw. Mittelmiozän einige Arten neu auf: Aralia lucidoides, Boehmeria raria, Carex hartauensis, Carex pseudocyperoides, Carpinus miocenica, Cladium oligovasculare, Cladium palaeomariscus, Eomastixia hildegardis, Koelreuteria reticulata, Myrica ceriferiformis, Naumburgia subthyrsiflora, Sambucus pulchella.

Dieser Gemeinsamkeit von ,alten“ und ,jungen" Florenelementen in allen drei Lokalfloren ist besondere Beachtung zu schenken. Darüber hinaus sind einige Arten nach bisherigen Erkenntnissen so kurzlebig, daß ihnen biostratigraphischer Leitwert zukommen kann: Actinida germanica ist bisher nur aus dem Mittelmiozän (Florenkomplex Kleinleipisch) bekannt. Eomastixia hildegardis ist eine Art der Florenkomplexe Klettwitz und Schipkau sowie der basalen $\mathrm{Cy}$ prisschiefer in Westböhmen (Florenkomplex Františkove Lázně). Typisch für einen kurzen Abschnitt in der voralpinen Süßwassermolasse ist auch Potamogeton schenkii (,dehmii“-Verband, OSM-1, Typus Langenau; Gregor 1982). Bisher völlig neu im Gebiet und daher biostratigraphisch nicht einzuordnen sind die Arten Pilea bashkirica (aus dem osteuropäischen Pliozän) und Solanum foveolatum (Obermiozän des Schwarzmeergebietes).

Aus diesen Untersuchungen über die stratigraphische Reichweite der nachgewiesenen Arten wird deutlich, dass alle drei Lokalfloren, bestimmt aber die vom Bauersberg, Zeche „Einigkeit", zu mittelmiozänem Alter tendieren.

Knobloch (1971) vertrat die Ansicht einer Altersgleichheit der „burdigal-helvetischen Floren" des kohleführenden Tertiärs im Becken von Chomutov-Most-Teplice in Nordwestböhmen (= Florenkomplex „Brandis-Bílina“ unserer Auffassung) mit jenen des kohleführenden Tertiärs der Rhön. Er wies aber auf einen wesentlichen Unterschied zwischen den Floren der Rhön (in diesem Falle Bischofsheim) und denen des genannten Florenkomplexes hin. Das ist das häu- fige Vorkommen von Fagus attenuata, die bisher auf jüngere Schichten beschränkt erschien und im Westböhmischen Tertiär fehlt. Gegen eine Einordnung in den Florenkomplex Brandis-Bílina spricht auch das Fehlen solch wichtiger Charakterarten wie Aracispermum canaliculatum, Comptonia schrankii, Quasisequoia couttsiae, Calamus daemonorops, Symplocos germanica, "Trapa" credneri und Tubela baltica in den Rhön-Braunkohlen; dafür allerdings das Vorkommen solcher alttertiärer Elemente wie Carya rostrata und Microdiptera minor oder der Neueinsetzer Boehmeria raria, Cladium oligovasculare, Cladium palaeomariscus und Koelreuteria reticulata.

Mit einem radiometrischen Alter von 20,5 bis 19,2 Mio. J. (Hemmor) paßt der Komplex auch zeitlich zu den Datierungen des Vulkanismus in der Rhön. Auch Kelber \& Gregor (1987) plädieren beim Bauersberg für eine Einstufung als „Tief-Miozän“, Gregor (1990) für Kaltennordheim als „tiefes Miozän“. Hierfür hält Gregor (1990) auch das seltene Auftreten von Eomastixia hildegardis in Kaltennordheim für ein wichtiges Kriterium. Andererseits spricht derselbe Autor (Gregor 1982: 80) von „einer offensichtlichen Schichtlücke“, die zwischen ,escheri-Schichten“ und den Kaltennordheimer Schichten liegen und ein jüngeres Alter derselben bedingen soll („Helvet, Torton“).

Ein obermiozänes oder gar pliozänes Alter (Elborg 1956, Rein 1961, Rutte \& Wilczewski 1995) ist sicher auszuschließen.

Da die meisten Elemente der MastixioideenFloren fehlen, ist eine Einordnung in den Florenkomplex Wiesa-Eichelskopf (Äquivalent in der Süßwassermolasse: Schwandorf-Wackersdorf) unmöglich. Damit verbliebe nur noch die $\mathrm{Zu}$ ordnung in den Florenkomplex KleinleipischFrantiškove Lázně, der zeitlich schon mit Mittelmiozän (jünger als 17,5 Mio. J., Faunenzone Mein-5, Karpatium) anzusetzen ist (vgl. Mai 2001b). Das ist ein erheblicher Altersunterschied zur Datierung des unterlagernden Basaltes am Bauersberg mit 20 bis 21 Mio. J. (Lippolt in Martini et al. 1994) und die zeitliche Lücke müßte etwa 3 Mio. Jahre betragen. Die Mikroflora vom Bauersberg, durch Hottenrott (1992) dokumentiert, entspricht indessen sehr genau dem Spektrum aus den Prososthenien-Schichten von Frankfurt a. Main und damit dem höheren Untermiozän bis tieferen Mittelmiozän im Mainzer Becken (Absolutes Alter der Basaldecke über den Prososthenien-Schichten von 15 bis 16 Mio. Jahren). In dieser Hinsicht stimmen die Er- 
gebnisse der Datierung durch Makroflora und Mikroflora zumindest am Bauersberg überein. Auch die Kaltennordheimer Schichten liegen nach den palynologischen Untersuchungen von Hottenrott (1988) im höheren Untermiozän und zeigen das sog. „Prososthenien-Bild“ nach dem ersten coryphaeus/rurensis-Gipfel. Diese Erkenntnisse wurden am Profil von Theobaldshof (Pflug in Moayedpour 1977) gewonnen und lassen sich auf die im gleichen Braunkohlenbecken von Kaltennordheim gelegenen Fundorte Hochrain und Kaltennordheim, Zeche am ,Alten Berg“, übertragen. Nach den uns vorliegenden Makrofloren zeigen die Fundorte Hochrain und Kaltennordheim völlige Übereinstimmung und damit auch gleiches Alter. Welchem Florenkomplex wir diese Floren und die Flora vom Bauersberg, Zeche „Einigkeit" zuordnen sollen, bleibt vorläufig auf Grund der geringen Artenzahlen an den Fundstellen offen. Wir neigen mehr der Einordnung in den untermiozänen Florenkomplex zu und meinen, daß einige der Unstimmigkeiten in den bisher ungenau bekannten stratigraphischen Reichweiten der ausgewerteten Pflanzen-Arten begründet sein könnten.

Naturgemäß zeigt die Vegetation des in den großen Tieflandsgebieten der Lausitz und den Braunkohlenbecken Westböhmens definierten Florenkomplexe „Brandis-Bílina- oder Kleinleipisch-Františkove Lázně" zum Vorgebirgsland der Rhön einige deutliche Unterschiede, die mit der geographischen Position zusammenhängen. Auffällig ist das Hervortreten von Cercidiphyllum helveticum, Fagus attenuata (wahrscheinlich Fagus saxonica) und Zelkova zelkovifolia in den "Mixed mesophytic forests", die Gebirgsnähe signalisieren. Auch die ausgeprägte „Glyptostrobus-Nyssa-Sumpfwaldgesellschaft" mit viel Spirematospermum wetzleri ist typisch für Braunkohlenbecken mit Nährstoffeintrag vom Beckenrand her, also besonders den intramontanen Braunkohlenbecken. Schon lange in der Literatur bekannt sind Massenanreicherungen von Wasserpflanzen in tertiären Braunkohlen, z. B. Ceratophyllum-, Potamogeton-, Salvinia- oder Stratiotes-Arten (u.a. Zenker 1833, Kirchheimer 1930, 1937, 1957, vgl. auch Mai 1985), die bei ihrem Auftreten in den Braunkohlenflözen den Beweis liefern, daß die betreffenden Schichten unter Wasserbedeckung entstanden sind und besondere Trophiegrade der zufließenden und abfließenden Wässer der Braunkohlenmoore existierten.

Für die Rhönbraunkohlen ließen sich Laichkraut-Submersengesellschaften (,Potamogeton
schenkii-Assoziation" Gregor 1982, Bauersberg) und eine „Ceratophyllum lusaticum-Submersengemeinschaft" (Hochrain), freischwimmende Süßwassergesellschaften (,Salvinia cerebrataSchwimmpflanzendecke“, "Stratiotes kaltennordheimensis-Gemeinschaft"; beide am Bauersberg, Hochrain und Kaltennordheim), sowie Ansätze von Röhrichten, Rieden und Großseggen-Sümpfen aus Carex hartauensis, C. pseudocyperoides, Cladiocarya trebovensis, Cladium oligovasculare, Dulichium marginatum, Microdiptera minor, Naumburgia subthyrsiflora, Saururus bilobatus und Typha tambovica (alle drei Fundorte) nachweisen. Deren Standorte waren meist während des größten Teiles des Jahres oder ständig überflutet. Sie zeichneten sich vornehmlich durch Rohhumusböden und Torfablagerungen im Flözbereich aus. Das sind Bedingungen, wie sie auch für entsprechende Florenkomplexe in der Lausitz und Westböhmens analysiert wurden (Boulter et al. 1993, Mai 2000b, 2001b).

\section{Danksagung}

Die Arbeit über die Tertiärfloren der Rhön wurde nur durch die wohlwollende Unterstützung des Paläontologischen Instituts des Museum für Naturkunde der Humboldt-Universität $\mathrm{zu}$ Berlin in kurzer Zeit möglich. Sie ist deren Direktor, Herrn Prof. Dr. H.-P. Schultze, in Dankbarkeit zum 65. Geburtstag gewidmet. Für die umfangreichen technischen $\mathrm{Ar}-$ beiten sei Frau R. Förster, Frau C. Radke, Frau D. Raspe und Frau Dr. E. Wäsch aus dem gleichen Museum herzlich gedankt. Materialeinsicht und geologische Informationen verdanken wir auch E. Kramm in Fulda und dem Heimatmuseum Kaltennordheim/Rhön.

\section{Literatur}

Baumhauer, R. 1990. Lagerungsverhältnisse von Basalt und Braunkohlentertiär am Südrand der Langen Rhön und im südlichen Vogelsberg. - Zeitschrift der deutschen geologischen Gesellschaft 141: 79-86.

Berger, J.-P. 1983. Charophytes de l',Aquitanien“ de Suisse Occidentale. Essai de taxonomie et biostratigraphie. Geobios 16 (1): 5-37.

Berger, W. 1953. Studien zur Systematik und Geschichte der Gattung Carpinus mit Beschreibung einiger neuer Arten aus dem Altpliozän des Wiener Beckens. - Botaniska Notiser 106 (1): 1-47.

Boulter, M. C., Hubbard, R. N. L. B. \& Kvaček, Z. 1993. A comparision of intuitive and objective interpretations of Miocene plant assemblages from north Bohemia. - Palaeogeography, Palaeoclimatology, Palaeoecology 101: 81-96.

Braun, A. 1854. Einige Beiträge zur Flora der Tertiärzeit. Neues Jahrbuch Mineralogie, Geognosie, Geologie und Petrefaktenkunde 1854: 138-147.

Brongniart, A. 1822. Description des végétaux fossiles du terrain de sédiment supérieur. In Cuvier, G. \& Brongniart, A., Description géologique des environs de Paris: 353-571, Dufour, G. et d'Ocagne, E., Paris.

- 1828. Notice sur les plantes d'Armissan, près Narbonne. - Annales Sciences Naturelles 15: 43-51. 
- 1833. Notice sur une conifère fossile du terrain d'eau douce I'île d'Iliodroma. - Annales Sciences Naturelles 30: $168-176$.

Brown, R. W. 1935. Miocene leaves, fruits and seeds from Idaho, Oregon, and Washington. - Journal of Paleontology 9 (7): 572-587.

Bůžek, Č. 1963. Endocarpy Sparganium trebovense n.sp. (Sparganiaceae, Pandanales) ze spodniho tortonu od Semanína u České Třebova. - Časopis pro Mineralogii a Geologii 8 (2): 126-134; (In czech., res. engl.).

Bůžek, C. \& Holý, F. 1964. Small-sized plant remains from the coal formation of the Chomutov-Most-Teplice basin. (Drobné rostlinné zbytky ze slojového souvrství chomotovko-mostecko-teplické pánve). - Sborník geologickych věd, paleontologie, řad $P$ 4: 105-138.

Bůžek, C., Holý, F. \& Kvaček, Z. 1967. Eine bemerkenswerte Art der Familie Platanaceae Lindl. (1836) im nordböhmischen Tertiär. - Monatsberichte der Deutschen Akademie der Wissenschaften zu Berlin 9 (3): 203-215.

- 1996. Early Miocene Flora of the Cypris shale (Western Bohemia). - Acta Musei Nationalis Pragae, Series B, Historia Naturalis $52(1-4)$ : 1-72.

Chandler, M. E. J. 1925. The Upper Eocene flora of Hordle, Hants. I. - Monographs Palaeontographical Society (London) 77: 1-32.

- 1960. Plant remains of the Hengistbury and Barton beds. - Bulletin British Museum Natural History Geology 4 (6): $191-238$.

- (1963). The Lower Tertiary Floras of Southern England III. Flora of Bournemouth Beds; the Boscombe, and the Highcliff Sands. - 169 pp. British Museum Natural History, London.

Czeczott, H. \& Skirgiełlo, A. 1967. The fossil flora of Turow near Bogatynia. II part: Systematic description of plant remains. - Prace Muzeum Ziemi 10: 97-166.

Dorofeev, P. I. 1955. Méotičeskaja flora iz okrestnostej g. Odessy. - Trudi Botaničeskogo Instituta Akademii Nauk SSSR, ser. 1, 11: 109-143.

1957. Materialy k poznaniju Zapadnosibirskoj tretičnoj flory (iskopaemaja flora s. Ekateriniskogo bliz g. Tary). Sbornik pamjati A.N. Kryshtofovicha Botaničeskij Institut Akademii Nauk SSSR, pp. 277-312.

- 1958. Novye dannye ob oligocenovoj flore d. Belojarka na r. Tavde v Zapadnoj Sibiri. - Doklady Akademii Nauk SSSR 123 (3): 543-545.

- 1959a. O tretičnoj flore d. Ležanki na Irtyše. - Paleontologičeskij Žurnal (1959) 2: 123-133.

- 1959b. Ob oligocenovoj flore s. Kozjulino v ust'e r. Tomi. - Doklady Akademii Nauk SSSR 127 (5): 1103-1105.

- 1959 c. Materialy k poznaniju miocenovoj flory Rostovskoj oblasti. - Problemy Botaniki 4: 143-189.

- 1962. Megaspory, semena i plody iz tretičnych otloženij. In „Biostratigrafija mezozojskich i tretičnych otloženij Zapadnoj Sibiri“" (Trudi SNIIGGIMS, 22): 369-415.

- 1963. Tretičnye flory Zapadnoj Sibiri. - 345 pp., Izd. Akademii Nauk SSSR, Moskva-Leningrad.

- 1969. Dekil'ka odnodol'nich iz neogenovoj flori Ukrajni. - Ukrainskij Botaničnij Žurnal 26 (1): 3-9.

- 1974a. K istorii roda Glyptostrobus Endl. - Botaničeskij Žurnal 59 (1974) 1: 3-13.

- 1974b. Cabombaceae, Nymphaeaceae, Ceratophyllaceae, etc. In Takhtajan, A. L. (Red.): Iskopaemye cvetkovye rastenija SSSR tom 1 - Izd. „Nauka”, pp. 52-88, Leningrad.

- 1975. K sistematike nekotorych Taxodiaceae. - Paleontologičeskij Žurnal (1975) 1: 105-116.

- 1977a. Simbuginskaja flora (russ.) In Fauna i flora Simbugino. - Izd. „Nauka”, 235 pp.; Moskva.

- 1977b. K sistemtike iskopaemych Decodon J. F. Gmelin (Lythraceae). - Botaničeskij Žurnal 62 (5): 664-672.

- 1982a. K sistematike tretičnych Typha. - Paleokarpologičeskie issledovanija Kajnozoja Izd. Nauka i technika: 5-26, Minsk.
- 1982b. Ulmaceae, Moraceae, Cannabaceae, Urticaceae, Fagaceae, Betulaceae - semena i plody. In Takhtajan, A. L. (Red.) - Iskopaemye cvetkovye rastenija SSSR tom. 2 - Izd. „Nauka”. 7-176.

- 1986: Iskopaemye Potamogeton. Posobie dlja opredelenija iskopaemych plodov. - 134 pp., Izd. „Nauka”, Leningrad.

Elborg, A. 1956. Geologie des Bauersberges bei Bischofsheim v. d. Rhön. Ein Beitrag zum Vulkanismus der Rhön. - Dissertation Universität Freiburg/Br., $129 \mathrm{~S}$.

Endlicher, S. 1847. Synopsis Coniferarum fossilium. 368 pp., Scheitlin et Zollikofer, Saugalli.

Engelhardt, H. \& Kinkelin, F. 1908. Oberpliozäne Flora des Untermaintales. - Abhandlungen der Senckenbergischen naturforschenden Gesellschaft 29 (3): 151-281.

Ettingshausen, C. 1866, 1868, 1869. Die fossile Flora des Tertiärbeckens von Bilin I-III. - Denkschriften der kaiserlichen Akademie der Wissenschaften, mathematisch naturwissenschaftliche Klasse 26, $28,29$.

- 1872. Die fossile Flora von Sagor in Krain. 1. Teil. Denkschriften der kaiserlichen Akademie der Wissenschaften, mathematisch naturwissenschaftliche Klasse 32: $159-202$.

- 1890/1891. Die fossile Flora von Schoenegg bei Wies in Steiermark. I - Denkschriften der kaiserlichen Akademie der Wissenschaften, mathematisch naturwissenschaftliche Klasse 57: 61-112.

Eyde, R. H. 1972. Note on the Geologic Histories of Flowering Plants. - Brittonia 24: 111-116.

Florschütz, F. \& Jonker, F. P. 1942. Über die Flora des Mindel-Riss-Interglazials in den Niederlanden. - Receuil Traveaux Botanique Néerlandais 39: 176-188.

Gaussen, H. 1960. Les Gymnospermes actuelles et fossiles: Genre Pinus. - Traveaux Laboratoire Forêstiere Toulouse 6 (1960) 11: 1-272.

Geissert, F. 1967. Mollusques et nouvelle flore plio-pleistocène à Sessenheim (Bas Rhin) et leurs correlations villafranchiennes. - Bulletin Services Carte géologique Alsace-Lorraine 20: $83-100$.

Geyer, R., Jahne, H. \& Storch, S. 1999. Geologische Sehenswürdigkeiten des Wartburg-Kreises und der kreisfreien Stadt Eisenach. Das historische Braunkohle-Bergbaurevier bei Kaltennordheim. - Naturschutz im Wartburgkreis 8: $172-174$

Gilkinet, A. 1922: Plantes fossiles de l' argile plastique d' Andenne. - Annales Sociétè Géologique Belgique, Mémoire 2: $25-40$.

Gleason, H. A. 1963. The new Britton \& Brown, illustrated flora of the Northeastern United States and adjacent Canada. - vol. 1: Pteridophyta, Gymnospermae and Monocotyledonae, 482 pp. - vol. 2: Choripetalous Dicotyledonae, 655 pp. - vol. 3: Sympetalous Dicotyledonae, 595 pp. - Third edit., Hafner Publ. Comp., Inc.; New York and London.

Goeppert, H. R. 1855. Die tertiäre Flora von Schoßnitz in Schlesien. - XVIII + 52 S., Görlitz.

Gregor, H.-J. 1982: Die jungtertiären Floren Süddeutschlands. - 278 pp., Verl. F. Enke, Stuttgart.

- 1990. Der Erstnachweis von Mastixien in den neogenen Sedimenten von Kaltennordheim (Rhön). - Documenta Naturae 59: 30-33.

Hartz, N. 1909: Bidrag til Danmarks tertiaere og diluviale Flora. - Danmarks geologiske Unders $ø$ gelse II 20, 292 pp.

Hassencamp, E. 1860. Geologisch-paläontologische Untersuchungen über die Tertiärbildungen des Rhöngebirges. - Würzburger naturwissenschaftliche Zeitschrift 1: 195-213.

Heer, O. 1855-1859. Flora tertiaria Helvetiae. - (Die tertiäre Flora der Schweiz Bd. 1-3), Verl. Wurster \& Co., Winterthur.

Herbst, G. 1844. Die Kiefern- Reste in der Braunkohle von Kranichfeld bei Weimar. - Neues Jahrbuch für Mineralogie, Geognosie und Petrefaktenkunde: $173-179 ; 567-568$. 
Hirsch, L. 1937. Tertiärgeologische Untersuchungen in der Rhön. - Dissertation Universität Giessen, 166 S., Würzburg (Triltsch).

Hottenrott, M. 1988. Palynologie, Stratigraphie und Paläogeographie im Tertiär von Mittelhessen und Umgebung. - Geologisches Jahrbuch Hessen 116: 113-168.

- 1992. Die stratigraphische Position des tertiären Braunkohlenflözes vom Bauersberg bei Bischofsheim a.d. Rhön aufgrund palynologischer Untersuchungen. - Giessener geologische Schriften 48 (Festband Stibane): 61-72.

- 1998. Mikrofloren aus den Bohrprofilen Sieblos 1994/1 und 1994/2 an der Wasserkuppe/Rhön (Eozän-Unteroligozän). - Geologische Abhandlungen Hessen 104: 201-213.

Jähnichen, H., Mai, D. H. \& Walther, H. 1977. Blätter und Früchte von Engelhardia Lesch. ex Bl. aus dem europäischen Tertiär. - Feddes Repertorium Berlin 88 (5-6): 323-363.

- 1980. Blätter und Früchte von Cercidiphyllum Siebold \& Zuccarini im mitteleuropäischen Tertiär. - Schriftenreihe geologische Wissenschaften 16 (1980): 357-399.

Keilhack, K. 1896. Über die Zugehörigkeit der Gattung Folliculites zu der lebenden Hydrocharidee Stratiotes. - Zeitschrift der deutschen geologischen Gesellschaft 48: 987-989.

Kelber, K.-P. \& Gregor, H.-J. 1987. Makrofloren aus dem Tertiär der Langen Rhön: Erste Ergebnisse von Neuaufsammlungen. - Documenta Naturae 41: 11-13.

Kinkelin, F. 1903. Die Originale der paläontologischen Sammlung im Senckenbergischen Museum und die auf dieselben bezügliche Literatur. - Berichte Senckenbergischen naturforschenden Gesellschaft 1903: 1-88.

Kirchheimer, F. 1930. Die fossilen Vertreter der Gattung Salvinia Micheli. II. Über Sporangienreste einer miozänen Salvinie. - Planta 11 (1930): 169-206.

- 1936. Beiträge zur Kenntnis der Tertiärflora. - Palaeontographica, B 82: 71-141

- 1937. Grundzüge einer Pflanzenkunde der deutschen Braunkohlen. - Verl. W. Knapp, 153 S., Halle.

- 1942. Zur Kenntnis der Alttertiärpflanzen von Wiesa (Sachsen). - Planta 32: 418-446.

- 1949. Zur Kenntnis der Pliocaenflora von Soufflenheim im Elsaß. - Berichte Oberhessischen Gesellschaft Naturu. Heilkunde, Neue Folge, naturwissenschaftliche Abteilung 24: 206-230.

- 1955. Fruchtreste von Nyssa Linné aus dem südwestdeutschen Tertiär. - Paläontologische Zeitschrift 29 (3/4): $109-118$

- 1957. Die Laubgewächse der Braunkohlenzeit. - 783 S. Verl. VEB W. Knapp, Halle.

Knapp, R. 1965. Die Vegetation von Nord- und Mittelamerika und der Hawaii-Inseln. - Vegetationsmonographien der einzelnen Großräume Bd. 1/hrsg. von $\mathrm{H}$. Walter 373 S., Fischer-Verlag, Jena.

Knobloch, E. 1964. Haben Cinnamomum scheuchzeri Heer und Cinnamomum polymorphum (A. L. Braun) Heer nomenklatorisch richtige Namen? - Neues Jahrbuch Geologie und Paläontologie Monatshefte (1961) 10: 597-603.

- 1971. Berichtigung zur miozänen Flora der Rhön mit Bemerkungen zur Altersstellung. - Mitteilungen Bayerische Staatssammlung für Paläontologie und historische Geologie 11: $251-262$.

- 1977. Fossile Potamogeton-Funde aus dem tschechoslowakischen Jungtertiär und Altquartär. - Časopis pro mineralogii a geologii 22 (1977): 29-42.

- 1978. Die Untermiozäne Flora von Šafov in Südmähren. - Věstník Ústředního ústavu geologického 53: 153-162.

Knobloch, E \& Kvaček, Z. 1976. Miozäne Blätterfloren vom Westrand der Böhmischen Masse. - Rozpravy Ústředního ústavu geologického 42: 1-31.

Kownas, St. 1955. Trzeciorzędowa flora z Dobrzyńia nad Wisła. - Acta Geologica Polonica 5: 439-516.
Kräusel, R. 1938. Die tertiäre Flora der Hydrobienkalke von Mainz-Kastel. - Paläontologische Zeitschrift 20 (1938): 9-103.

Kryshtofovich, A. N., Palibin, I. V., Baikovskaja, T. N., Grubov, V. I. \& Iljinskaja, I. A. 1956. Oligocenovaja flora gory Aschutas v Kazachstane. - Trudy BIN. Akademii Nauk SSSR, ser. 8, Paleobotanika 1: 1-171.

Kvaček, Z. 1970. A new Platanus from the Bohemian Tertiary. - Paläontologische Abhandlungen Berlin, Abt. B, 3 (3/4): 435-439.

- 1976. Towards nomenclatural stability of European Tertiary conifers. - Neues Jahrbuch für Geologie und Paläontologie, Monatshefte 5: 284-300.

1986. Fosilní Tetraclinis Mast. (Cupressaceae). - Časopis Národního Muzea v Praze, řada přirodovédna 155 (1-2): $45-52$.

Lańcucka-Środoniowa, M. 1979. Macroscopic plant remains from the freshwater Miocene of the Nowy Sacz basin (West Carpathians, Poland). - Acta Palaeobotanica 20 (1): $1-116$

Langeron, M. 1899. Contributions à l'étude de la flore fossile de Sézanne. - Bulletin Societè Histoire naturelle Autun 12: $431-455$.

Lippolt, H. J. 1982. K/Ar Age Determinations and the Correlation of Tertiary volcanic Activity in Central Europe. Geologisches Jahrbuch D 52: 113-135.

Loveless, C. M. 1959: A study of the vegetation in the Florida Everglades. - Ecology 40: 1-9.

Ludwig, R. 1857. Fossile Pflanzen aus der jüngsten Wetterauer Braunkohle. - Palaeontographica 5 (3-4): 81-109.

- 1859. Fossile Pflanzen aus der ältesten Abteilung der Rheinisch-Wetterauer Tertiärformation. - Palaeontographica 8: $39-154$.

Mädler, K. 1939. Die pliozäne Flora von Frankfurt am Main. - Abhandlungen Seckenbergischen naturforschenden Gesellschaft 446: 1-202.

- 1955. Zur Taxionomie der tertiären Charophyten. - Geologisches Jahrbuch 70: $265-328$.

Mai, D. H. 1960. Über neue Früchte und Samen aus dem deutschen Tertiär. - Paläontologische Zeitschrift 34: 73-90.

- 1964. Die Mastixioideen-Floren im Tertiär der Oberlausitz. - Paläontologische Abhandlungen Berlin, Abt. B, 2 (1): $1-192$

- 1965. Eine pliozäne Flora von Kranichfeld in Thüringen. - Abhandlungen zentralen geologischen Instituts Berlin, 1 (1965): 37-64.

- 1973. Die Revision der Originale von R. Ludwig 1857 ein Beitrag zur Flora des unteren Villafranchien. - Acta Palaeobotanica 14: 89-117.

- 1981. Der Formenkreis der Vietnam-Nuß [Carya poilane (Chev.) Leroy] in Europa. - Feddes Repertorium Berlin $92(5 / 6): 336-382$.

- 1985. Entwicklung der Wasser- und Sumpfpflanzengesellschaften Europas von der Kreide bis ins Quartär. Flora Jena 176 (1985): 449-511.

- 1986. Über Typen und Originale tertiärer Arten von Pinus Linné (Pinaceae) in mitteleuropäischen Sammlungen. Ein Beitrag zur Geschichte der Gattung in Europa. Feddes Repertorium Berlin 97 (9-10): 571-605.

- 1987. Neue Arten nach Früchten und Samen aus dem Tertiär von Nordwestsachsen und der Lausitz. - Feddes Repertorium Berlin 98 (1-2): 105-126.

- 1998. Paläokarpologische Untersuchungen im Alttertiär von Sieblos/Rhön. In E. Martini \& P. Rothe, Hrsg.: Die alttertiäre Fossillagerstätte Sieblos an der Wasserkuppe/ Rhön. - Geologische Abhandlungen Hessen 104: 215-239.

- 1999a. Die untermiozänen Floren aus der Spremberger Folge und dem 2. Flözhorizont in der Lausitz. Teil I: Farnpflanzen, Koniferen und Monokotyledonen. - Palaeontographica B $250(1-3)$ : 1-76. 
- 1999b. Die untermiozänen Floren aus der Spremberger Folge und dem 2. Flözhorizont in der Lausitz. Teil II: Polycarpicae und Apetale. - Palaeontographica B 251 $(1-3): 1-70$.

- 2000a. Die untermiozänen Floren aus der Spremberger Folge und dem 2. Flözhorizont in der Lausitz. Teil III: Dialypetale und Sympetale. - Palaeontographica B 253 (1-3): 1-106.

- 2000b. Die untermiozänen Floren aus der Spremberger Folge und dem 2. Flözhorizont in der Lausitz. Teil IV: Fundstellen und Paläobiologie. - Palaeontographica B 254 (4-6): 65-176.

- 2000c. Die mittelmiozänen und obermiozänen Floren aus der Meuroer und Raunoer Folge in der Lausitz. Teil I: Farnpflanzen, Koniferen und Monokotyledonen. - Palaeontographica B 256: 1-68.

- 2001a. Die mittelmiozänen und obermiozänen Floren aus der Meuroer und Raunoer Folge in der Lausitz. Teil II: Dicotyledonen. - Palaeontographica B 257: 1-40.

- 2001b. Die mittelmiozänen und obermiozänen Floren aus der Meuroer und Raunoer Folge in der Lausitz. Teil III: Fundstellen und Paläobiologie. - Palaeontographica B 258: $1-85$.

Mai, D. H. \& Gregor, H.-J. 1982. Neue und interessante Arten aus dem Miozän von Salzhausen im Vogelsberg. Feddes Repertorium Berlin 93 (6): 405-435.

Mai, D. H. \& Walther, H. 1978. Die Floren der Haselbacher Serie im Weißelster-Becken. - Abhandlungen Staatliches Museum Mineralogie und Geologie Dresden 28: 1-101.

- 1985. Die obereozänen Floren des Weißelster-Beckens und seiner Randgebiete. - Abhandlungen Staatliches Museum Mineralogie und Geologie Dresden 33: 1-260.

- 1988. Die pliozänen Floren von Thüringen. - Quartärpaläontologie 7: 55-295.

- 1991. Die oligozänen und untermiozänen Floren NWSachsens und des Bitterfelder Raumes. - Abhandlungen Staatliches Museum Mineralogie und Geologie Dresden 38: $1-230$.

Malz, H. \& Moayedpour, E. 1973. Miozäne Süßwasser-Ostracoden aus der Rhön. - Senckenbergiana Lethaea 54: 281-309.

Martini, E., Rothe, P., Kelber, K.-P. \& Schiller, W. 1994. Sedimentäres Tertiär der Rhön (Exkursion I am 9. April 1994) - Jahresberichte und Mitteilungen oberrheinischen geologischen Verein, Neue Folge 76: 219-244.

Menzel, P. 1913. Beitrag zur Flora der niederrheinischen Braunkohlenformation. - Jahrbuch preußischen geologischen Landesanstalt 34: 1-98.

Moayedpour, E. 1977. Geologie und Paläontologie des tertiären „Braunkohlenlagers“ von Theobaltshof/Rhön (Miozän, Hessen). - Geologische Abhandlungen Hessen 76: $1-135$.

Müller-Stoll, W. R. 1936. Zur Kenntnis der Tertiärflora der Rhön. - Beiträge zur naturkundlichen Forschung Südwestdeutschlands 1: 89-128.

Negru, A. G. 1969. O sistematičeskom položenij miocenovych ostatkov Carpinus v Moldavii. - Botaničeskij Žurnal 54: 760-765.

- 1972. Rannjesarmatskaja flora severovostoka Moldavii. 169 pp., Izd. „Schtiinza”, Kishinev.

- 1986. Mèotičeskaja flora Severno-Zapadnogo Pričernomor'ja. - 157 pp., Izd. „Schtiinza”, Kishinev.

Nikitin, P. A. 1929. The systematic position of the fossil genus Diclidocarya E. M. Reid. - Journal of Botany 67: 33-38.

- 1935. Semenaja miocenovaja flora u g. Tomska. - Doklady Akademii Nauk SSSR 3 (3): 133-136.

- 1948. Pliocenovye flory $\mathrm{s}$ reki Obi $\mathrm{v}$ raione Tomska. Doklady Akademii Nauk SSSR 61 (6): 1103-1106.

- 1957. Pliocenoye i četvertičnye flory Voroneshskoj oblasti. (Pliozäne und pleistozäne Floren im Gebiet von Woronesh). - Izdatel'stvo Akademii Nauk SSSR, 205 pp., Moskva-Le-ningrad.
- 1965. Akvitanskaja semennaja flora Lagernovo Sada (Tomsk). - Izdatel'stvo Tomskogo Universíteta, $120 \mathrm{pp}$, Tomsk.

Palamarev, E. 1968. Karpologische Reste aus dem Miozän Nordbulgariens. - Palaeontographica B (Weyland-Festband), 123 (1-6): 200-212.

- 1970. Fosilni flori ot tri $\mathbf{v}^{\mathbf{c}}$ gliscni basejna $\mathrm{v}$ jugozapadna B'lgarija (Fossile Floren aus drei Braunkohlenbecken in Südwestbulgarien). - Izvestija na Botaničeskija Institut bulgarska Akademija Naukíte 20: 35-79.

- 1972. Die Gattung Tectochara im Pliozänbecken der Grube „Bolschewik”. - Izvestija na Botaničeskija Institut bulgarska Akademija Naukíte 22: 127-133.

Palfálvy, I. \& Nagy, E. 1960. Révision paléobotantique de la coupe de la briqueterie Wind d'Eger. - Magyar Állami Földtani Intezet Évi Jelentése - 1960 ról: 223-263 (ungar., franz. Zusammenf.).

Reid, C. \& Reid, E. M. 1908. On Dulichium vespiforme sp. nov. from the brick-earth of Tegelen. - Verslaten Konigliche Akademie van Wetenschappen Amsterdam, Wisen Natuurkd. Afdeling 16 (2): 898.

- 1910. The lignite of Bovey Tracey. - Philosophical Transactions Royal Society Series B 201: 161-178.

- 1915. The pliocene floras of the Dutch-Prussian border. Mededeeling van de Rijksopsporing van Delfstoffen 6 : $1-178$.

Reid, E. M. 1920. Recherches sur quelque graines pliocènes du Pont-de-Gail (Cantal). - Bulletin Société géologique France, Séries IV 20: 48-87.

Rein, U. 1961. Die Möglichkeiten einer pollenstratigraphischen Gliederung des Miozäns in Nordwestdeutschland. - Meyniana 10: 160-166.

Rutte, E. \& Wilczewski, N. 1995. Tertiär. In Mainfranken und Rhön. Sammlung Geologischer Führer 74: 3., überarb. Aufl.: 61-76, Verl. Gebr. Borntraeger, Berlin-Stuttgart.

Sandberger, F. 1879. Über die Braunkohlenformation der Rhön. - Berg- und hüttenmännische Zeitung 38: 177-181, 189-191, 200-202, 209-211, 225-239.

Schenk, A. 1890. Palaeophytologie. In Handbuch der Palae ontologie/Hrsg. v. K. A. Zittel. - 958 S., München, Leipzig.

Schmeer, D. 1964. Tertiärer Vulkanismus in der Rhön. - Erläuterungen geologische Karte Bayern 1:500000, 2. Aufl.: 224-228, München.

Sternberg, K. M. v. 1820-1833. Versuch einer geognostischbotanischen Darstellung der Flora der Vorwelt. - Heft 1-6, 220 + LXXI S., Leipzig, Prag.

Szafer, W. 1947. Flora plioceńska z Krościenka n Dunajcem (The pliocene Flora of Krościenko in Poland) I-II. Rozprawy polska Akademia Umiejêtnoci Wydzialen matematyczno-przyrodniczego B 72 (1-2): 1-375.

Unger, F. 1838. Reise-Notizen vom Jahre 1838. - Steiermärkische Zeitung 2: 26-33.

Unger, F. 1840. Über die Pflanzen- und Insekten-Reste von Radoboj in Kroatien (Ung. Reise-Notizen vom Jahre 1838). - Neues Jahrbuch für Mineralogie, Geognosie und Petrefactenkunde 1840: 374-377.

- 1841-1847. Chloris protogaea. Beiträge zur Flora der Vorwelt. - H. 1-10: 150 S., Verl. Wilhelm Engelmann, Leipzig.

- 1850. Die Gattung Glyptostrobus in der Tertiär-Formation. - Sitzungsberichte der kaiserlichen Akademie der Wissenschaften, Mathematisch-naturwissenschaftliche Klasse 5: 434-435.

- 1852. Iconographica plantarum fossilium. - Denkschriften kaiserliche Akademie der Wissenschaften, Mathematisch-naturwissenschaftliche Klasse 4 (Lfg. I): 71-118.

- 1861. Sylloge plantarum fossilium I. - Denkschriften kaiserliche Akademie der Wissenschaften, Mathematischnaturwissenschaftliche Klasse 19: 1-48.

- 1866. Sylloge plantarum fossilium III. - Denkschriften kaiserliche Akademie der Wissenschaften, Mathematischnaturwissenschaftliche Klasse 25: 1-76. 
- 1867. Die Flora von Kumi auf der Insel Euboea. Denkschriften kaiserliche Akademie der Wissenschaften, Mathematisch-naturwissenschaftliche Klasse 26: 27-87.

Voigt, J. C. W. 1782. Mineralogische Reisen durch das Herzogtum Weimar und Eisenach $u$. einige angrenzende Gegenden, in Briefen. 1.Band: 6 Briefe, Weimar.

Wang, C.-W. 1961. The forests of China with a survey of grassland and desert vegetation. - (Maria Moors Cabot Foundation) 5: 313 pp., Cambridge (Mass.).
Weber, O. 1852. Die Tertiärflora der Niederrheinischen Braunkohlenformation. - Palaeontographica 2: 117-236.

Zenker, C. J. 1833. Folliculites kaltennordheimensis, eine neue fossile Fruchtart. - Neues Jahrbuch für Mineralogie, Geognosie, Geologie und Petrefaktenkunde 1833: $177-179$. 